\title{
EFEITOS DO MANEJO DA RESTEVA DE TRIGO, DO PREPARO DO SOLO E DE HERBICIDAS NO CONTROLE DE PLANTAS DANINHAS NA CULTURA DA SOJA [Glyeine $\max (\mathrm{L}$.) Merr.]
}

\author{
ELEMAR VOLL
}

Pesquisador da EMBRAPA-CNP Soja

Orientador: Prof. Dr. RICARDO VICTÓRIA FILHO

Tese apresentada à Escola Superior de Agricultura "Luiz de Queiroz", da Universidade de São Paulo, para a obtenção do título de Doutor em Agronomia. Área de Concentração: Solos e Nutrição de Plantas.

$P I R A C I C A B A$

Estado de São Paulo - Brasil

Junho $=1987$ 
EFEITOS DO MANEJO DA RESTEVA DE TRIGO, DO PREPARO DO SOLO E de HERGICIDAS, NO CONTROLE dE PLANTAS DANINHAS NA CULTURA DA SOJA [GIycine $\max (L$.$) Merr.]$

ELEMAR VOLL

Aprovada em: 05.08 .1987

Comissa julgadora:

Prof. Dr. Ricardo Victoria Filno ESALQ/USP Profopr. Robinson Pltelli UNESP/Jaboticabal

Dr. Robert Deuber COOPERSUCAR

Dr. Norman Neumaier EMBRAPA/CNPSO

Prof. Dr. Kelgo Minami ESALQ/USP

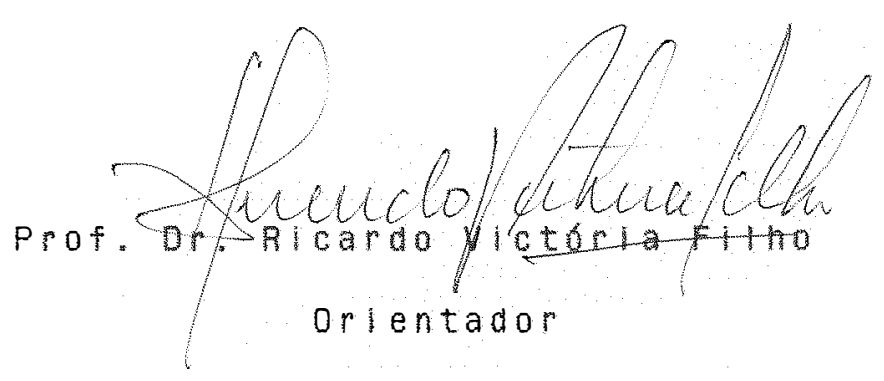


Aos meus pais.

com admigaco orgulho.

Ao meu Irmão,

pelo apolo recebldo.

A minha esposa, fllha e fllhos.

pelo estimulo e paciencla.

DED 160 


\section{AGRADECIMENTOS}

A Escola Superion de Agrloultura "Lulz de quelrón, pelo ofereclmento do curso e pelacontribulga aे formacou cientifica e cultural.

A Empresa Braslieira de Pesquisa Agropecuarla (EMBgapa), que atraves do Centro Nacional de pesquisa de sola (CNPSO), proporcionou a oportunidade e as demals vantagens para a realizaca do curso e pelo elevado esplitito de compreensão numana.

Ao Prof. Dr. Ricardo Victóla Fllho, pela orientacóa e amizade dispensadas.

Ao prof. Dr. Geraldo Victorino franca, pela orientaca e amizade dispensadas.

Aos demals professores, componentes da Banca Examinadora pelas criticas e sugestores apresentadas.

Aos funclonarlos do Departamento de solos, Geologla. e Fertillizantes e do Departamento de Agricultura e Horticultura da ESALOIUSP.

Aos colegas do curso, pelo apolo e pela troca de ldolas.

\section{- Acrescentando:}

A North Carolina State University (NCSU), EUA, pelo apolo dado execuço da presente pesquisa.

Aos Profs. Dr. Arch D. Worsham e Dr. Frederick T. Corbin da NCSU, que orlentaram a ase inicial do desenvolumento da mesma, bem como o reconhecimento aos demals.

Aos Drs. J.T. Sneets, Ross beldy e Nancy Hermann pela assistencla e amizade demonstrada no decorrer de trabalnos no Laboratorlo de Pesticlas/nCSU.

Aos funclonarlos e colegas da NCSU, que me deram apolo e possibltaram a troca de ldelas.

Pela compreensâ, estimulo e aluda de multos ourros nessa camlinada. 
SUMÁR 10

Pá̀ina

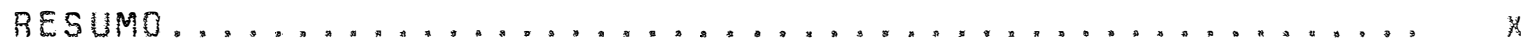

SUMMARY ......................................

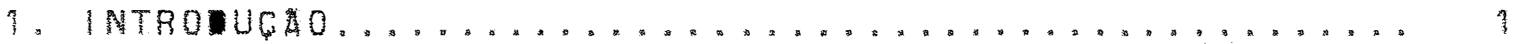

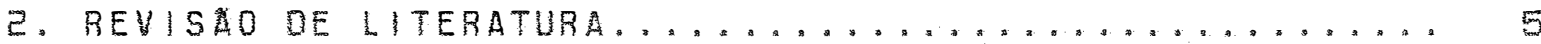
2.1. Efeitos da resteva no desenvolvimento das plantas. 5

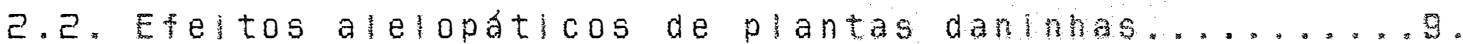

2.3. Controle de plantas daninhas: manelo da

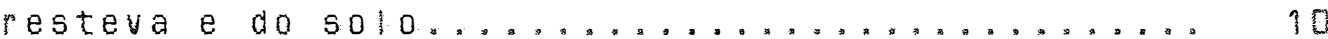

2.4. Herbicidas de manejo................... 15

2.5. Interacão de herblcldas e seletividade........ 18

2.6. Absorço, trans/ocacão e metabolismo

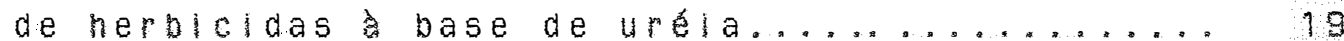

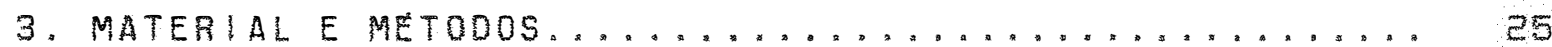

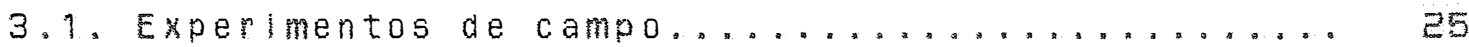

3.1.1. Avallagos de controle de plantas

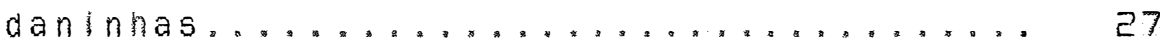

3.1.2. Populaço de plantas................ 28

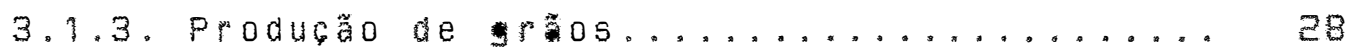

3.1.4. Anal|se estatistica................. 28

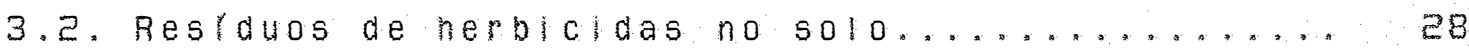

3.2.1. Blensalos para determinaca de peslduos

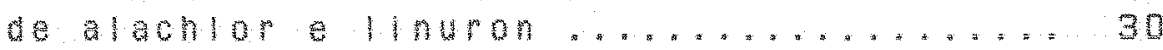

3.2.2. Detarminacio de residuos de

alachlor e linuron por cromategrafla

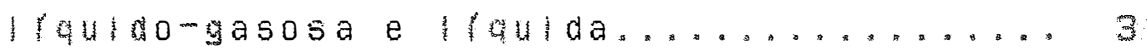




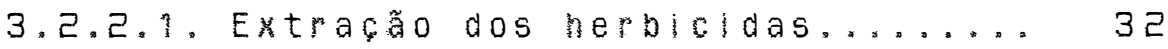
3.2.2.2. Separąåo por cromatografla em camada $f$ |na $(\mathrm{CCF}) \ldots \ldots . \ldots . . .32$ 3.2.2.3. cromatografia |quido-gasosa.... 34 3.2.2.4. cromatografia lquida........ 34 3.2.2.5. Analise estatistica............35 3.3. Experimentos em casa-de-vegetacấ........... 35 3.3.1. Efeitos da interacão de ácldo

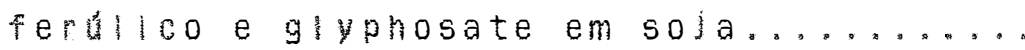

3.3.2. Estudo da interacão dos nerbicidas

alachlor e linuron, em tres diferentes

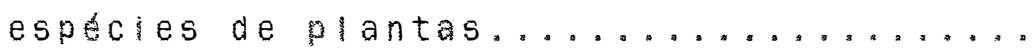

3.4. Experlmentos em camara-de-crescimento......... 38

3.4.1. Estudos prel|minares.................39

3.4 .2 . Cultura de plantas....................... 39

3.4.3. Tratamento qurmico................4 4

3.4.4. Absoŕão de água de c-1inuron........4 41

3.4.5. Extracão de c-linuron e metabolitos.... 42

3.4.6. Metablitos de c-11nuron...........44

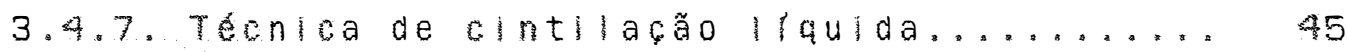

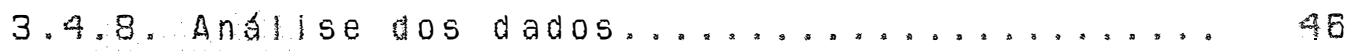

3.4.9. Autoradlografia .................48

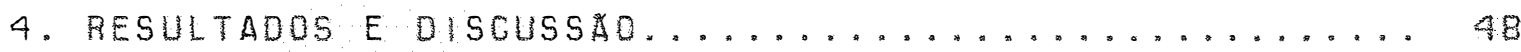

4.1 Expertmentos de campo................. a

4.1 .1$. Interacão 100 al e ano na producta de 50 la 48 4.1.2. Efeltos do manejo da pesteva.........4B 4.1.2.1. Efentos na producão de sola... 51 
4.1.2.2. Efeltos no controle das lantas

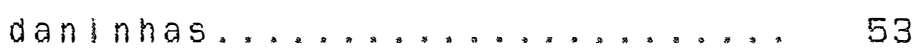

4.1.3. Efeltos do manelo do solo............. BE 4.1 .3 .1$. Efeltos na produca de sola..... 4.1.3.2. Efeltos no controle das plantas daninhas....................... 64

4.3.4. Interacôes do manejo da resteva e do solo 72 4.1.4.1. Efeitos interativos sobre as

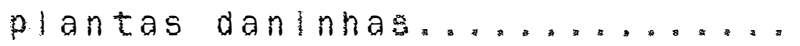

4.1.5. Efeltos dos nerbicidas de manejo.....74 4.1 .5 .1 . Avallacão dos nerbicldas de manelo 74 4.1.5.2. Efeltos da aplicaca dos nerbicidas reslduals junto com os nerbicidas de $\operatorname{mane} 10 \ldots \ldots \ldots \ldots \ldots$

4.1 .5 .2 .1 . Efeitos na producăo de sola......75 4.1.5.2.2. Efeitos sobre as espécles daninhas 76

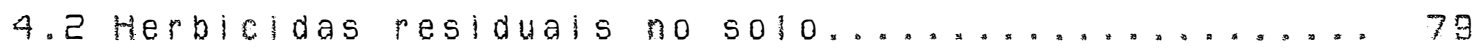
4.2.1. Ensalos blologlcos para reslauos de

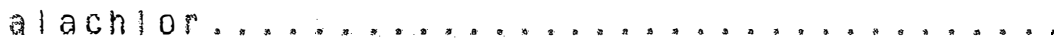

4.2.2. Determinacoes anallticas para res/auos de alachlor e linuron................ 84

4.3. Experimentos em casa-de-yegetaça........... 8в 4.3.1. Efeltos da Interacão do ácido ferullco e 9 lyphosate na sola $\ldots \ldots \ldots \ldots \ldots \ldots$

4.3.2. Respostas do pepino, sola e ancarinha branca a Interacóces de a achlor e linuron 9 ? 
4.4. Experimento em camara-de-crescimento.........99 96 19 4.4 .1 . Absorfão de c-linuron e água.........9.98 4.4.2. Blomassa fresca de partes da planta...... 100 4.4.3. Distribulcão da radioatividade na planta. 104 4.4 .3 .1 . Contagem por cintilacäo liquida 104 4.4.3.2. Autoradiografia............ 108

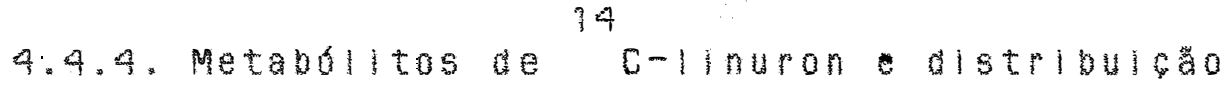

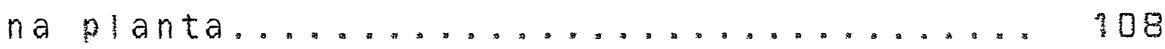
4.4.5. Distribulcão do ${ }^{14}$ e metabolitos na solucia nutritiva...................... 12a 4.4.5.1. Distribuibấo do c em extratos de água e cloroformio.. T29 4.4.5.2. Metabutitos a co na soluca nutpltivan............... 125

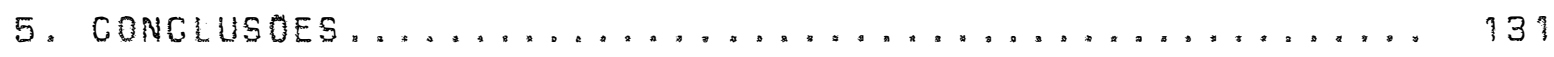

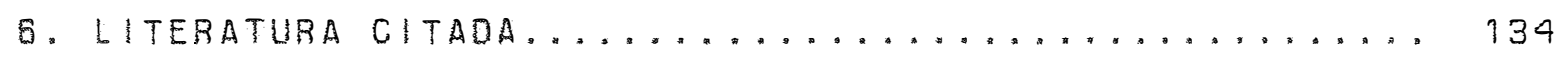

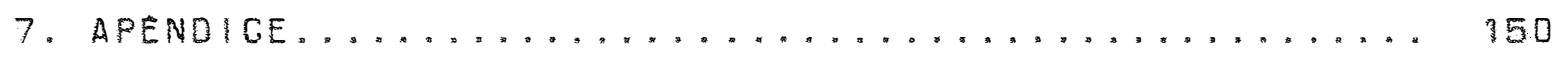


efeltos do manejo da resteva de trigo, do preparo do SOLO E de hergicidas no controle de plantas dANINHAS NA CULTURA DA SOJA [GIycine $\max (L.) \operatorname{Mer} r$.

Auton: ELEMAR VOLL Orientador: PROF. OR. RICARDO VICTORIA FILHO

RESUMO

Como obletivo de avaliar os exeltos do manelo da resteva de trigo (TPItlcum aestivum L.) CV. "MCNaIr I813', do preparo do solo e do uso de herblcldas, no controle de plantas daninhas na cultura da soja (Glycine max (L.) Merr. cv....Ramson", foram conduzldos experimentos de campo em Clayton e Rocky Mount, Canolina do Norte, EuA, em 198$\}$ e 1982. Os tipos de solo nos respectlyos locals foram wagram" barro-arenoso, com zo de matérla organlca (m.o.), e counbar. arenoso, com? \% de mo.. os tratamentos de manelo da resteva foram: permanência, queima, remogão e remocão com reposifäo; os de preparo de solo: plantio direto (PD) e cultivo minimo (CM), este com duas gradagens de 10 cm de profundidade: e os herbicidas de manelo: paraquat a 0,56 kg/ha mals surfactante a $0,2 \%$ v/y e glyphosate a 1,08 kg/ha, Foram usados os herbicidas residuals alachlor e linuron em todos os tratamentos, exceto em tratamentos extras de paraquat e demals grupos de variaveis fo citados. Foi usada o delineamento blocos casuallzados, em tatorlal 4xexe, com 
quatro repeticões.

Producões de sola foram iguals sob diferentes manelos da resteva de trigo, em condicões normals de populacão. Beducões significativas de populacăo e de produtividade da sola ocorreram com a quelma da resteva, quando coincidiu comperlodo seco de plantio, equando fol delkada a resteva em solo com alto teor de umidade. Na houve d)ferencas na producão de sola entre Po e GM, sob semelnantes populacões de plantas. As producões foram malores com paraquat do que com glyphosate.

Nas avallacoses yisuals de controle das espécies daninhas, em préplantio da soja, na foram observadas diferencas entre glyphosate e paraquat. As combinacốes destes com a mistura de alachlor e linuron controlaram Digitarla sanguinalls, chenopodium album, Ambrosla artemislifolla, Mollugoverticlllata e Amaranthus spp., não controlando cyperus esculentus, lpomoea spp. e Tritlcum aestivum. A quelma da resteva feduzin a infestaga de T. aestivum aumentando a de A. artemisilfolla, D. sangulnalls e M. verticlliata, sugelindo quebra de dormencla as sementes. Delxar a resteva, sem alachlor e finuron, roduziu D. sanguinalls e M. verticlllata; C. album e $A$. artemisilfolia foram reduzidas com a quelma, em ano seco de plantio: Amaranthus spp. e C. esculentus não roram aretadas pelo manelo da resteva, ocormendo tendanclas para reducáo das Intestacões de ipomoea spp. com a sua permanencla. o po reduziu as infestacoes nas demais espécies daninhas sob 
qualquer manejo de resteva, com excessão de co esculentus. reduzida pelo GM. Interacôes de manejo da resteva e do solo resultaram emmalores infestacões de A. artemislifolla em PD, com todos os manejos da resteva, exceto com a sua quelma, aumentando a infestacão no CM.

Esses resultados permitem concluir que: 1) a guelma da pesteva de trlgo restringlu o estableclmento da cultura da sola em perlodo seco e a permanencia da resteva fol polutol a sola em solos com alto teor de umidade; ambas as sltuacões comprometeram a germinacão da sola: 2,2 ) o manejo da palna e do solo podem contribulr, Juntamente com o uso de nerbicldas, para o controle de plantas daninhas na cultura da soja. 
MULCH, TILLAGE, AND HERBICIDE EFFECTS ON WEED GONTROL IN DOUBLE GROPPED SOYBEANS [G|YcI Be $\max (\mathrm{L}$.$) Merf.]$

Authon: ELEMAR VOLL Adviser: PROF. OR. RICARDO VICTORIA FILHO

SUMMARY

In order to evaluate wheat Tritlcum aestlvum L.) Cv. 'MCNalr $1813^{\prime}$ mulch, tillage and hepblclde management effects on weed control, in double cropped soybeans folycine $\max (L$.$) Merpa cv. "Ramson", fleld experiments were carpled$ out at clayton and Rocky Mount. North Carolina, USA, In 1981 ano 1982. Soll types at the respective sites were wagram" sandy loam, with $2 \%$ of organlc matter (o.m.), and 'Dunbar' fine sand, with $1 \%$ o.m.. The mulch treatments used were: leaving, burning, removing, and removing and replacing; as soll management: no-tH (NT) and reduced thlage (RT), done with two diskings at $10 \mathrm{~cm}$ depth; as herblcide management: papauat at $0.56 \mathrm{~kg} / \mathrm{ha}$ plus surfactant at $0.2 \%$ v/l and glyphosate at $1.08 \mathrm{~kg} / \mathrm{ha}$. Alachlor and Inuron residual nerblcides were used with all treatments, except in extra treatments with paraquat with those varlables before mentioned. A pandomzed block deslgnexperiment, with a factorial axzk2, and pur replications were used.

Soybean yields showed no diffences for mulch managements under nommal stands. Burning mulch reduced 
soybean stand and yield in a very dry planting season, and so by leavingmulch, with high molsture in the soll. soll management showed no yleld differences between NT and RT under simllar stands. Herblolde management favored ylelds with paraquat as compared to glyphosate.

No visual differences for weed species control In pre-lanted soybeans were observed between glyphosate and paraquat. Combinations with alachlor and linuron controlled Digitaria sanguinalis, Chenopodium album, Ambrosla artemislifolia, Mollugo verticlllata and Amaranthus spp., with no control over cyperus esculentus, Ipomoea spp. and Triticum aestivum. Burning mulch peduced $T$. aestivum Infestation and increased those of A. artemis|lfolla, 0. sanguinalls and $M$. vertlclllata, suggesting breaklng of domancy. Leaving mulch, without alachlor and linuple reduced $D$. sangulnalis and $M$. verticillata; $C$. aldum and $A$. artemlsilfolla were reduced by burning the mulch, in a ary planting season: Amaranthus spp. and c. esculentus were not affected by the mulch management, showing a trend for reduction of Ipomoea spp. by leaving the mulch. NT revced all weed species infestations, with any mulch management, but c. esculentus, which was peduced in RT. Mulch and soll managment interactions resuled in higher lnfestations of $A$.

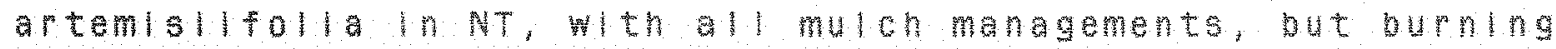
1t, which increased its infestation in RT.

These results allow to conalude that: l) wheat mulch burning pestricts soyean crop stablishment in a dry 
season, as well as leaving the mulch on solls with hign level of moisture: both conditions are unfavorable for soybean germination: and ᄅ) mulch and soll management may contribute, together with the use of herblcides, to weed control in soybeans. 


\section{INTRODUCAO}

- Sistema convencional de preparo do solo, atraves do uso de arado e grade, visando facilitar a semeadura elou reduzir os problemas de interperencia das plantas daninhas com as culturas, tem causado graves problemas para a conservacão e a manutencão da feptilidade do solo, devido a erosão provocada pela chuva elou vento.

No sentido de diminuir os problemas de ordem fislca, quimica e/u blologlca do solo, os quals causam reducão na producão das culturas, várias praticas conservacionlstas sajo atualmente usadas, Inclulndo o slstema de plantl. direto. Neste, o solo não é movimentado e desagregado a não ser o necessalo para a deposicão das sementes e do adubo, mantendo-se na superflcle os restos das cultupas anteriores e a vegetação dessecada, através douso de hepblcidas. os efeltos da permanencla desta cobertura morta no solo, sua destrulcão pelofogo, ou a sua pemocão, para atender outras finallades, temsio a razão de multas pesousas, em funcan de diferentes condiós proporolonadas pelo cultivo de difenentes cuturas.

No sistema de plantio direto o não revolvimento do solo, bem como a manutencâa da cobertura mopta concentrada ha superficie, tem appesentado um papel 
multo importante na complementacão do controle das plantas daninhas pelos herblcidas. o revolvimento do solo tende a ser continuadamente reduzida com o passar dos anos, como uso de manelos eficientes. os efeltos quantitativos da cobertura morta das culturas anteriores, tambsm chamadas de resteva, restos ou residuos culturals, refletem-se na reducão da intensldade luminosa que atinge a supericie do solo, assim como na reducão da temperatura, em intensidade e amplitude de variacão. Isto afeta o processo da quebra de domancla sementes de plantas daninhas no solo. Em termos qualitativos, em funcão da especie vegetal que prove a cobertura morta, a acão das águas das chuvas lixivia substanclas alelopáticas, toxicas ao desenvolvimento de certas espécles daninhas, que infestam determinada cultura, inibindo a sua germinacão e o seu desenvolvimento.

Apesar de reconhecldas as vantagens da eliminacão ou reducão do cultivo do solo e manutencão da pesteva, ou de uma sucessão cultural adequada, que pode resultar num controle de plantas daninhas vantaloso, varias diflculdades podem ser observadas com tals praticas, embora algumas vezes pesultem malores producóes or unidade de área do que no sistema convencional.

Resultados experimentais de produgo, tem mostrado pequenas alterengas entre queimar os restouos ou não. Em algumas stucónes. restevas de inverno delxadas na superficle, tem causado dificuldades paraplantios da sola, como atrasos na germinaca e no crescimento da cultura, 
resultando em menores producónes. Atribuem-se estes efeltos em parte a compostos naturals tóxicos, soluvels em águ, IXiviados das restevas. Por outrolado, efeltos benficos sä́ observados devido a inibla da germanga do do crescimento das plantas daninhas. A quelma da resteva. prática usada com certa intensidade na Regiäo sul do Brasll, pop sua vez não pode ser considerada vantabosa, principalmente sob o aspecto da conservacão do solo, melnopla ou manutencăo da sua sentlidade, especialmente onde o solo é arenoso e teor de materia orgânica balko. A eliminacăo das plantas daninhas nas culturas pelo uso de hepblcidas, năo pode prescindir do uso de um conjunto de praticas de manejo do solo e da resteva, num sistema integrado de cultivo. Neste contexto, desenvolveu-se a presente pesquisa com os seguintes objetivos:

a) determinar os efeltos do manelo da resteva sobre o controle das plantas daninhas;

b) comparar os efeltos do preparo do solo no controle das plantas daninhas:

c) avallar dols diferentes herblcidas de manelo, näo seletivos, no controle das plantas daninhas:

d) quatificar os nivels dos nerbicias mesiduls no solo e suas relabos como contole das plantas daninhas:

e) observar padrós de absopăo, translocaca e metabollsmo de 14c-linuron nas plantas de sola e pepino, na ausâncla e presenca de alachlor e posslvels indicaçes no 
controle das lantas daninhas.

f) observar os efeltos sobre a cultura de sola. 


\section{REVISAO DE LITERATURA}

\subsection{Efeltos da resteva no desenvolvimento das plantas}

Plantar soja na pesteva de uma cultura anterior de inverno, como trigo, emulto importante sob o

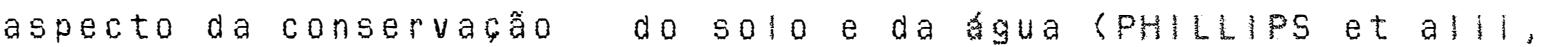
1980). Produtividades de sola, em experimentos de plantio direto, mostram-se multas vezes lguals ou superiores aos do plantio convencional (COX, 1977 e FRENCH R SANTELMANN, 979), princlpalmente por conservar a umidade critica do solo na época do plantio. quando um controle eficlente das plantas daninhas é obtido. isto ropotiona mellot populacâdo de plantas e melnor desenvolvimento iniclal das mesmas. Producoes dy soja de experimentos mostram-se tamber Interlores a os do plantlo convenclonal, por causada ala dade controle adequado das invasoras HHARDCASTLE, 1973, MGKIETA et a111, 9977 e KAPUSTA, 1979) ou quando as pestevas säo delxadas na superficle do solo, em comparacão com a quelma ou

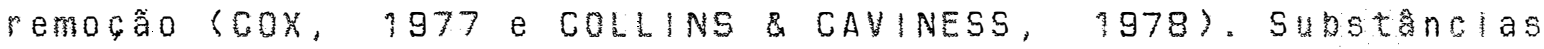
fitotoxicas, presentes em pesiduos em deqomposican sob contiges de lavouna mostram-se capazes de atetap a geminaco e o crescimenty de culturas e de diterentes

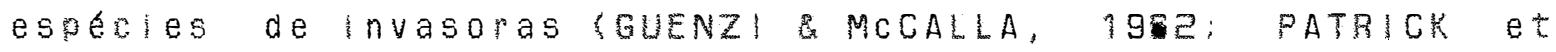


a111, 1983; GUENZ1 et a111, 1987: KIMBER, 3973; Cox, 1977; COCHRAN et aI11, 1977; COLLINS KAVINESS, 1978 e LIEBL, 1982).

Efeltos fitotoxlcos mostram-se proporolonals a quantidade de reslduos presentes na superflcie do solo (cox, 1977 e COLLINS \& CAVINESS, 1978). Estas substânCIas são compostos soluveis em agu (GUENZl et al11, 1967). Reslduos de diferentes espécles de plantas possuem também diferentes graus defitotoxlcldade (GUENZ) et ali1, 1967; KIMBER, 1973; COLLINS \& CAVINESS, 1978 e ALMEIOA \& RODRIGUES, 1986).

o estado de decomposigão tem sido relacionado com a quantidade de substinclas liberadas (GUENZl et ali, 1967). A fitotoxiclade é mals severa dos 10 aos 25 dlas de decomposicão, diminuindo com periodos mais extensos. Proppledades estimulatólas são multas vezes observadas apos 30 dlas de decomposicão (PATRICK et a|11, 1963). KIMBER (1973), estudando o efelto de perlodos de decomposicano das palhas de algumas gramineas e leguminosas sobre o crescimento de plântulas de trigo, mostrou que, cortando plantas em estado alnda verde, ocorre producão de toxicldade mals elevada do que quando cortadas maduras. STONE et aill (1951) mostraram que a ligniflcacõomáma ocorre em plantas de trigo maduras e que os ácldos fentlicos são importantas na formacão da lignina. Eles sa Intbldores da oxidase do aclo IndolactICo (GORTNER \& KENT, I958).

Diferentes partes das plantas mostram diferentes graus de efeltos Inibitomios. GUENzl at alil 
(1957) observaram que extratos aquosos de colmos de trigo, aveia, sorgo e milho apresentaram malor efelto inibitorio em plantulas de trigo. Os extratos continham material de grande amplitude de peso molecular e valores de pH aumentavam com malores pertodos de decomposliô, segundo BELl RDEPE (1972). ALMEIDA et ali (1986) Identiflcarammalores efeltos inibitorlos da parte a spa de Brachlarla plantaglnea do que da raiz, em soja. ALVES et alil (1986) observaram que a ordem decrescente da aca inlbitorla de caruru (Amaranthus retroflexus) fol: folnas, inflorescencia, ralz e caule.

GUENZI \& MCCALLA (1986) Identificaram cinco compostos de aclaos fenolicos, comuns em reslduos de millo. trigo, sorgo e avela, sendo eles os acidos ferúlico, pcumálico, sirtiglco, vantlico e p-hidroxibenzolco.o ácido. cumarico achava-se presente em malores concentracoses do que os demals e e proválel que, llberado em quantidades suficlentes em areas localizadas do solo, possa afetar o crescimento das plantas. Voll (1986), usando ate 1000 ppm de acido ferulico em soja e caruru (A. retroflexus), observou que a geminaca da soja sofreu atrasos e que a altura de plantas tendeu a aumentar commaiores doses do produto; o inverso ocorreu com o caruru, que apresentou menor geminacão. A biomassa seca do dossel de ambas as esperies fol reduzida, sendo o capuru afetado em malor grau do que a sola.

PATRICK et alif (1963) mostraram que injurias de substanclas tónicas, causadas em plantulas be al ace e 
espinafre, epam restritas àuelas partes em contato ou nas Imedlacós de framentos de plantas em decomposicão no solo.

Dentre os muitos tipos de inlbidores de crescimento produzidos por plantas vivas, ou liberados pela decomposicão de partes de plantas por acão microbiana e IXIVIaGão (MCCALLA \& HASKINGS, 1969 e NORSTADT \& MCCALLA, 1989), os ácldos fenollcos e compostos relacionados. depivados atraves do metabolismo do ácldo xiqulmico, são os mais comuns (GUENZI \& MCCALLA, 198E e PATTERSON, 1981). Alterąão da permeabllidade celular, resultando em aumento da exudacão de aminóacidos, um dos mals importantes efeltos, Peoultando em aumento de fitotoxlcldade. A atividade microblana tambem aumenta a fitotoxiclade de substancias em decomposIfão (NORSTAOT \& MCGALLA, 1968).

A producio de substancias fitotónlcas pode ser afetada por métodos de preparo do solo. GUENZI \& MCGALLA (1966) extralram maiores quantidades de ácido fephlico e cumarico de solos sob cultivo minimo, quando comparado com solo a to ado.

As condigós ambientais, que precedem a formacão elou liberacão das substanclas fitotónlcas originadas das coberturas mortas, são geralmente condi, ncoues limidas e balkas temperaturas (COCHRAN eta 111,1977$), 04$ solo umido (NORSTAOT \& MCOALLA, 198E). O aumento da precipltacão anual tem mostrado corpelaca com a reducão da produra a da culturas, bem como com aumentos dos restos culturals de culturas imediatamente anterlores (PAPENDICK \& MILLER, 9977 ). 
A toxicidade do solo; devido a constituintes organicos, mostra-se mais frequentemente associada a solos pesados, mal arelados, ou InUndados (PATRIOK KOCK, 1958).

Sintomas de campo comumente pelatados são: reducão na geminacão, falta de vigor e morte das plantulas, amapelecimento follar, reducão no perfllihamento e no enralzamento, e parte área estimulada ou deformada Gouenz: et a 111,9987$)$

\subsection{Efeltos alelopaticos de plantas daninhas}

Multos compostos de plantas podem causar a teracoes fislologicas ou morfologlcas em outras, dependendo da sua concentracão (PATTERSON, 1981). BHOWMIk \& DOLL (1982a) observaram que extratos de caruru (A. retroflexus) em mino e sola, são capazes de reduzir a duracão da area follar, a pazão de peso follar e blomassa seca total. Residuos do capim-rabo-de-paposa (Setarla faberil) reduzem a taxa de cresclmento e a duracão da area follan em mino e a blomassa seca total de milho e sola. BHowMIK \& DOLL (1982b) tambem observaram que extrato aquoso de chenopodlum al bum e de A. retroflexus, entre outros, iniblua elongaca da radcula do milno; e extrato de $c$ album reduzlu o crescimento do colebptilo: o extrato de A. retroflexus tambem

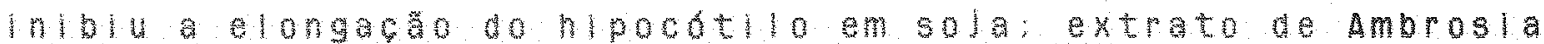
artemisilfolla Iniblu o cresclmento domilno e da sola em casa de vegetacäo. ALVEs et alti (1985) compararam os efeltos alelopkticos de carupu(A. retroflexus), obsepados em 
pepino, com os efeltos de outras espécies, que apresentaram menor acão Inibitóla. VIOAL et al11 (1985), observaramque o efeito alelopatico do extrato aquoso do dossel do capimmarmelada (a. plantaginea) eramals acentuado do que o efeito causado pelas razes. 0 extrato do dossel reduzlu 0 comprimento do cauliculo do fellão, centelo, azevem, tremoco e envilhaca. o desenvolvimento da sola não fol afetado, bem como a sua germinacão e a das demals especles, inclulno-se mino e tigo. ALMEIDA et all (1986), em ensaios de casade-vegetacão, observaram que efeltos alelopaticos de caplmmarmelada emsoja, manifestaram-se pela reducão da blomassa seca das ralzes e do dossel, da altura de planta e da nodulą̧̃o.

2.3. Controle de plantas daninhas: manelo da resteva e do solo

ALMEIDA \& RODRIGUES (1985), no Parank, observaram que extratos aquosos da parte aérea de algumas culturas de inverno, como trigo, avela, centelo, nabo, tremoco e colza, eram capazes de peduzir, em diferentes graus, a germinacăo de sementes de plantas daninhas como capim-marmelada ( 8. plantaglnea), caplm-car raplono (cenchrus echinatus) e pleăo-preto (日ldens pllosa), sano mals acentuados os efeltos exercidos pelas tres ultimas culturas; a germinacão do amendoim bravo (Euphorbla neterophylla), fol reduzida a zero pelacolza, porém, fol pouco afetada pelo 
nabo: a germinacão não fol afetada pelos demals extratos de plantas. Em trabalhos de campo, com culturas de inverno, adicionals as citadas, a ervilinaca, a serradela e o naboforragelro foram as culturas que menores infestacón del xaram para as culturas de verão. ALMEIOA \& RODRIGUES (1986) observaram que as coberturas mortas de avela e nabo forpagelro reduziram signiflcativamente infestacöes de plantas daninhas antecedendo culturas de verão, seguldas pelas de tremoco e centelo, sendo mals infestadas as de trigo e pousio. Menores blomassas foram observadas nas culturas de milho, com nabo-forrageiro, na sola, com avela e centelo e, no algodão, com avela. A composicãoflorfsticafol alterada pelas coberuras mortas de nabo-forragelro, tremoco e trigo, que não tiveram aça sobre o caplm-marmelada, enquanto que, avela e centeio, restriglu o seu desenvolvimento. A acão das coberturas mortas pareceu depender não só da especle que ine deu orlgem, como tambem da sua quantidade de material e veloclate de decomposicão. O usa complementar de herblcldas poderla ser necessarlo em funcão tos nivels de infestacão.

\section{ALMEIDA \& RODRIGUES (1985), em labopatirio,} estudaram tambem a influêncla de extratos aquosos da parte aerea de algumas culturas como trigo, avela, centelo, tremoco a nabo sobre a popcentagem de sementes germinadas, compinento de folma e ralz das culturas de fellão, mino e sola, e observaram efeltos signiflcativos na redufão do milno pelo naboe, efeltos significativos na reducão do comprimento da folna e da raz nas tres culturas, sendo mals acentuado 
nos extratos de tremoco e nabo.

o controle de plantas daninhas, como resultado de substanclas fitotoxicas produzldas pop reslduos de vegetals e preparo do solo no slstema de plantio direto, tem sido de grande importancia em experimentos de campo conduzidos por LIEBl (1982), em reduzlr populacoses de lpomoea nederacea, Sida spinosa, cassla obtusifolla e xanthium pensllvanicum. LEEL \& WORSHAM (1983a), USando acido

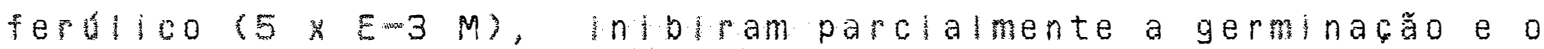
comprimento da ralz de l. nederacea e de S. spinosa. A germinaç̃o de olgltarla sanguinalls fol inlbida totalmente. STEINSIEK et ali (1980), em bloensalo de laboratorlo, observaram reducão no cresclmento e germinacão de varias Invacoras com extrato de palha de trigo, como l. nederacea, nั̃o atetando 1. Iacunosa.

PUTNAM et alil (1982) separaram controle frsico de invasoras causado por palnas, do controle quimico, ao usar uma cobertura fisica de raspa de madelifa em comparacio com palhas de centelo, trigo ou cevada. os autores relatam que populacöes de espocies daninhas foram reduzldas em ate $80 \%$ pelas palhas do centelo e, somente 10 a $43 \%$, pelo efelto fisico da cobertura inerte.

Sistemas de manelo do solo e seus efeitos no controle de plantas danlnhas em cultumas, mostrames de grande Importancla para reduzir infestacos das mesmas. LIEBL \& WORSHAM (19830) observapam a a a ellminacudo do cultivo do solo, sem o uso de hepblaldas, contribulu para peduzl as 
infestacoes de 1. nederacea, s. spinosa e c. obtuslfolla. ThIPP et ali1 (1983) não encontraram diferengas slgnificativas em producoes de sola entre tratamentos de plantio convencional e direto. Contudo, como aumento das densidades das invasoras, navia uma tendencla para maiores producões no plantlo direto, numa sequencla de dols anos. VEDOATO \& WIES (1975), num estudo integnado de controle de plantas daninhas em sola após trigo, no Nopte do Parano. observaram que o numero de plantas daninhas aumentou significativamente com o cultivo minimo do solo em relacão ao plantio dipeto. ALMEloA et alil (1982) conclulram que, desde que os herblcidas residuais sejam aplicados nas condicos por eles exigidas, atuam bem em qualquer dostres sistemas de manejo do solo. No entanto, o cultivo minimo ruma escarificacão + uma gradagem) tendeu a apresentar resultados de controle inferiores em relacöo a plantlo direto (manelo de herbicldas dessecantes + residuals) e preparo convencionat (aracão + duas gradagens), após a cultura dotrlgo. Folon \& ZAGATO (1984) observaram que o melnor controle de plantas daninhas em milho fol obtido em plantio convencional, seguldo do plantio direto e, por útimo em cultivominimo. A producão de milno, no entanto, fol malor em plantio dipeto. Nas respectivas testemunas, pop sua vez, as producoses segul am os niveis de controle das plantas daninhas obtido.

BULLCK \& JEFFERY (1980) Observaram que a pemocão da palna de trigo do campo pela entardadeira aumentava a Incldencia da tipirica (cyperus esculentus) em 
plantio convencional, mas não sob plantio dipeto. DRost \& DOL (1980) mostraram que extratos aquosos da tirica esculentus) são capazes de a etar o cresclmento da sola através de efeltos alelopicticos.

Moss (1981), conduzindo experimento a campo, comparou a quelma da pal ha de trigo com a sua simples remocaro fisica. A quelma pesultou em menop infestacão de Alopecurus myosuroldes na superifie do solo, numa subsequente semeadura direta de trigo. D controle da espéciefol proporcional à quantidade de palha quelmada. Sementes embebidas de a gua foram menos susceptiveis destrulcâo pelo calor do que sementes secas. Apos a queima da palha, a supepflcie do solo apresentava melhores condlcố para a geminacão de sementes ou desenvolvimento das plantulas, do que sob condla a do resteva. BooUET \& WALTER (1981) relatam que a quelma da resteva aumentou a populaco de sola, sem afetar a sua producão.

A atividade dos herbicidas residuais tem sidn peduzlda devido a permanencia ou quelma das palnas CTOTH \& MILHAN, 1973; ERBACH \& LOVELY, 1975; BANKS \& ROBISON, 198D $e$ Moss, 1981). Mas a resteva delxada na superficle do solo pode compensar a perda de atividade dos herblcidas através do sombreamento e efeltos alelopticos nas invasoras CPATRICKet, a 111, 1983; BHOWMIK \& D EL; 198בa: LIEBL, 198ב e PUTNAM et a 11, 1982). LOWDER \& WEBER (1979) relatam que uma chuva de $10 \mathrm{~mm}$, Imediatamenta, ou sete dias apds uma aplicago de atrazine, removeu aproximadamente 87 e 77 do herbleldade 
plantas frescas de avela e de reslduos secos de milno, respectivamente. STEINSIEK \& DLIVER (1979) concluram que os restiduos de palnas ou cinzas na supepflcle do solo peduziram o controle das invasoras pelos nerblcidas, o que, no entanto, fol evitado com o aumento da dose dos mesmos. A atividade do nepbleida alachlor fol a menos afetada. oxyfluofen e opyzalin foram mals aterados e o aumento da dose não se sobrepôs intelramente a reducão no controle devido aos restaus de palna e clnzas am excesso. BANKS ROBINSON (1980) relatam que o alachlor e o metribuzin näo apresentaram diferencas signiflcativas na concentracão de nerbicida entre tratamentos com ou sem resteva, exceto pama as amostras do dia da aplicacão, nem os nerbicidas persistiram em apreciaveis quantidades passados zo dias apos otratamento. Difepencas significativas em concentracous de oryzalin foram observadas entre tratamentos com resteva e sem resteva em todas as datas de amostragem. quantidades slanlfleativas de oryzalin persistiram durante 55 das do perrodo de amostragem nas parcelas sem pesteva. ERBACH \& LOVELY (1975) relatam que reslduos de plantas de milno não afetaram significativamente o controle das invasoras quando os hepbloldas foram aplicados nas doses recomendadas, mas aumentou sua infuncla no controle quando as doses foram

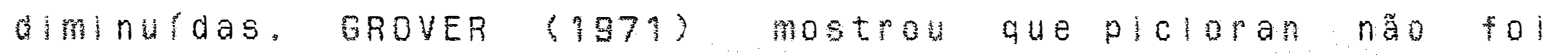
adsorvido pela materila organica do solo. WALKER \& CRAWFORD (1968) estudando a adsorpa de nepblcidas do gruo das triazinas em solos, observou que material de plantas no 
inlcio da decomposica no a e ra multo adsortivo.

BANKS \& ROBINSON (9980) relatam malor eficacla de controle de Amaranthus spinosus, Ipomoea purpurea e outras invasoras pela palna, do que pelo herblcida em areas sem palna. No entanto, melnom controle de gramerneas foi obtido com o herbicida nas areas sem palna, do que com hepblolda nas apeas com palha. THILSTED \& MURPAY (1980) pelatam o controle de chenopodium album por todas as combinacós de nerbicidas usadas sem encontrar aferencas entre cobertura de palnas ou no, observado tambem nas testemunhas sem nerbicidas: Amaranthus retroflexus, controlada pelos herblcldas, diferlu quando comparado com a testemuna sempalnas, nâ diserlndo com a presenca das mesmas.

A cinza resultante da quelma da resteva tem reduzldo o controle de Invasonas pela inativara do nepbicidas. NYFFELER \& BLAIR (1978) observaram que a cinza na superficie do solo incorporada a $2 \mathrm{~cm}$ reduziu a atividade dos herbicidas contra A. myosuroides. TOTH \& MHHAM (1973) demonstraram que a cinza da lueima de Themeda australls. peduziu o controle de invasoras dos nerblcidas linuron. diuron, atrazine, simazine e outros quando companados com tratamentos sem a queima desta vegetacio. Tambon olnza de Paspalum sp. apresentou consideravel adsorga de diuron, segundo TOTH \& MLHAN (9975).

2.4. Herblcldas de manejo 
o sistema de plantio dipeto requer o uso de nerblcidas de manejo para destruir plantas daninhas presentes anterlopmente ao plantio e, herblcidas residuais para controlar aquelas que surgem apos o plantlo. os nerbloldas tem sido usados sozinhos ou em mistura de tanque. Para a dessecaco da vegetaca os herbicidas mals importantes tem

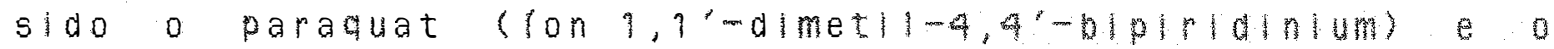
glyphosate $(N-(f o s f o n o m e t \mid 1)$ glicine $)$, resultando em controle eficiente das invasoras anuals, nas cuturas de milh e soja SHARDCASTLE, 1973; WORSHAM \& LEVIS, 1973; ROGERS \& WORTHINGTON, 1976 e SOMODY et ali1, 1978). Glyphosate temse mostrado mais eficaz que o paraquat em controlar invasoras perenes (CHAPPEL, 1974; ROGERS \& WORTHINGTON, 1976 E BULLOGK \& JEFFERY, 1980). Paraquat elimina apenas a parte abrea das plantas daninhas, sem atividade resinal no solo fTYLER,

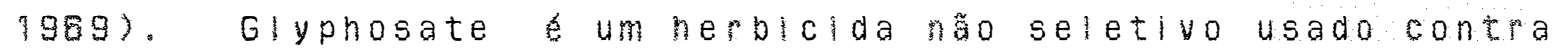
Invasoras anuals e perenes e, aparentemente, não mostra atividade residual no solo (BAlRDet al11, 1971). Herbicidas residuals, como alachior e I inuron, temmostrado controle mals prolongado de gramineas anuals quando combinado com tratamentos semelnantes de glyphosate do que com paraquat (HARDCASTLE, 1973 E WORSHAM \& LEWIS, M973). MaIOTES producós foram relatadas para milho e sola como resultado de um controle as invasoras por um perlodo mals prolongado (WORSHAM \& LEWIS, 1973). Como resultado de controle reduzido de Invasoras, producóes em plantio direto tem-se mostrado multas vezes inferlores do que em plantios convencionals 
(HARDCASTLE, 1973; SANFORD et a111, 1973 e KAPUSTA, 1979), 0 controle de invasoras pode ser reduzido em plantio dipeto devido ao maiop desenvolvimento das plantas daninhas na epoca da aplicacão dos herbicidas, e a quantidades de chuva Insuficlentes (KAPUSTA, 1979). Efeltos de fatores ambientes como temperatura, umidade do solo, umidade relativa, estado de crescimento e deficiencla de agua na eflciancla destes nerbiclas tem sido pelatados (WHLS, 1978: AHMADI et alli, 1980: MCWORTHER \& WILLS, 1980 e WHITWELL et a111, 9980).

\subsection{Interacão de nerblcldas e seletividade}

A seletividade flsiologlca de plantas em relacão a herblcidas pode ser afetada por suas comblnacos. que podem aumentar ou reduzir a sua acofofitotóna. LADLIE et a 111 (1975) relatam que trifiuralin reduzlu o crescimento das palzes, peduzindo muito a absorcão de ch-atrazine e ${ }^{14}-$ metribuzin e dos teores na planta de sola, quando estes dois nerbiclas foram aplicados em misturas. As injurias em sola. devidas a metribuzin, a pH elevados, também foram reduzidos por trifluralin, bem como a quelas causadas por baluas doses de atrazine, sendo o espectro de controle aumentado (WORSHAM \& LEWIS, 1973; LADLIE et a111, 1976 e LADLE, 1977). YORK \& SLIFE (1981) observaram que alachlor antagonizou as injurias de butidazole emmilno, quando ambos os herbicidas roram Incopporados em préplantio. Resultados similares foram encontrados para algus outros herbicidas testados do grupo 
acetanllidas. No controle de plantas daninhas, o antagonismo entre butidazole e alachlor tambem ocorreu com xanthium pensylvanicum e Ipomoea hederacea, mas näo com outras especles testadas. Alachlor aumentou a susceptibllidade de 1. nederacea a aplicacio de butidazole em pos-emergencla. Nenhum efelto antagonico fol observado quando alachlor fol incluldo na aplicacễo de butldazole em posmemengencla. LEAVIT \& PENNER (1978) observaram que plantulas de milho foram protegidas das injurlas de herbloidas do grapo acetanulldas, como alachlor, por protetores como R-25778 ( N$N-d|a| q u|1-2,2-d| c \mid 0$ roacetamida) devido a aumentos nos teores de glutatione nas palzes de mllno (CARRINGER et alli, 1978). NIFFELER et ali (1980) olservaram que metolachlor com o protetor CGA-43089 (a-(clanometoxilmino)-benzacetonitrila) aumentou a tolersncla de Brachiarla plantaginea, Eleusine spp., Panicum mellaceum e oryza sativa. Resultados preliminares indicaram que alachlor a 2,0 kg/ha protegeu plantas de pepino fCucumls sativus L. cy.wisconsin sMR 58 Pickles) dos efeltos do linution na dose de $0,5 \mathrm{~kg} / \mathrm{ha}$, em cerca de $50 \%$, quando comparado com a testemunha. Por sua vez, alachlor sozinno produzlu inlatas que representaram 77 $\%$ da perda de blomassa fresca das plantas.

2.6. Absorfão, translocacão e metabollsmo de herblcldas a base de urella 
recomendados para uso em diversas culturas para controle de um largo espectro de plantas daninhas de folnas langas e estreltas (Weed Sclence Soclety of America Handbook, 1983). A combinacão destes dols herbicidas é comumente usada em sistemas de plantio convencional e direto, paracontrole de diversas espécies de plantas daninhas. Linuron $(3-8,4-$ diclopofeni1)-1-metoxi-1-met|lupéla), é indicado para controle de plantas daninhas em germinacão e aquelas recem estabelecidas, através de aplicacós de pré e pós-emergancia. Linuron é mals prontamente absorvido atraves do sistema radicular das plantas e menos, através das folnas e caule. A trans|ocacaso é, prlmariamente, acrópeta, no xilema. Linuron é um forte inlbidor da reacão de HHI. Alachlor (2-

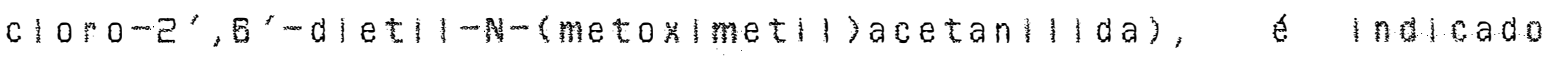
para controle de diversas espécies de plantas daninhas em aplicacós de pre-emergencia. Alachlor e absorvido principalmente pelas folnas de plantas em germinaca e secundarlamente, pelas ralzes, parecendo |n|b|r a sintese de proteinas em plantas susceptivels. Felloes e avela, apresentaram inibiga do crescimento como resultado da

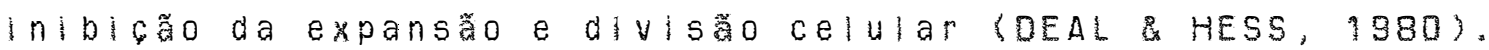

A seletividade dos nerblcidas em plantas tem se mostrado dependente de vaplos fatores como taxa de absorcuo, translocacoso, acumulaca e metabolismo. SMITHet ali (1958), estudando a aboprôno de hemblcidas do grupo a clopoacetanlidas por algumas espécies de plantas, observaram que milho, uma das especies mals resistentes, absorveu menor 
quantidade do produto do que avela e peplno, especles susceptrvels. por sua vez, sola, a outra especie resistente, absorveu cerca de tras vezes aquela do milno. HOGUE \& WARAEN (1988), observaram que IInuron era prontamente absorvido pelas ralzes de tomatelro e distriburdo atraves da planta. mas a malor parte permanecla nas ralzes de parsinaca sativa. Linuron havia sldo amplamente metabollzado nas folnas de $P$. sativa enquanto que poucos metabolltos foram encontrados em tomate. o herbicida causou rapla e completa inlalca da fotossintese em tomate e em P. sativa ela fol iniblda, mas temporariamente. GolBy (1965) mostrou que o nerblclda clopamben em sola fol todo transformado num conjugado de glucose, contudo a espécle susceptivel cevada, continna somente uma pequena porcentagem do cloramben na forma conlugada.

ROSEMOND et all (1975) mostraram que o controle seletivo de Munlembergla schreberi J.F. Gmel. empoa pratensls La ambas as especles tratadas via follar, metabollzaram 30 e 50 do llnuron absoryldo, respectlvamente, a outros compostos. Por sua vez, o materlal 19

de c translocado fol de 36 e 22 \% os metabolltos predominantes foram ldentiflcados em ambas as especles sendo

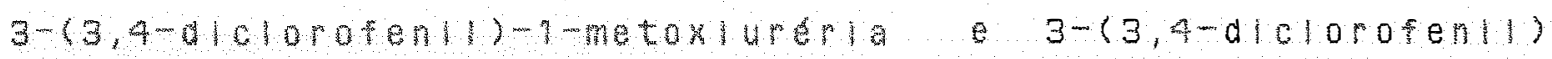
Uf ela (figura 1$)$ NASHEO \& LNIOK (1970) determinam fracôes de metabolitos como $3-(3,4-d) c \mid 0$ rofen 1$)-1-$ metoxiunela, $3,4-d i c l o n o n i l i n a$ (Figura 1$\rangle$ e um conjugado protelco de Innuron, representando 15 a $25 \%$ do nerblolda 
absorvido. Fol observado tambem, que a absoráa de linuron pelas ralzes, parece ser passlva e governada pela absorfaro de agua. SWANSON \& SWANSON (1980) mostraramque um disco de folna de algodão, uma especie resistente a dipon, num curto perfodo de sete noras, metabolizou monuron a $1-\mathrm{cp}^{-}$ clorofen|1)-3-metiluréa, $1-(p-c|0 r o f e n| 1)$ urela e pc) on onilida.

GEISSEIILER et al11(1975) discutem os mecanismos de transformaca das fenllunblas em plantas. sugerindo que estes mecanismos ocorrem em duas fases de reacoes. A fitotoxicidade dos metabolitos de N-monometile usualmente menos pronunclada do que os compostos originals dealquilados, desaparecendo com a reacâo de demetilacấo (SMITH \& SHEETS, 1967: GOREN, 1989 e STRANG \& ROGERS, 1971). Possivel ldentificaráo de anllinas radioativas IVrestem Sido Impossivel, como citado por GEISSBULER et alli(1975), talvez devido a uma transformaca paplda posterior da amina aromatica. Em adico aos metabólitos N-dealquilados, outros produtos muito mais polares c formando conjugados glucos/dicos, em quantldades slgniflcativas, fonam obsepados com monuron por Frear \& swanson (1972)*, cltado por GEISSB||LER et al|1 (1975) e revelaram ser estruturas de dols B-D-g)ucos(d)os (F)gura 1$)$.

LEE \& FANG (1973), estudando o metabolismo d. monumon em folnas isoladas de plantas de millo WFREAR, D.S. \& SWANSON, H.R. PHytochemistPy, 11, 1919, 1972. 
- LINURON E METABÓLITOS

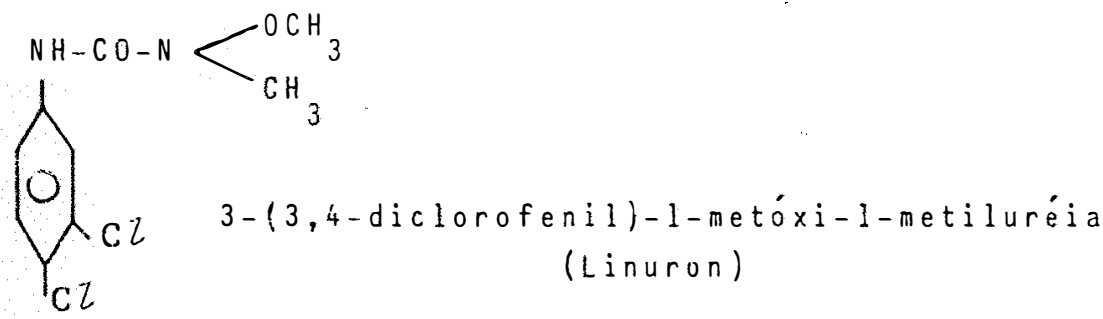

a) Demetil ação

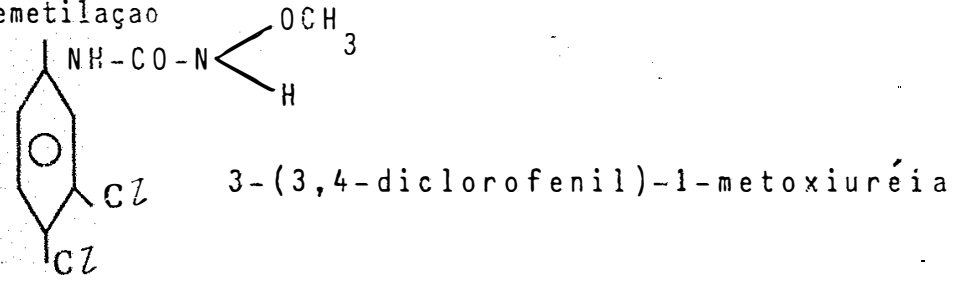

b) Demetoxilaçào

c) Hidrólise
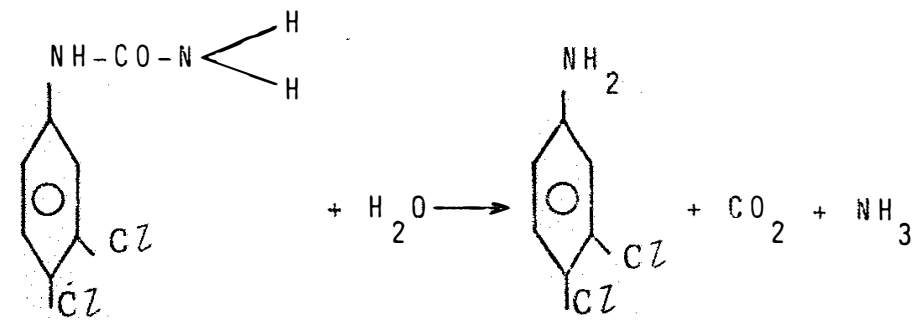

$3-(3,4-d i c l o r o f e n i l)$ uréia

3,4-dicloranilina

\section{- MONURON}

d) Conjugaçào<smiles>CC1CCC(CO)OC1COCN(C)C(=O)Nc1ccc(Cl)cc1</smiles><smiles>[CH]c1ccc(NN(N)C(=O)N(N)COCC2OC(CO)C3CCC2C3CO)cc1</smiles>

FIGURA 1. Fases de formação de metabólitos de linuron e monuron (conjugados), observados em plantas. 
efeliano, por melo de cromatografla em camadafina, separaram diversos picos de radioatividade, que numa sequencla de varlos intervalos, mostravam um gradual decréscimo do monupon $\left(N^{\prime}-(2-h) d r o x i-9-c \mid\right.$ orofenil) $-N-N-$ dimetiluréa), semple acompantiado por um aumento sequencial de $N^{\prime}-(4-c \mid 0$ rofen 1$)-N-$ metiluréla e, subsequentemente, p-clorofenlluréla. Em Feliano, os confugados desconnecldos que permaneceram na or $1 \mathrm{gem}$ da placa de cromatografia, foram separados após por melo de outras composläes de solventes, mostrand um plco com Rf 0,20 (mals próximo da origem) e, outro, com Rf $0,63$. A procura de outros compostos no primelro pico, permitiu Identificar um complexo monuron-polipeptidico; no segundo pico fol possivel identisicar outro complexo monuronpolipeptidico e um polipetidio complexo de $N^{\prime}-(4-c)$ orotent $)-$ N-metiluréla e B-D-glucostalos de $N^{2}-(2-n \mid d r b \times-4-$

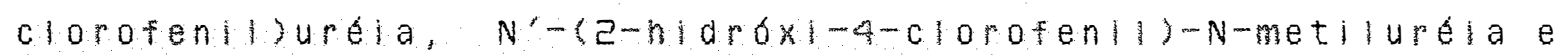
N-(hlaroxi-4-chorofenl)-N, N-dimathurela, não sendo ldentiflcada a cloroanllina, peferida por outros autores para esta clase de nerblcldas. 


\section{MATERIAL E METODOS}

\subsection{Experlmentos de campo}

Dols experimentos comsola, suscedendo trigo, foram conduzidos em condiofes de campo, em clayton (CL) e Rocky Mount (RM), no Estado da Camolina do Nopte, Estados Unidos da Ambrica do Norte, nos anos de 1981 e 1982. Em Clayton, os experimentos foram conduzidos na central crops Research station, em solo "Wagram" barro arenoso, com 2\% de materla organica (moo.). Em Rocky Mount, os experimentos foram conduzldos na upper coastal plain Research station, em solo "Dunbar" arenoso, com $1 \%$ de m.o.

Ds experimentos foram localizados em areas preulamente copplidas guato a acldez a a fertllidade do solo, com base nas recomendacos do North carolina Agrlcultural Extenslon serulce, para a instalaca dacultura do trigo. os experimentos consistiram dos geguintes tratamentos: a) Parcelas principais paramanelo da pesteva de $\operatorname{trlgo}$ - (1) Remocâo da resteva cortada, com a colnadelra, (2) Remofo e peposifo da resteva apos a aplicafốo dos nerblcidas, (3) Pemanencla da resteva e, (4) ouelma da resteva: b) pafcelas subalvidadas, paramanelo do solo-(1) cuitivo minimo (CM), fazendo-se duas gradagens a lo cm de 
profundidade, usando grade com uma serle de discos dentados e outra de discos lisose, (2) plantiodireto (po), usando-se uma maulina Allis-chalmens de quatro linhas, com um disco ondulado, seguldo por um sulcador para abertura e deposlcăo das sementes no solo; e, c) Parcela sub-subdivididas, para os nerbiclas de manejo-(3) glyphosate a $1,08 \mathrm{~kg} / \mathrm{ha} e$, paraquat a $0,56 \mathrm{~kg} / \mathrm{ha}$ mals $0,2 \% \mathrm{y} / \mathrm{y}$ de surfactante. As dimensoses da parcela sub-subdividida varlaram de quatro a sels flielras de sola, espacadas de $0,9 m$ por 12,2 m de comprimento. Foi usado o delineamento blocos casualisados, em fatorlal 4xटxट, com quatro repeticós. Foram usadas parcelas extras para os tratamentos de manejo da resteva e do solo. com lqual largura por $5.0 \mathrm{~m}$ de comprimento, com paraquat apenas e surfactante, para verificar os ereitos no controla das plantas daninhas, sem os herbicldas residuais.

A cultura precedente de trigo (cy. Monair $\left.1813^{\prime}\right)$ fol colnida por ocasläo da maturacaro com colnedelra, a uma altura de 15 a $20 \mathrm{~cm}$, sendo a resteva distribulda unformemente sobre as papcelas. A quantidade de resteva delkada sobre a supepflcle varlou de 3.500 a $9.00 \mathrm{~kg} / \mathrm{ha}$.

Dez a 15 dias apos a colnelta do trigo, semeouse em sucessavo sola cy. "Ramson' em todos os locals e anos. Procurouse estabelecer uma densidade meda de 20 a 25 platas/mna Inna. A protund dade de plantio vanlou de 3 a $5 \mathrm{~cm}$. A adubaca fol realizada somente na cultura do trigo, plantada anterlomente no sistema convencional. Abo o plantio da sola foram aplicados os tpatamentos nemblcidas, 
incluindo-se os produtos residuals em mistura de tanque (alachlor 2,24 kg/ha e inuron $0,56 \mathrm{~kg} / \mathrm{ha}$ ), exceto nas parcelas extras.

os herbicidas foram ap/icados atraves de um pulverizador costal a coe, calibrado a pressão de $1,4 \mathrm{~kg} / \mathrm{cm}$ e consumo de calda de 172 //ha $A$ barra de apllcacáo consistiu a quatro blcos tipo cone, com câmara de turbulencla, 190.02 , espacados $0,50 \mathrm{~m}$ e mantidos a uma altura de $0,30 \mathrm{~m}$. Após as pulverizacós a restevafol peposta no tratamento Remover-Repor.

\subsubsection{Avaliagôes de controle das plantas daninhas}

Uma escala porcentual de zero a 100 <ero=sem controle e, $100=$ controle totall folusada para avaliar Visualmente o controle das plantas daninhas por especie. A primelira avaliaca de cada experimento fol reallzada entre 10 e 19 dias após o plantio e a outra, sete dias após, para avaliar os rebrotes.

Na avallacoses por contagem das plantas daninhas fol usado um retangulo de ferro, nas dimensöes de $0,15 \times 0,80 \mathrm{~m}$. Estas avallacoes foram feltas nos tratamentos estabelecidos com os herbicidas residuais e nas partas extras. Em 1981, foram feitas tres amosiragens por unidade experimental e, em 1982, quatro, feltas ao acaso na área abranglda pelas duas Inhas centrais, realizadas entretres a quatro semanas após a emergêncla a sola. os dados da contagem foram anallsados apos a transformaco para ralz de 
$x+1$ e apresentados em numero de plantas por metro quadrado.

$$
\text { As espécies de plantas daninhas encontradas }
$$

nas áreas experimentais săo apresentadas na Tabela ?.

3.1.2. Populacão de plantas

o numero de plantas de sola pormetro linear fol determinado em 2 m de linha, nas duas Inhas centrais, ao acaso.

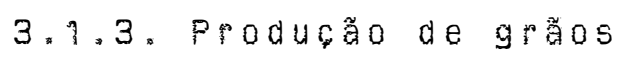

Na maturacão as producões de grãos de sola foram colntdas com uma colnedelra de parcelas. A area utilda parcela fol de $1,8 \times 12,2 \mathrm{~m}$. As ppodugóes de grasos foram pesadas e transformadas em $\mathrm{kg} / \mathrm{ha}$.

3.1.9. Analise estatistica

os dados foram analisados pela andise da Varlancla, aplicano-se teste-f e as medas comparadas usando-se o teste de Duncan ao hlyel de slgniflchncla de 5 \%

\subsection{Reslduos de herblcldas no solo}

Foram conduzidos ensalos blologicos a realizadas antises qumicas de laboratomo, atraves de cromatografia lquldo-9asosa e lfaula, para os hepbloldas alachlop e linuron. A finalidade fol determinar quantidades destes nerblcidas no solo, que posslvelmente interferem de 


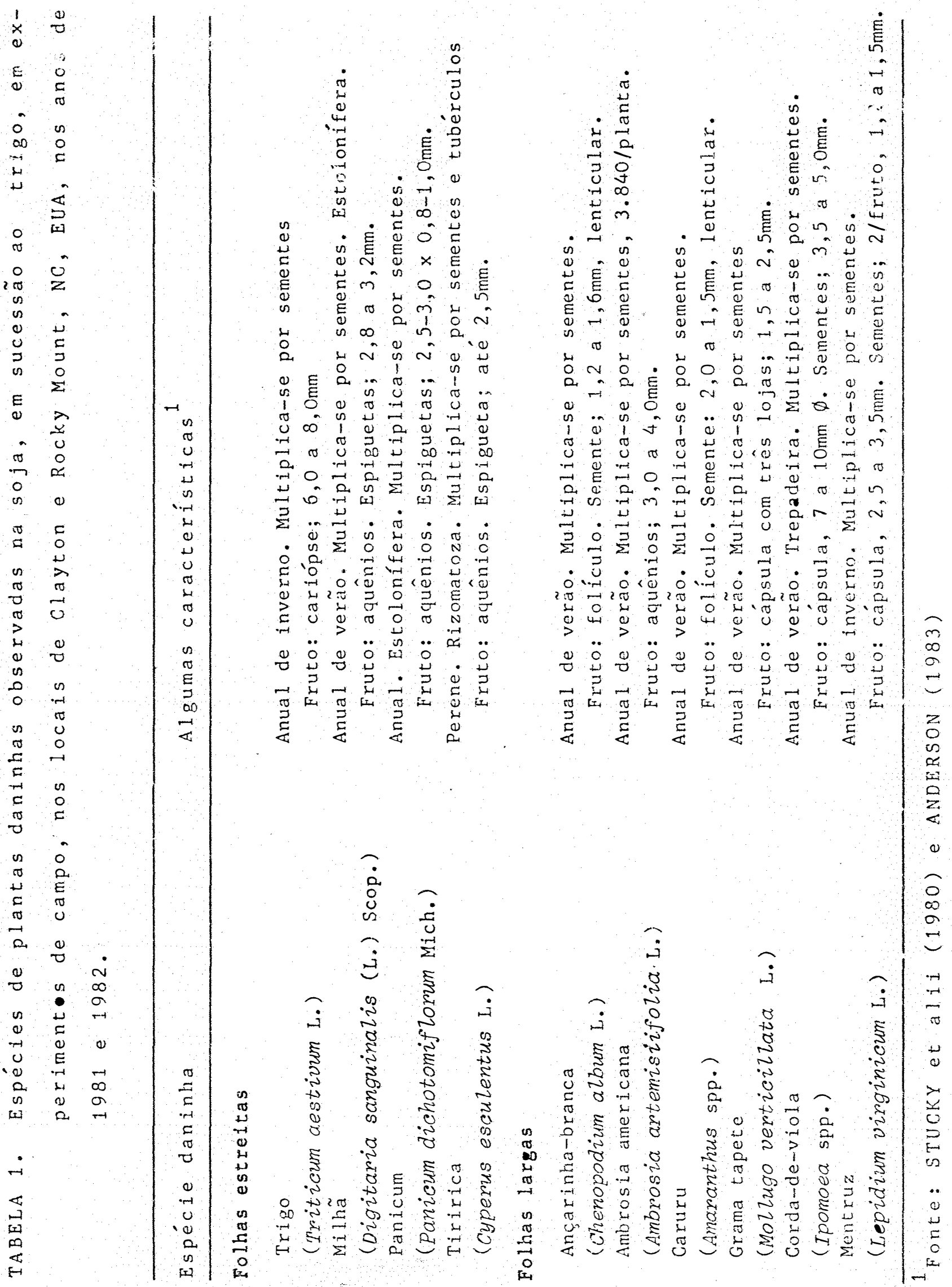


modo diverso no controle das plantas daninhas, sob as diversas situacóes de manejo da resteva e do solo.

3.2.1. Bloensalos para determinacão de alachlor e linuron

os bioensalos foram conduzidos com amostras de solo coletadas nos experimentos de campo, em 9 gal. As amostras de solo foram coletadas tpes a cinco dias apos a aplicacão dos herblcidas, em areallure da presenca da resteva. Dezesseis subamostras por amostra/subparcela (paraquat + glyphosate), foram coletadas a $7.5 \mathrm{~cm}$ de profundidade, ao acaso, na area das duas linhas centrais de sola, usando um amostrador de solo tubular. As amostras, apos homogenelzadas e colocadas em sacos plasticos, foram colocadas no dla seguinte em vasos de papel encerado ("Nestrlte") de 500 m de capacldade, em casa-de-vegetacão. Foram feltos furos na basedos vasos para drenagem e a umidade mantlda acima de $50 \%$ do poder de embebloão. para determinar os resfduos do herblcida no solo de clayton, foram usadas plantas testes de Panlcum mellaceum L., para alachlon e sorghum blcolor L. ,protegldo contra danos de alachlor por N,N-dialli-dicloro-acetamida, usado para possibilitar a detecoăo dos restudos de inuron. No experimento de Rocky Mount, substituiram-se as especies anteriores por olgltarla sanguinalls e cucumis sativus cy. "Wisconsin sMR 58 pickles', fespectivamente. solugöes padros dos herbicidas alachlor e In nuron foram preparadas, combinadas nas respectivas doses e adiclonadas a solos näo tratados, coletados prónimos as 
respectivas areas experimentals, para comparacões de resultados. As diferentes especies foram plantadas a $1,0 \mathrm{~cm}$ de profundidade e delkabas tres e duas plantas/vaso, respectivamente. A soluga nutritiva de Hoagland fol aplloada na instalaço do experimento e após, uma vez por semana. A reposifão de rgua fol feita sempre quando necessala. As determinacốs consistiram do peso da biomassa fresca da parte area, ou dossel, sendo os dados transformados em porcentagem da testemunha. A duraca dos experimentos variou entre 18 g 25 dias. Os tratamentos foram dispostos num experimento de blocos casualizados, com quatro repetíñes. os dados romam submetidos a analise da variancla e as módias separadas pelo teste de Duncan ao nivel de signifloñola de $5 \%$.

3.2.2. Determinaça de reslduos de alachlor e linuron por cromatografia liquldo-gasosa e liquida

Em 1982, as amostras de solo foram coletadas apenas no experimento de Rocky Mount, No, e determinadas anallticamente para os reslouos de alachlor e inuron. As amostras foram coletadas 10 dias a ós o plantio e foram compostas de 10 subamostras por subparcela caphosate t paraquat), coletadas ao acaso, a $7,5 \mathrm{~cm}$ de profundidade, na area aranglda por duas linhas centrats da soja, usando um amostrador de solo tubulam. As amostras form delmadas a secar ao ar durante a noite e apos, peneiradas em tamis de 2 mom. As amostras foram estocadas a o $G$, ate proceder-se a

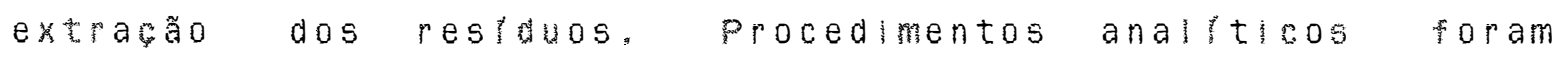


baseados em HUNT et a $11(1980)$, pana a lachlor, e em KHAN et a 11 (1975) e WALKER ZIMBDAHL (1981), para IInUron, sendo parcialmente modiflcados pelo autor, descritos a segulr.

3.2.2.1. Extracão dos nerblcidas

Uma amostra de solo de $25 \mathrm{~g}$, corrigida para 0 teor de umidade de G肯, Fol colocada num captucho de celulose de $80 \times 33 \mathrm{~mm}$ com um pedago de lä de vidro no topo. Um volume de 200 m de etll acetato fol entornado em frasco de fundo chato de $500 \mathrm{ml}$. Um aparelho soxhlet fol usado para extrair os herbicldas alachlor e linurondosolo. o etll acetatofoi claclado por cerca de cinco horas, sendo cada clalo de cerca de 25 minutos. o extrato fol del xado esfriar or 15 minutos. adicionando-se $25 \mathrm{ml}$ de etil acetato no extrator, para Ixlviar os reslduos remanescentes no solo. o extrato de solvente com o herblclda fol evaporado a ponto de nâa a dão ao vidro, num evaporador rapido, a 40 c. 0 residuo fol lavado do srasco com tres porboes de 2 m de nexano para dentro de um vidro de $20 \mathrm{mi}$, sendo posteriormente evaporado com um fluxo de ar para um volume de 2 mi, para separaconopor cromatografla em camada fina.

3.2.2.2. Separaca por cromatografia em camada tina (CCF)

os $2 \mathrm{ml}$ de extrato foram gotelados sobre placas de vidro de $20 \times 20 \mathrm{~cm}$ com camada de sllicagel of 1000 um de espessura, atlvadas previamente a 70 p por 30 minutos delmadas resfriar a semperatura ambiente. ouas 
amostras por placa foram goteladas com uma seringa de 500 ul, usando um apl|cador norizontal num finofilete, separados um do outro de $? \mathrm{~cm}$ na or lgem. As placas foram reveladas numa solucão de solvente de éter de petróleo, clorofómio e etanol a $95 \%(7: 2: 1$, y/y/y). os padros dos nerbicidas téchicos tambom foram aplicados nas placas, reveladas e locallzadas sob luz ultravioleta (UV) a $254 \mathrm{~nm}$ de comprimento de onda. Um valor de Rf de 0,E fol determinado para linuron e de 0,43 para alachlor. Falxas de alachlor e linuron foram enta comparativamente detectadas e demarcadas nas placas dos tratamentos com os reslduos do solo, sob luz UV. Após, estas falxas de material foram raspadas e colocadas em vidros de 20 ml de cintilacão liaulda. Os herblcldas foram extraldos da sllica cométer et/lico anidro, acrescentandomenos de $20 \mathrm{ml}$ do solvente, agitando e transferindo a extracão após um pepouso, para um segundo vidro. A fim de se obter uma posslvel extracãofinal de $95 \%$ a operacão fol repetida por quatrovezes. O segundo vidro, comosextratos, fol delxado evapopar sob a campanula sob comente de ar, apos cada ad cano do extrator. A bitima extracão fol precedida por uma flltragem através dum cartucho de florlsll sep-pack e transferdo para um teroelro vidro para evaporaconototal. As - lubcos das amostras foram reestabeleclas parclalmente com hexano para cromatografla gasosa e lfalda, para alachlor e Inuron, pespectivamente. Placas com conheddas gantidades dos herblcidas téchicos foram preparadas e usadas para determinar quantidades porcentuais de recuperaco. 
3.2.2.3. Cromatografia Ifquido-gasosa

A andise dos reslduos de alachlor hoj pealizada com um equipamento Tracor-MT 220 com uma coluna de vidro de $180 \mathrm{~cm} \times 7,1 \mathrm{~mm}$ 01, preparada com $4 \% 5 E-30+0 F-?$ em Gas chrom o (80/100 Mesh). A deteça fol felta com 83

detector de captura de eletrons de Ni. is parametros de operacão para a detecóa de alachlor foram: porta de injega 230 C, coluna 190 C e detector a 290 C: o $14 x 0$ de nitrogento (gás carregador) fol de $50 \mathrm{~m} / \mathrm{min}$ e o purgamento do detector de $20 \mathrm{mitmin;}$ a atenuaco fol alustada a 18 \% z

10 AFs: "bucking" Intepulo 6; velocidade do grafico? $\mathrm{cm} / \mathrm{min}$ : inlecão automatica de 3 ul da amostra cada $20 \mathrm{~min}$. A amostra padräo de alachlor com ?,025 ug/ml e amostras de solo compeslduos foram adiclinadas de hexano ate os ioml de volume. 0 tempo de retencáa de alachlor fol de 5 min. sob condicóes ambientais.

3.2 .2 .4$. Cromatografia ligulda

- sistema de deteça consistiu de uma bomba Water $6000 \mathrm{~A}$, um detector waters 490 UV alustado a $254 \mathrm{~nm}$, um programador de solventes waters 800 e um registrador de dados Waters Data Module 730. A coluna usada foi una Dupont Zopbax

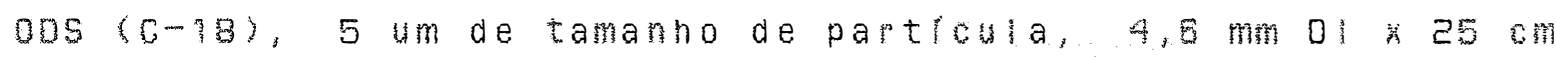
de comprimento. o sistema envolve oromatografla por fasa peversa numa coluna c-18 Hplo e uma fase movel de $50: 50$ agua/acetonitila. o sistema de solventes usado fol 
acetonitrila HPLC-grade e agua alonizada. o sistema de solventes fol flltrado atraves de um filtro de 0,5 um Milipore, tipo FH. A clarificacão das amostras fol felta com Wateps c-18 sep-packs. 0 inuron técn|co $(99,9 \%)$ fol usado para preparar a solucão padrão de $1,0 \mathrm{ppm}$ em nexano. 05 extratos de 5010 de linuron foram obtidos atravs de procedimentos de cromatografla emplacas (CCF), comola referldo anterlormente e, dilurdo em $10 m$ de hexano. Dez microlitros ga padrão e, Iguals de extrato de solo, foram injetados diretamente no cromatágrafo. 0 fluxofol de 1,5 ml min, dando um tempo de retencão de $13 \mathrm{~min}, 50$ b condicós ambientais. A recuperacão do linuron padrä́o de duas amostras de 5010 fol de cerca de $90 \%$

3.2.2.5. Analise estatistica

Os dados foram transformados em ppm dos nerbicidas e submetidos a analise da variancla, sendo as medas separadas pelo teste de buncan a noul de $5 \operatorname{lgn}$ ificincla de $5 \%$

\subsection{Experlmentos em casa-de-vegetaca}

3.3.1. Eseltos da Interacia de aclao fertico e de glyphosate na 50 ia

Um experimento com sola cy. 'Ramson' fol instalado em casa-de-vegetacão com o objetivo de deteminar os posstuels efeltos de acido fepulico ácido a-nidroxi-3- 
metoxi-t-c|namico), substancla alelopatica encontrada na resteva do trigo, em interacão com glyphosate, um nerbiclda sistêmico, não seletivo, ue em doses reduzldas possul atividades fitonormonais.

o experimento fol conduzldo em vasos de papel encerado ("Nestriten) de 1000 m, enchidos com 1250 g de terra $3: 2$ arglla/arela, sendo determinada a capacidade de campo. Foramfettos furos na base dos vasos para drenagem e escoamento de coe. Sola cy."Ramson'fol plantada, usando quatro sementes/vaso, a $2 \mathrm{~cm}$ de profundidade. 5olucos padrós de aclo ferulico foram preparadas em agua e tamponadas com NazHPOA (menos que $1,0 \mathrm{M}$ ) para alcancar pH 8,0 e facllitar a sua solubllizacão. As doses de aclodorullco usadas foram D, 75, 150, 225 e 300 ppm. Metade de cada dosefol aplicada, em guals volumes de soluça, na epoca do plantio, derramando as mesmas sobre o solo nos vasos ate a capacidade de campo, previamente determinada. Glyphosate fol pulverlzado apos as apllcacões de acldo ferulloo, usando um pulverizadop costal a.coz, com barra de pulverizacão sustentando um blco em cone, com camara de turbulência, 110.02, pressão de $1.9 \mathrm{~kg} / \mathrm{cme}$ e com consumo de calda de 172 1/na. As doses de glyphosate usadas foram: $0,0,75,1,50$, 2.25 e $3,00 \mathrm{~kg} / \mathrm{ha}$. Quatro dias apos a emergencla da sola, a segunda mela dose do ácido terullófol aplicada a derimando as respectuas solucos com os tiatamentos na superficle do solo. As plantas de sola foram paleadas para duas plantas/vaso. A solucão nutritiva de Hoagland fol usada 
uma vez por semana para suppir os nutrientes necessarios e felta a in pacáo sempreque necessuria, para manter a umidade acima de 50 \% da capacidade de campo. As determinacos finals foram: a) altura de plantas de sola, med da da base ate a insepcão da gema teminal; b) blomassa fresca do dossele, c) blomassa seca do dossel e das ralzes. A duracio do experimento fol de $2 e$ dias. 0 delineamento experimental fol blocos ao acaso, fatorial $5 \times 5$, com quatro repetiós. os dados foram submetidos a anallse da variancla e as méd as separadas pelo teste de ouncan ao noul de $\operatorname{significancla~de~} 5 \%$

3.3.2. Estudo da interaco dos hepbicldas alachlor e linuron. em tres diferentes espécles de plantas

o objetivo deste experimento fol o de verificar possuels efeitos da interagão dos nerbicldas alachlor e Iinuron em pepino (cucumis sativus L.), soja e ancarinha-branca (chenopodlum aloum $L$. ), quando aplicados em mistura de tanque. o experimento fol conduzldo em vasos de papel encepado ("Nestrite") de $500 \mathrm{ml}$, enchidos com $450 \mathrm{~g}$ de terra seca a ar, numa proporgão de $3: 2$ de arela/arglla. A capacidade de campofol determinada. Foram ineltos furos na base dos vasos para drenagem. Peplno, cy. "Wisconsin SMR 58 Plokes" gola, pu. "Ramson", fonamplantados am vasos a $1,5 \mathrm{~cm}$ de profundldade e, a ansaplnha-branca, ou simplesmente ancarinha, como sera denominada daqu parafrente, a 0,5 cm de profundidade. 0 del Ineamento experimental para pepinofol 
b|ocos ao acaso, com 13 tratamentos (fatorial |ncomp|eto), e tres repeticões. Ds tratamentos foram combinacões de doses de Inupon a $0,0,0,12,0,25,0,5$ e 1,0 ppm e, suas combinacões com $2,0 \mathrm{ppm}$ de alachlor e, comblnacốes de 0,25 , 0,5 e 1,0 ppm de alachlor, com 0,5 ppm de linuron. os experimentos com sola e ancarinha tiveram seus tratamentos distribuldos num delineamento em blocos ao acaso, fator|al 5 * 5, com tres pepeticoos. As doses de alachlor foram: 0,o, $0,12,0,25,0,5$ e 1,0 ppm: as doses de linuron foram:0,0, $0,08,0,12,0,25$ e 0,5 ppm. As solubốs padröes de alachlor e inuron foram preparadas, combinadas e adicionadas aos Wasos, com quantidades de agua para atingir a capaclade de campo. A solufa nutritiva de Hoagland foi usada uma vez poin semana para supplif os nutrientes necesapios. Agud de torneira fol usada para repor a umldade do solo nos vasos. mantida acima de $50 \%$ da capacidade de campo. Apos a emergancla, as plantas de pepino, sola e anorinna foram raleadas para tres, duas e quatro plantas/vaso, respectivamente. As determinapos finals foram: blomassa fresca do dossel e, blomassa fresca das ralzes, parasola e ancartnha. As duracóes dos experimentos foram de 28 dias. As blomassas frescas do dossel e das ralzes foram transformadas em porcentagem da testemunha. os dados foram submetidos a andise da varlancla e as medias separadas pelo teste de Duncan ao nlvel de significancla de 5 ga 
3.4.1. Estudos preliminares

Doses subletals dos nepblcidas alachlor e Inuron foram determinadas em melo de cultura, parasola e 14

pepino, para estudos de G-linuron e alachlop (Flgura 2 ). As doses escolnidas foram: a) para a sola, alachlor 1, o ppm, e I Inuron 0,32 ppm, que causamam reductes de 17 e $57 \%$ na blomassa fresca do dossel, respectivamente: para o pepino, alachior 0,12 ppme Inuron $0,08 \mathrm{ppm}$, que causaram reducốs de 14,3 e $68,6 \%$ na blomassa fresca do dossel, fespectlvamente. A escolna das doses baseou-se em injurias menores do que $25 \%$ para o alachlore, menores do que $75 \%$ para o Hinuron. Essa injuria para o alachor năo causaria reducoes signiflcativas d blomassa do dossel da planta e darla protecấo contra os efeltos do innuron. A metodologia usada fol baseada em PINTO 8 CORBIN (1980).

3.4.2. Cultura de plantas

Sementes de sola e pepino foram germinadas em vasos plasticos contendo uma mistura de vermiculita, musgoe cascalno $(1: 1: 3, \quad y / v / y)$. Aga destliada fol adicionada diarlamente. Aos tres ou quatro dias apos a gemmaföo, as plântulas foram bem lavadas com a para frascos de Elenmeyer re 250 ml contendo $100 \mathrm{ml}$ de solucổo nutpltiva de Hoagland, $50 \%$ dllulda, compH $6,0,24$ horas antes do tratamento quimico. Duas plântulas pop frasco (envolvido com folna de alum(nio) foram cultivadas numa 

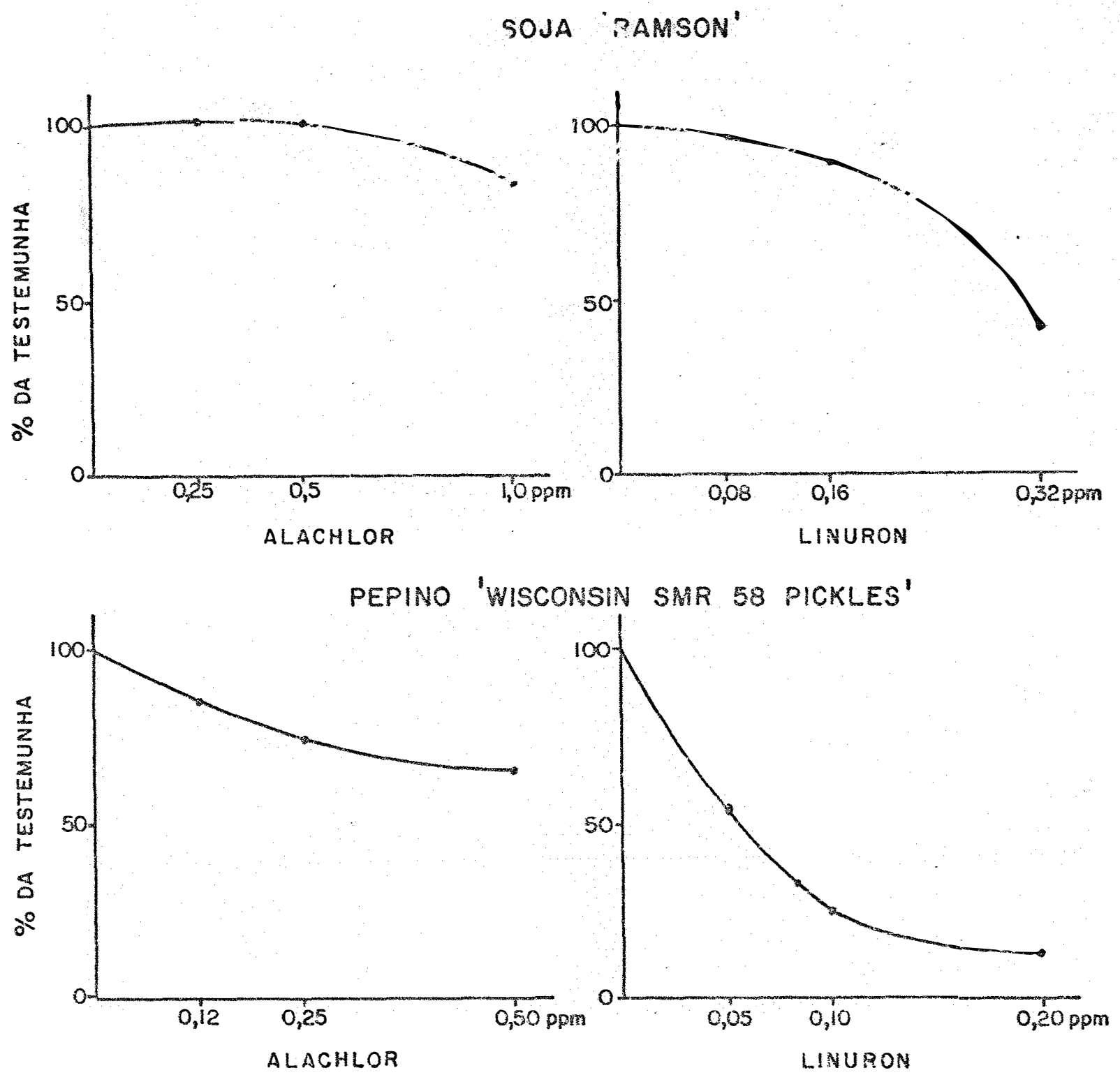

FIGURA 2. Reduções da biomassa fresca do dossel de plantas de soja e pepino, baseado na testemunha $(=100 \%)$, nos tratamentos de alachlor e linuron, em experimentos pre 1 iminares. 
camara-de-crescimento com luz, numa combinapäo de bulbos de luz fluopescente e incandescente, numa intensidade de iz h) ux, posicionado a $0.5 \mathrm{~m}$ acima das plantas em cresclmento. 0 comprimento do dia e a temperaturaforam mantidos a 13 noras e $28^{0}$ C, respectivamente.

3.4.3. Tratamento quimico

Linuron tonico 14 -radioativo fol fornecido pela bu pont, tendo uma atividade especiflca de 5,84 uci/mge 14

pureza em c-linuron emmais de $99 \%$. Uma solucão estoque de 14

5 uci de c-linuronfol preparada emágua destilada. A dose de linuron radioativo aplicada a cada too ml de melo de cultura por frascofol de 25 ug $(0,19$ ugl) e de 7,6 ug (0,05 uci), para sola e pepino, pespectivamente. os tratamentos para sola e pepino foram: testemunha (sem hepbicldas). alachlor, c-linurone c-linuronmals alachlor. As doses peviamente determinadas para uso em soja foram: alachlor 1, o ppme linuron $0,32 \mathrm{ppmm}$ em pepino foram: alachlor 0,12 ppme Inumon 0,08 ppm. Tres experimentos sequenclats em delineamentos inteiramente casualizados foram conduzldos para soja e apenas um para pepino, com duas piantas pop frasco de Enlenmeyer, com duas repetifoes cada. os dados foram analisados atraves da anablise da variancla e as medias separadas usando-se o teste DMs $(0,05)$.

3.4.4. Absorgão de agua e de ${ }^{14}$ C-linuron

A absorco de água fol determinada díarlamente 
e cada frasco retornado a $100 \mathrm{ml}$ do volume inicial. A 19

absorgano do c fol medida pela contagem díarla da radloatividade em amostras de $2 \mathrm{ml}$ da solucão nutritiva. A radloatividade fol corriglda para contagens díarias (DPMc), baseada na solucão radloativa iniclal de Hoaglana (H), sem plantas, através da fómula OPMC = DPMdia + [DPMdia

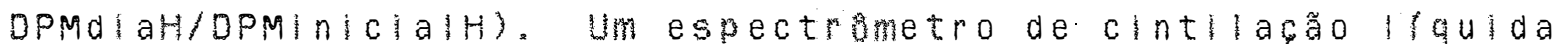
Packard Tri-Carb Mod. 3225 fol usado.

14

3.4.5. Extracăo de c-linuron e metabolitos

o procedimento de extracão de 14 o-linuron e metabolitos pode ser visualizado na Figuna 3. As plantas foram colnidas aos olto e nove dias após o tratamento e seccionadas em folhas simples e compostas, cotiledones, eplobtl10, hipocotilo e raizes, estas lavadas com agua destliada e secas com papel-toalna. os pesos de blomassa fresca das seccões de plantas foram determinados. Linuron 19

G-radloativo e metabolitos foram extraldos das partes das plantas seccionadas de uma repetíño de duas plantas/expepimento, com a $\mathrm{ml}$ de metanol, após terem sldo mantldas perrigeradas e, enta trituradas num triturador de tecido servall ommimixer. o homogenelzado fol filtrado atraves de papel filtro, num segundor de flitromillpore, e

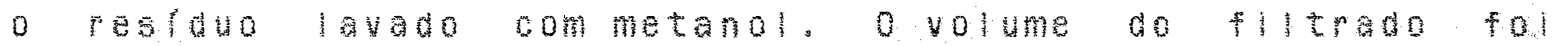
determinado (60 a $80 \mathrm{~m}$ ). uma alfauta de $2 \mathrm{ml}$ do filtrado fol retirada para a deteminacão da radioatividade soluvel em

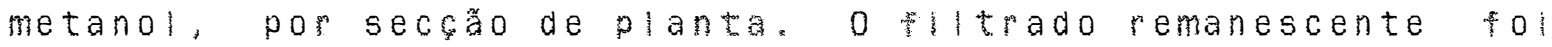




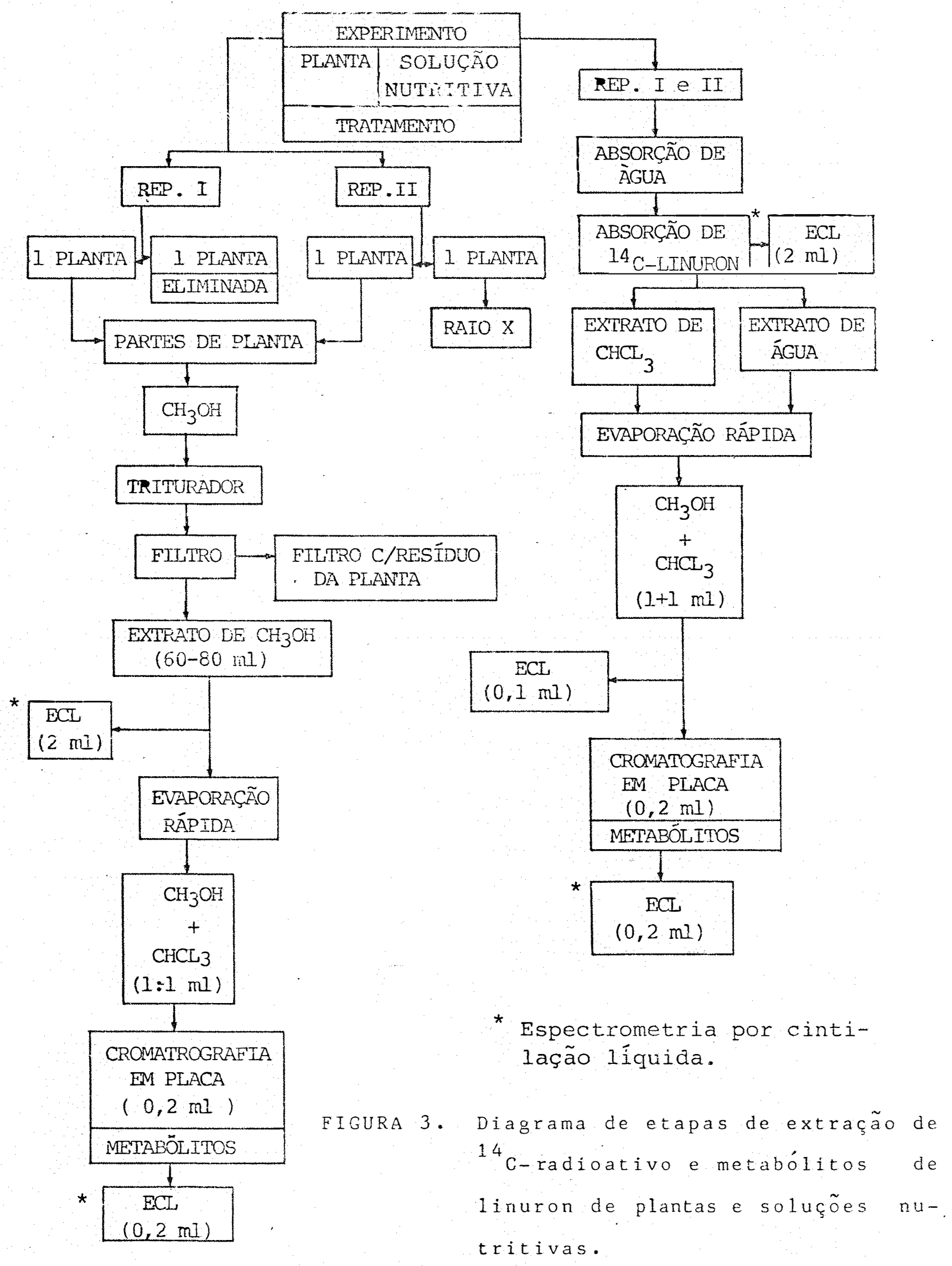


evaporado a ponto de nâo adesâ a vidro e pemovido do frasco com metanol e clorotumlo (1: 1 m), paracromatografia em placas de vidmo (CGF) e determinaço das pracoses de metabolitos, sendo usados o, e mi por borräplaca. os restanos radioativos insoluvels delxados no filpo, dos homogenelzados de plantas, nấo foram determinados.

o lnuron madioativo e os seus metabútitos foram extraldos das solucões nutrltivas de Hoagland com 200

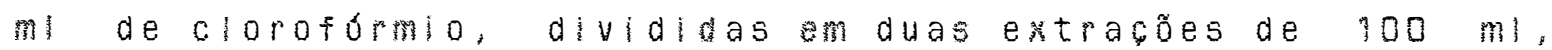
usando um funil separator para separap as fracoes soluvels em clorofirmio e agua. Estas fracões foram evaporadas a o poto e

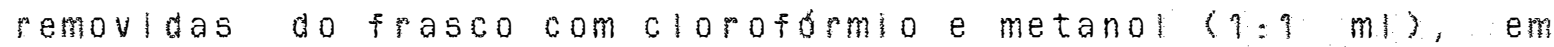
$\stackrel{4}{4}$

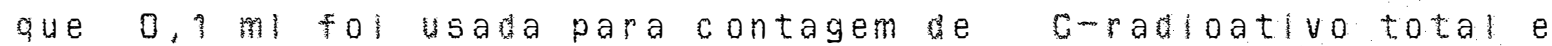

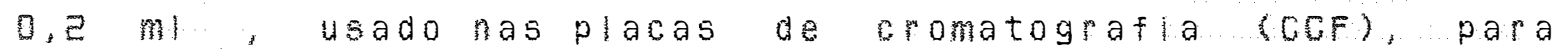
determinaço das fracón de metabulitos.

14

3.9.8. Metabulitos de c-1inumon

os extintos de metanol, previamente concentrados de partes a plantas e da solucâ nutritiva,

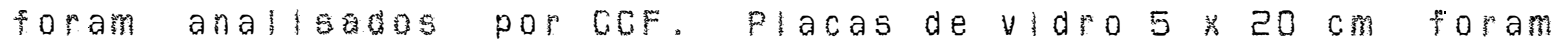

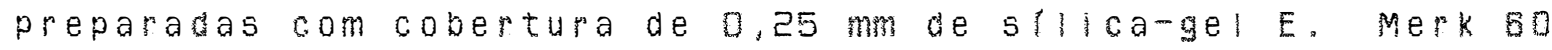
HF-259. Uma racio de 200 ul de cada concentrado de extrato de metanol e clorofomio fol gotelado sobie uma place de cromatogufla. Estas placas foram neveladas num sistome de alventes benzeno e acetona $(2: 1$, w/v), para separar |

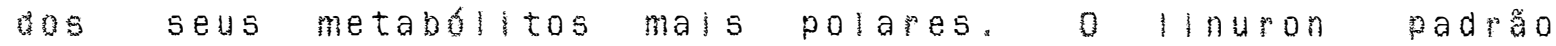

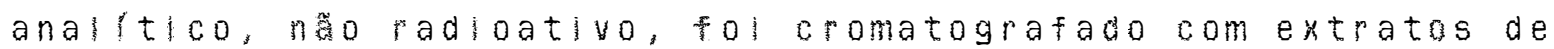


metanol, para comparacão com sua contraparte padroativa. Uma 1 uz ultravioleta $(254 \mathrm{~nm})$ fol usada papa determinacão visual do padrão analitico não radioativo. As posiposes dos picos de 14 14

c-linuron $(25$ ul $)$ e do c-inuron e seus metabolitos, de partes das plantas extraldas por metanol, foram determinadas por vapredura das placas con um equipamento Radiochromatogram Scannep Packard Mod. 7201. As areas padoativas foram raspadas das placas para vidros de cintllacão, para a medida da radioatividade por espectrometria de cintilacão la a da.

3.4.7. Técnlca de cintilacão lfquida

A radoatividade fol quantificada com um espectrometro de cintliacão. I quida Packard Tri-Garb Modelo 3225. As amostras foram contadas de acordo com procedimentos padrös de radioanálise (PATTERSON \& GREENE, 1985). A correcão das intepferênclas fol obtida pelo metodo da rază dos canals e pelo padrão automatico externo (PAE). o coquetel de cintliacão usado na quantificaño de cofol: a) amostras em metanol (para plantas e solucós nutritivas) $-1,59$ ppo $(2,5-|f e n| 10 \times a z 0 \mid e), \quad 0,3$ g popop $(1,9-b) 5(2-(4-m e t)-5-$ fen loxazol11) )-benzeno), 1000 ml de Triton $x-100$ e $2000 \mathrm{ml}$ de tolueno; b) materilal paspado das placas de cromatografla o coquetel indicado antes, mals sllica $4 \%$ mod 9 de sllica: $2500 \mathrm{~m}$ da solucão indlcado no (tem a). correcoes de interferpincla foram obtidas pelo uso das segulntes equacos: $Y=(P A E \times 57,5)+45,4$ e $Y=(P A E \times 25,3)+79,3$ previamente determinadas para os coquetels de cintilacão b b), 
respectivamente.

3.4.8. Andise dos dados

A absora cumulativa de agua em ml fol determinada. A contagem porminuto (CPM), durante cinco minutos, fol registrada no espectrometro por cintilaca

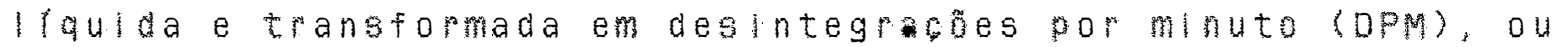
sela: DPM = (CPM $/ Y\rangle \times$ TDO. Estas foram transfomadas em 14

ug/g para c-linuron/biomassafpesca da planta, usando a 14

formula $\quad \mathrm{ag} / \mathrm{g}=$ (DPM/ Biomassafresca) / (2.220.000/ 19

150 ug c-linuron), e seus metabolitos. Tambem foram anallsados extratos em cloroformio e em agua dos melos de cultura, incluindo c-metabolitos. fol usado um experimento inteiramente casuallzado, com fatorlal. os dados foram submetidos a anallse da varlancla e as medias separadas usando-se o teste DMS $(0,05)$.

3.4.9. Autoradlografla

Uma repetlca de plantulas crescendo em cultura liquida, que continha o herbicida radioativo, como ja descplto anteplormente, fol lavada com agua destllada e seca com papel-toalha. As plântulas, separadas em folhas, cotiledones, calle e ralzes, foram prensadas entre papel toalna e secas a $70^{\circ} \mathrm{c}$, por 24 horas. Após a secagen, as partes das plantas foram montadas sobre papel e expostas a flime de ralo-x Kodak No Screen, por 20 a 25 dlas, 0 fime de rato-x fol revelado de acordo com as pecomendabos do 
fabricante. 


\section{RESULTADOS E DISGUSSAO}

\subsection{Experimentos de campo}

4.1. 1. Interaço local e ano na produco a de sola

Ao comparar diferentes locals e anos na produca de sola (Tabela 2 ), observa-se que as producóes em Glayton em 1981, foram malores do que as de clayton e Rocky Mount em 1982 (GL e RM/82). As menores producöes foram obtidas em RM/81. Condlcós ambientals tals comosolo, clima e varlacóes no controle das plantas daninhas, podem tei influldo nas producós de sola, uma vez que a mesma cultivar 'Ramson' fol usada em todos os locals e anos. A mals balxa producio de soja em RM/81, pode ser atrlbulda seca, a qual ocopreu antes e apos oplantio ae 19/00/81 (Apandice) 1 ), resultando em balxas populacues de plantas, pincipalmente quando a resteva fol quelmada (Tabela 3 ).

As anallses de variancla para os resultados dos experimentos de campo podam ser observadas nos apendices ᄅ

4.1.2. Efettos do manelo a pesteva 
TABELA 2. Produção de soja, nos experimentos de clayton Rocky Mount, NC, nos anos de 1981 e 1982 .

Produção de soja (kg/ha)

\begin{tabular}{cccc}
\hline \multicolumn{2}{c}{ Clayton } & \multicolumn{2}{c}{ Rocky Mount } \\
\hline 1981 & 1982 & 1981 & 1982 \\
\hline $1873 \mathrm{a}^{1}$ & $1618 \mathrm{~b}$ & $1096 \mathrm{c}$ & $1662 \mathrm{~b}$ \\
\hline
\end{tabular}

1 Médias seguidas pelas mesmas letras, não diferem significativamente entre si pelo teste de Duncan a $5 \%$ 
4.1. 2.1. Efeitos na producão de sola

$$
\text { As producos de sola dos diferentes }
$$

tratamentos de manelo da resteva de trlgo (Tabela 3 ) não

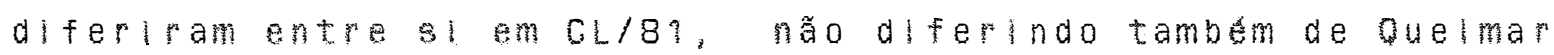
e Remover a resteva, em CL/8E e de Delxar e Remover-Repora pesteva, em RM/82, sendo todas estas supeniones producãodo tratamento ouelmar a resteva, que resultou na mals balxa produc ão em RM/81.

As altas producóes em CL/81 se devem a malor populacĩo de plantas, a qual não fol afetada pelos tratamentos de manejo da resteva. Ouelmar e Remover a resteva em CL/82, parece ter eliminado um excesso de resteva e umidade do solo, que prejudicaram as producões dos tratamentos Deikar e Remover-Repor. Deixar a resteva na superficle do solo tem mostrado reduzir a germinacio e o cresclmento, e balxar as producbes (MARDCASTLE, 1973; CoX, 1977; COLIINS \& CAVINESS, 1978; FRENGH\& SANTELMANN, 1978 \& STEINSIER \& OLIVER, 1979), ou atrasar a emergencia da sola (VOLL, 985). Efeltosfltotorlcos de substanclas soluvels em agu foram identificadas por Guenzl et a Substancias como os ácidos ferulico, p-cumáloo, siringlco, yantico e p-hidroxibenzolco săo capazes de apresentar efeltos inibltoplos em plantas (GUENZl \& MCCALLA, 1964). A

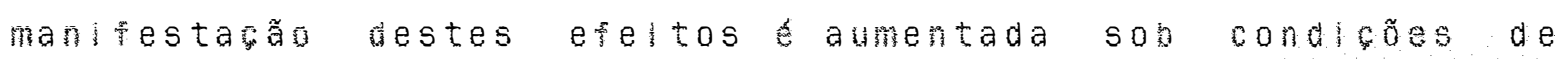
tempo ou solo umdos, balxas temperaturas, aumentos de precipitaco anual e malores quantidades de pesteva (NORSTADT \& MCCALLA, 1958; COCHRAN et AII1, 1977 E PAPENDICK \& MILLER, 


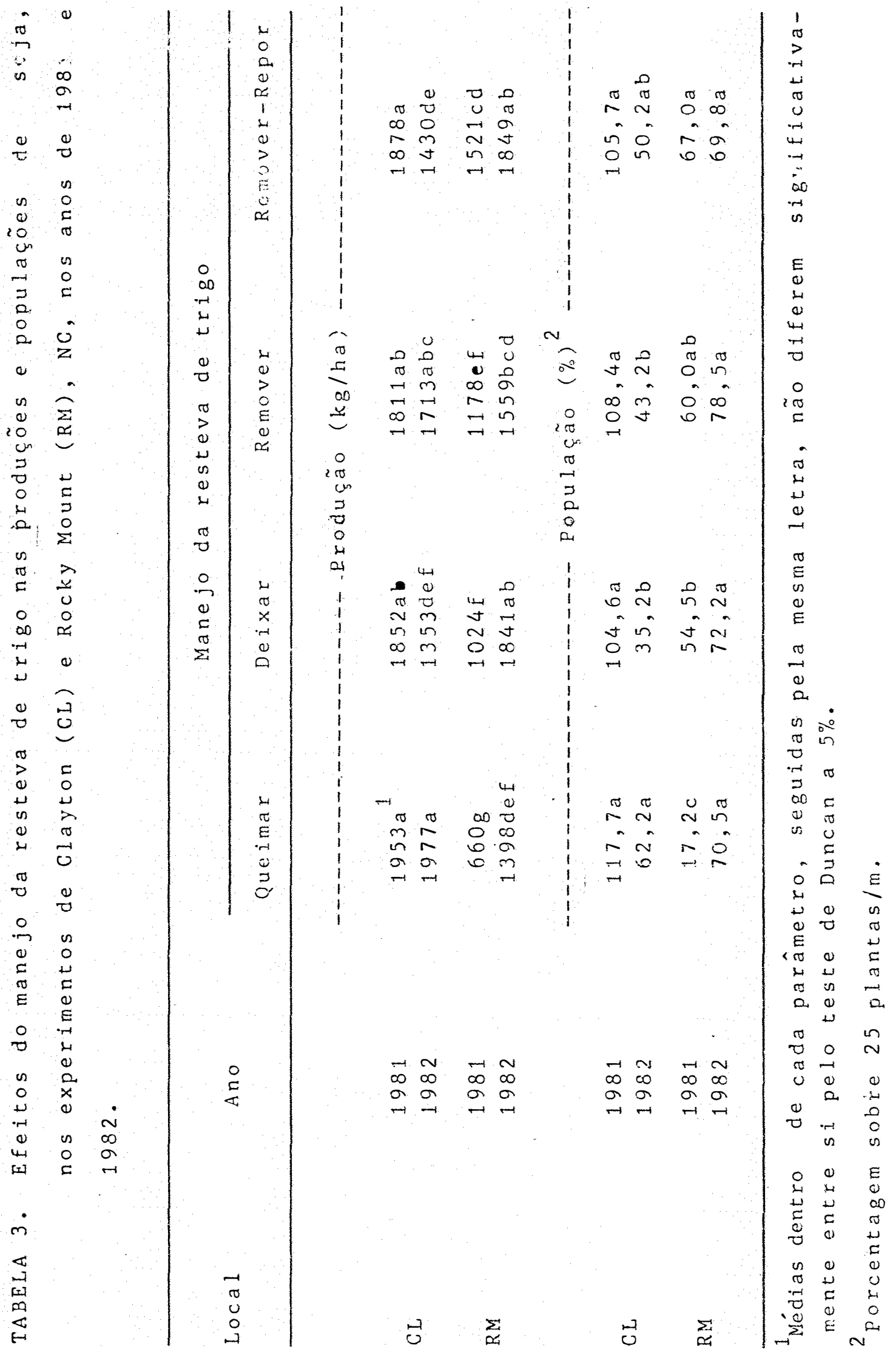


1977), sendo mais frequentemente associada a solos pesados, mal arelados ou inundados (PATRICK \& KocH, 1958). OS experimentos foram conduzidos em solos arenosos, bem drenados, exceto em clayton, em 9882, em que parcelas com resteva (Deixar) coincidiram com areas com maior umidade no 5010. No entanto, Queimar e Remover a resteva em RM/82, apresentaram as menores producoes, levando a acpeditar que

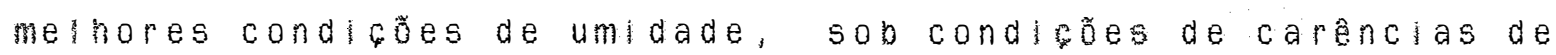
chuvas, possam ter permitido melhor crescimento da soja sob a resteva. A importancia da resteva em manter a umidade solo, com malor inflitracão de agua e menor evaporacão da umidade, fo discutida por PHILLIPS et al| (1980).

Os resultados de RM/B1 foram multo afetados pelas balkas condifós de precipltagão observadas por ocasia do platio. ocorrendo solo seco e poeirento, náo refietindo os registros de precipitacão ocopridos prónimos do local (Apêndice 1). As condicóes de seca acarietaram atrasos de germinacão e de crescimento, afetando de modo especial o tratamento quelmar, que apresentou a mals balxa populacão de plantas e a menor producão de sola neste experimento. A quelma da resteva delxa o solo exposto a os efeitos dessecantes do sol e dovento, pesultando em malor perda de umidade do solo por evaposacão. Ainda, a queima da resteva pode destrula especies de plantas daninhas, como o trigo, ou estimular a germinacão e emerancla de plantas daninhas pela ą̆̃o do calor ou penetraço da luz no solo, tendêncla observada para a somatórla de plantas daninhas de folnas 
largas (Tabela 4), bem como reduzir a acãonerbiclda pelas cInzas (TOTH \& MILHAM, 1973 e NFFELER \& BLAIR, 1978), afetando as producóes. Po ulacóes adequadas como os de CL/81, reduziramos efeltos de fatores adversos.

As médias de producão de sola (Tabela 4), nẫo acusaram diferencas significativas para eseitos de manelo da resteva de trigo, emora a sua presenca reduzisse a somatorla das plantas daninhas de folnas largas em Delxar e RemoverRepor a resteva e, efeitos do fogo, peduzlssemas infestafón de trigo, em oueimar a resteva. Varios são os fatomes responsaveis pelo nivelamento das diferencas.

4.1.2.2. Efeltos no controle das plantas daninhas

Queimar a resteva (Tabela 4), fol eflcaz em destruir e reduzir as infestacóes de trigo na superficie do solo, que ao germinarem competem com a cultura da sola durante o seu desenvolvimento iniclal. Exceto para ambosia, nenhuma diferenca de manelo da resteva fol observada entre as demals espécies. Diferencas signiflcatlvas foram observadas para milhã e grama-tapete, nas parcelas sem os heplicidas residuais.

A malor infestacão de ambrosla ou a malor densidade de plantas daninhas de folhas lapgas, no tratamento Quelmar, quando comparado com th go, poopla samo restiado da germina a a o sementes das camadas mais profundas do solo, cuja dormêncla rol guebrada pelo calor ou pela kuz, não sendo destruldas pela aç̃o do fogo. Ainda, sua malor germinacão e 


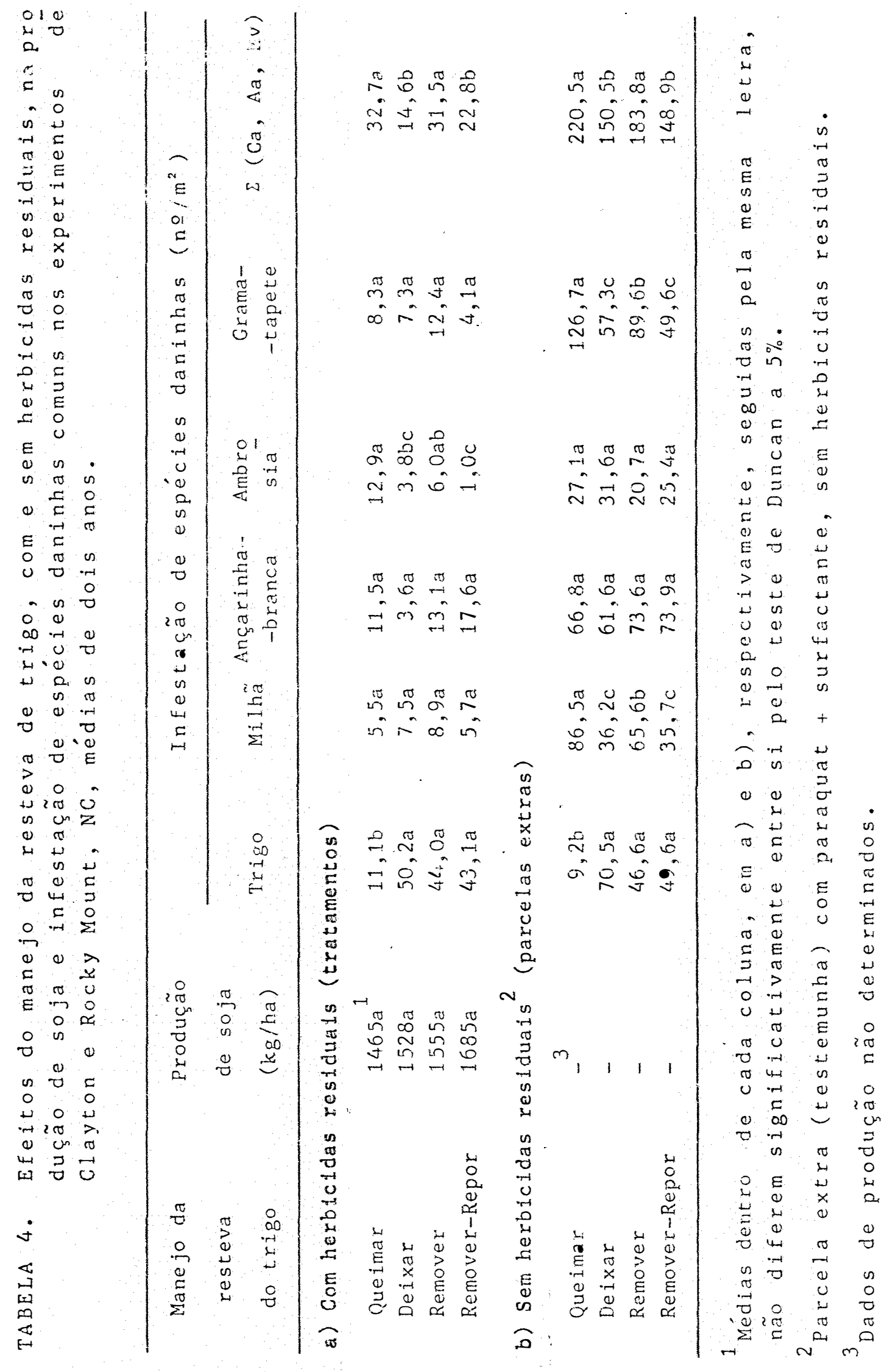


emergencla pode ser devido a clareiras abertas na superficie do solo com a remocão da resteva de trigoe, eliminacão de fatores alelopaticos. A analise dos dados sob o ltem interacáo de manejo da resteva e do solo (Tabela 13) proporciona consideracos mais adequadas para esta espécie. Por outro lado, sabe-se que a atividade dos herbicidas residuals pode ser reduzida pela interceptacia devida aे pesteva, ou pelo efelto adsortivo das cinzas na superficle do 5010 (TOTH \& MILHAM, 1973; ERBACH \& LOVELY, 1975; BANKS ROBINSON, 1980 e MOSS, 1981), näo oservada aqul e que depende da ocorrencia de chuvas após a aplicacão de nerbiclas (LOWDER \& WEBER, 1979) e tipos de herbleldas (BANKS \& ROBINSON, 1980).

De modo inverso, as menores infestacöes de ambrosia nos tratamentos Delxar e Removerarepor, ou suas tendênclas expressas pela somatóla de follhas largas, poderiam ainda ser devidas a efeltos alelopticos da resteva de trigo e/ou efeltos de luz e temperatura afetando esta(s) especie(s) daninhass) (PATRICK et alil, 1983: BHOMIK \& DOLL, 982a: LIEBL, 1982; PUTNAM et a11, 1982 \& ALMEIDA R RODR/GUES, 9985,1986$)$.

As reducoues na infestacão da milna e da gramatapete, observadas na ausênclados herblcias residuats. indicam a ocoprencla de efeltos aleiopaticos elou de luz e temperatura da resteva de trigo gobe estas popos daninhas. Ao contriplo, unas infestacoes maximas em quelmar sugerem quebra de domencla devidas ao calor da weima da 
resteva.

A Tabela 5, apresenta informacóos semelnantes a Tabela 4 para ambrosia, para CL/81. O nomero de plantas de trigofol reduzldo na operacia de Remover a resteva em $R M / 82$. possivelmente por carreamento das sementes para pora da parcela, por enfardamento a maquina, balkando a sua infestaça.

Na Tabela sõo apresentados os resultados da interąão do manelo da resteva de tpigo com locals e anos e, seus efeltos na reducão de infestacão de algumas especies daninnas, na ausencla dos hepblcldas residuais. Estes nesultados indicam que, ocaslonalmente, sob malores Infestacóes de ancarinha, como em CL/81, Delkar a resteva reduzlu sua infestacano, seja por efeltos alelopticos e/ou I uz e temperatura, no diferindo os demars tratamentos com malores infestacões. THLLSTED \& MURAY (1980) observaram que esta espécle ena controlavel pelos nerblcidas usados, não sendo susceptrvel aos efeitos da pesteva de trigo. portanto, concordando com os resultados da maloria dos locals e anos dos experimentos. Sob malores intestacões de ambosia, em CL/81, quelmar aumentou sua infestacono, sendo, por sua vez, diminulda em RM/81, ano em que o perlodo de plantlo da sola rol multo seco. Segundo Moss (1981), sementes de

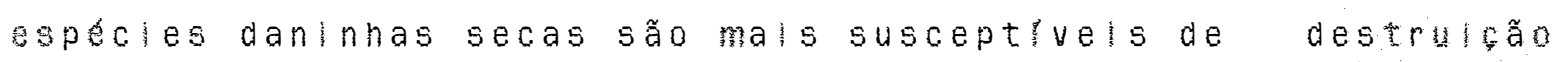
pelo calor do que sementes commalores teores de umidade. os demals manejos não indicaram eteltos alelopaticos elou de luz e temperatura sobre a espécle em funcão do ano e local. A 
TABELA 5. Efeitos do manejo da resteva de trigo e suas inte rações, com os herbicidas residuais, na infestação de éspécies daninhas, nós experimentos decláy ton (CL) e Rocky Mount (RM), NC, nos anos de 1981 e 1982 .

\begin{tabular}{|c|c|c|c|c|c|}
\hline \multirow{3}{*}{$\begin{array}{l}\text { Manejo da } \\
\text { resteva } \\
\text { do trigo }\end{array}$} & \multicolumn{2}{|c|}{ Infestação de } & \multicolumn{3}{|c|}{ espécies daninhas (no/m $\left.{ }^{2}\right)$} \\
\hline & \multicolumn{2}{|c|}{ Trigo } & \multicolumn{3}{|c|}{ Ambrosia } \\
\hline & $\mathrm{CL} / 82$ & $\mathrm{RM} / 82$ & $C L / 81$ & CL $/ 82$ & RM/ 82 \\
\hline Queimar & $5,1 c^{1}$ & $15,6 \mathrm{bc}$ & $31,0 \mathrm{a}$ & $1,8 c$ & $3,1 c$ \\
\hline Deixar & $60,2 a$ & $42,7 a$ & $9,3 \mathrm{bc}$ & $1,2 c$ & $0,2 \mathrm{c}$ \\
\hline Remover & $64,6 a$ & $28,5 b$ & $13,2 b$ & $1,6 c$ & $2,1 \mathrm{c}$ \\
\hline Remover-Repor & $51,9 a$ & $36,5 a$ & $0, a_{c}$ & $1,2 c$ & $1,0 c$ \\
\hline
\end{tabular}

1 Médias dentro de cada espécie daninha, seguidas pelas mesmas letras, não diferem significativamente entre si pelo teste de Duncan a $5 \%$. 


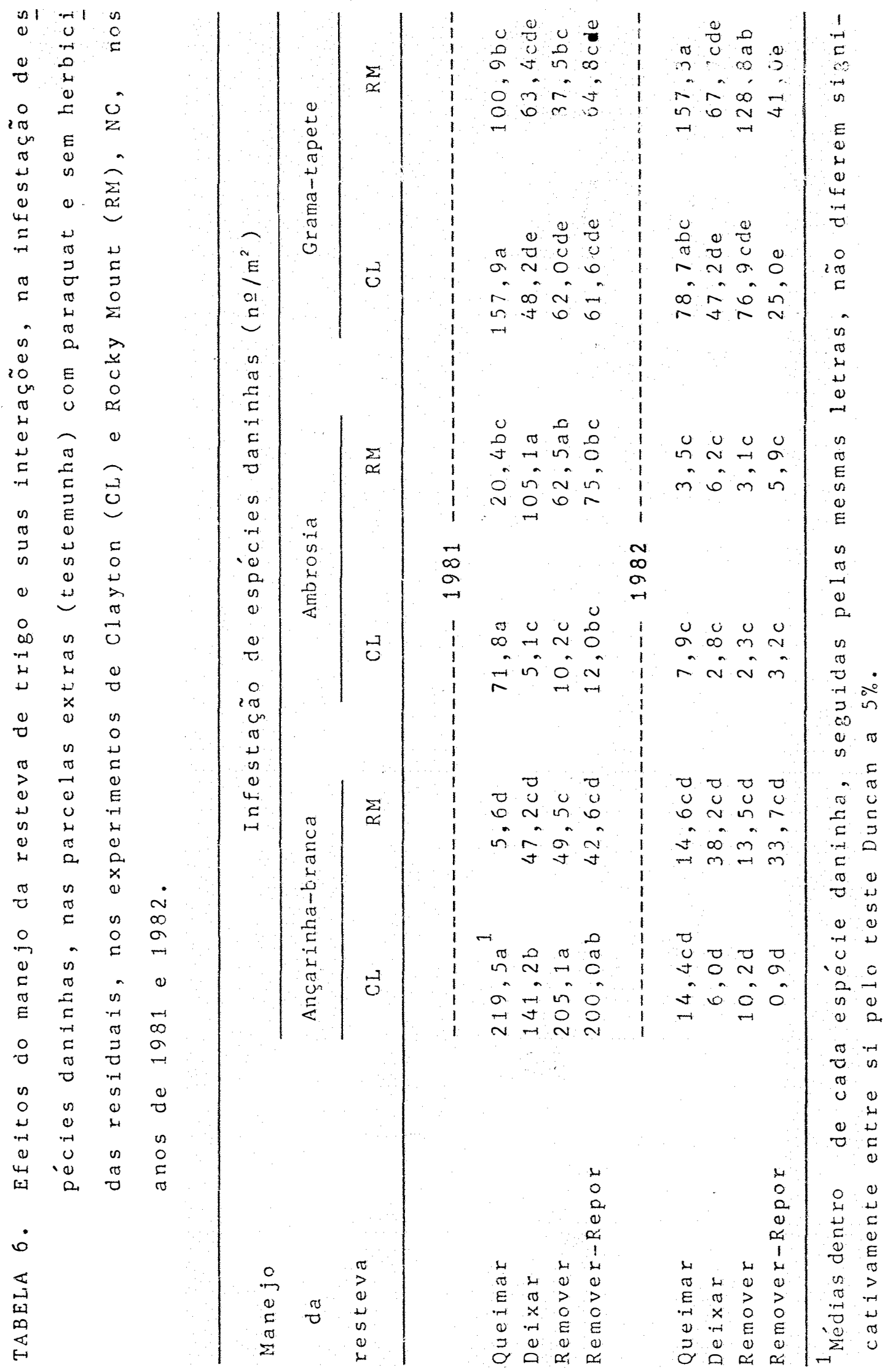


grama-tapete tendeu sempre a apresentar menores infestacốs em Deinar e Remover-Repor a resteva, seguldo por Remover, com Infestacôes máximas em quelmar.

o caruru, a tiririca e a corda-de-viola (Tabela 7) não foram espécles daninnas comuns nos experimentos. Estas espectes nãoforam afetadas de modo significativo pelos diferentes tratamentos de manelo da pesteva de trigo, sob efelto dos nerblcidas residuals.

De modo geral, observamse que infestacốes de trigo, não senslvels aos herblclas residuals, foram destruldas pelofogo. A intestacão de milhã, sensivelmente reduzida pelos nerbicidas, mostrou-se no entanto, sensivel também aos efeltos alelopatcos e/ouluz e temperatura da resteva do trigo na ausencla dos nerbicidas. (1883a) -3 L I EBL B WORHAM (1983a), usando acldo teptico a $5 \times 10$, um componente alelopatico das restevas de trigo, inibiram a germinaça da mina (D. sangulnalis) em 100\%, confirmando sua atividade sobre a espécie, observada nos experimentos em discussão. PUTMANN et a 11 (1982), atribuem um efelto malor da pesteva alelopatia do que ao sombreamento. Infestacồ de an ar inna e grama-tapete alem de serem reduzlas pelos nerbiclas peslauals, tambem mostraram ser peduzldas pelos efeltos da resteva do torigo, dapendendo do local e ano. Quelmar a pesteva tem aumentado as infestacốs de algumas especiles daninhas, posslvelmente quebrando a domencia das especies pelo efelto do calor. Observam-se semelnantes efelt sobre a ambrosia. o caruru (Amaranthus spp.) fol controlado pelos 
TABELA 7. Efeitos do manejo da resteva de trigo, na infestação de espécies daninhas, nos experimentos de Clay ton, NC, nos anos de 1981 e 1982 .

\begin{tabular}{|c|c|c|c|}
\hline \multirow{3}{*}{$\begin{array}{l}\text { Manejo da } \\
\text { resteva } \\
\text { do trigo }\end{array}$} & \multicolumn{3}{|c|}{ Infestação de espécies daninhas $\left(\mathrm{n} O / \mathrm{m}^{2}\right)$} \\
\hline & \multicolumn{2}{|c|}{ Clayton 1981} & Clayton 1982 \\
\hline & Caruru & Tiririca & Corda-de-viola \\
\hline Queimar & $40,6 a^{1}$ & $10,2 \mathrm{a}$ & $14,0 \mathrm{a}$ \\
\hline Deixar & $21,1 \mathrm{a}$ & $17,6 a$ & $8,0 \mathrm{a}$ \\
\hline Remover & $20,7 a$ & $13,4 a$ & $13,9 a$ \\
\hline Remover-Repor & $32,9 a$ & $0 ́, 8$ a & $i, 7 a$ \\
\hline
\end{tabular}

1 Médias dentro de cada coluna, seguidas pelas mesmas letras, não diferem significativamente entresi pelo teste de Duncan a $5 \%$. 
herbloldas residuals, sem ser afetado pelos manelos da resteva, confirmando resultados de STEINSIEK et a II (1980) e LIEBL (1982), contratiando pesultados de THILSTED \& MURAA (1980), para A. retroflexus. Por suavez, a tirirlca e a corala-de-viola não foram afetadas pelos herblcidas ou pelo manejo das restevas. A acão do a lor, em Quelmar, deve ter atingido apenas a parte aspea da tipipica permitindo o beu pebrote posterior em funcäo dos tubéculos existentes no 5010. BULLOCK \& JEFFERY (1980) tambem não observaram efeltos da resteva de trigo sobre a tipiploa em PD, observando aumentos de infestaço em plantios convenclonals com a sua pemocão, nos anos seguintes de conducão do experimento. Eteltos alelopaticos elou de luz e temperatura tenderam a manifestar-se apenas sobre a corda-de-viola (|pomoea spp.), constatados por STEINSIECK et aIII (1980) e LIEBL (1982), para 1. hederacea. BANKS \& ROBINSON (1980), por sua vez, relatam malop eficiencla de controle de l. purpurea na presenca da resteva, do que pelo herblclda alachlor em areas sem a mesma; no entanto, cltam melhor controle de gramineas com o hepblcida nas areas sem a mesteva, na observado para a mina (Tabela 4). Isto ocorre possivelmente em funcão de d ferentes condlỗes amblentals, como a ocorrêncla ou não ge chumas logo apos a aplicaga dos hapblclas. os atores

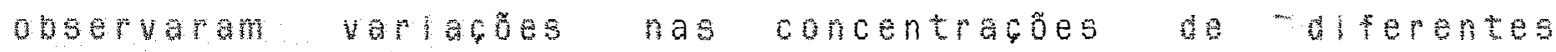
nerbiclas no 5010 em funfõo dos tratamentos com e sem resteva. 
daningas

decorrem das

caracteristicas

morfolologicas,

anatomicas e fislológlcas das mesmas, no sentido de garantirem a sua sobrevivencia sob condicos favoratels. CHANCELON (1982) relata a Importancia da heranca genetica e dos fatores ambientals como calor, umidade e luz, nos processos de dormancla e quebra de dormancla das espésies. Stevens (1932)*, cltado por ANDERSON (1983), pefere-se b quantidade de sementes, por planta, produzldas pelo caruru (A. retroflexus L.), de 117.900 sementes, e para ambrosia, de 3.380 sementes, o que pode indicar a presenca de diferentes mecanismos de sobrevivencia para uma e outra espécie. Segundo descrifoes resumidas para as mesmas, ap esentadas na Tabela 1, a relacão entre tipos de frutos e dispersão,

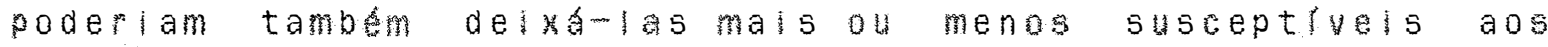
efeltos do melo ambiente, seja 15100 ou quimico.

4.1.3. Efeitos do manelo do 5010

9.".3.m. Efeltos na producão de 50 ja

As producós de sola não foram afetadas significativamente em funca do manelo do 5010 , nos localse anos dos expefimentos (Tabelas 8 e g). As populacós foram diferentes apenas em PM/81 (Tabela 8), a sendo mals elevado nas condicbes de plantio difeto (Po). De modo geral, as balkas populacós bservadas podem ser devidas a problemas de

*STEVENS, D.A. Am. J. Bot. 19:784-94, 1932. 
TABELA 8. Efeitos do manejo do solo sobre as produçóes e populàçóes desoja, nos experimentos de Clayton (CL) $\epsilon$ Rocky Mount (RM), NC, nos anos de 1931 e 1982.

\begin{tabular}{|c|c|c|c|c|c|}
\hline \multirow{3}{*}{ Loc a 1} & \multirow{3}{*}{ Ano } & \multicolumn{2}{|c|}{ Produção de soja ( $\mathrm{kg} / \mathrm{ha})$} & \multicolumn{2}{|c|}{ Popul ação. $(\%)^{1}$} \\
\hline & & \multicolumn{2}{|c|}{ Manejo do solo } & \multicolumn{2}{|c|}{ Manejo do solo } \\
\hline & & $\begin{array}{l}\text { Cultivo } \\
\text { minimo }\end{array}$ & $\begin{array}{l}\text { Plantio } \\
\text { direto }\end{array}$ & $\begin{array}{l}\text { Cultivo } \\
\text { minino }\end{array}$ & $\begin{array}{l}\text { Plantio } \\
\text { direto }\end{array}$ \\
\hline \multirow{3}{*}{ CL } & 1981 & $1904 a^{2}$ & $1842 a$ & $108,2 a$ & $110, \mathrm{Oa}$ \\
\hline & 1982 & $1626 \mathrm{a}$ & $1611 \mathrm{a}$ & $48,9 c$ & $46,4 c$ \\
\hline & 1981 & $982 a$ & $1209 a$ & $41,6 c$ & $57,8 b$ \\
\hline RM & - $\quad 1982$ & $1685 \mathrm{a}$ & $1639 a$ & $73,4 b$ & $72,1 \mathrm{~b}$ \\
\hline
\end{tabular}

${ }^{1}$ Percentagem sobre 25 plantas/m.

2 Médias dentro de cada parâmetro, seguidas pela mesma letra, não diferem significativamente entre si peío teste Duncan a $5 \%$. 
regulagem da semeadeira, balk undade no solo, e, possivelmente, problemas de qualldade das sementes usadas. TRIPP et al11(9883), por sua vez, encontraram diferencas significativas em producões de sola entre tratamentos de plantio convenclonal e dipeto. cox (1977) observougue os metodos de preparo do solo tinham pouco efelto sobre as producões, sob boas condliões de umidade do solo, com boas populacoes e plantas daninhas controladas. No entanto. varlavam sob condicões de umidade insuficientes em funcão do tipo de solo.

Generallzada predominancla de plantas danlnhas no CM comparado com o PD, reduzldas ou não pela acão dos nerblcidas (Tabelas 9 e 12), nãofol suflclente para afetar significativamente as produfões.

o preparo do solo, como ocorreu em RM/81, sob condlcões de balxa umidade, favopeceu rapla perda de umidade da camada de solo pevolvida sob cultivo mimo, pelos efeltos do 501 e do vento, o que veio a provocar atraso na germinacão de dols a trếs dlas, em relacão ao plantlo direto. Sob condicões de boa umidade no solo, uma germinacão e emergêncla mals antecipada fol observada nos tratamentos com GM, em comparaca com PD, em RM/Be. condicöes de precipltacão, mostrando as poucas chulas ocopldas ntes e apos a data de

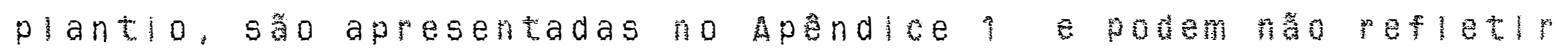
as chuvas caldas no local do experimento. 
Espécies como a milna $e$ a grama-tapete não apresentaram diferencas no controle devido as tratamentos de manelo do solo (Tabela 9), sendo indifepentes também ao manelo da resteva, como uso dos hepbicidas residuals. No entanto, houve reducão acentuada da in ap|icacão dos herbicidas residuals, conforme pode ser observado em relacão a os mesmos tratamentos sem herbloida, em que houve aumento significativo da infestacão no cM. por outro ado, menores infestacós de espécles daninhas como de ancarinha a ambrosia e o trigo foram observadas no po, comparado com o CM, nos tratamentos com os herbicidas resIduais. VEDOATO \& WILES (1976); ALMEIDA et aIII (1982) 2 LEBL \& WRSAM (1983b), para a culturada sola, eFOLON \& ZAGATO (1984), para a cultura do milho, também observaram que a reducão ou eliminacão do cultivo do solo contribul para a reducão da Infestacão de varlas espécies de plantas daninhas. Sem os herbicidas residuals (parcelas extras), sob malopes infestabes, o fato se repete independente do manelo da resteva, exceto para a amposia. Esta espécie merece malores conslderacöes no trem interacão de manejo da pesteva e do solo, com resultados apresentados na Tabela 13.

Na Tabela 10, sob efeltos residuals dos herblcinas, observa-se a interacão de algumas espécles ja discutioas, com locals e anos, Para o trigo, não so apresentaram os efeitos de reducão de infestacãono p, em CL/82, apresentados em RM/Be. No entanto, espera-se sempre malor infestacão de trigo em CM, que pelo melnor contato da 


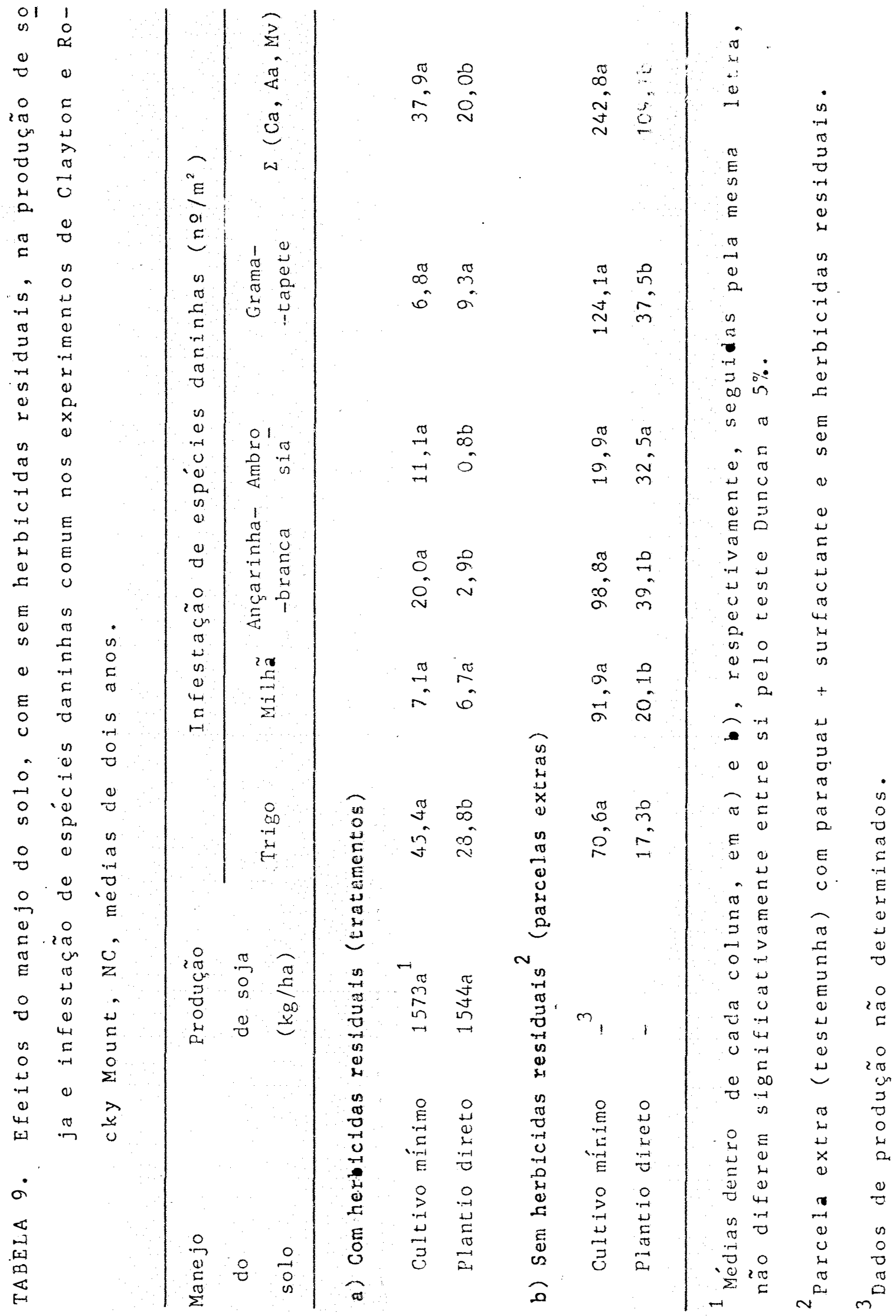




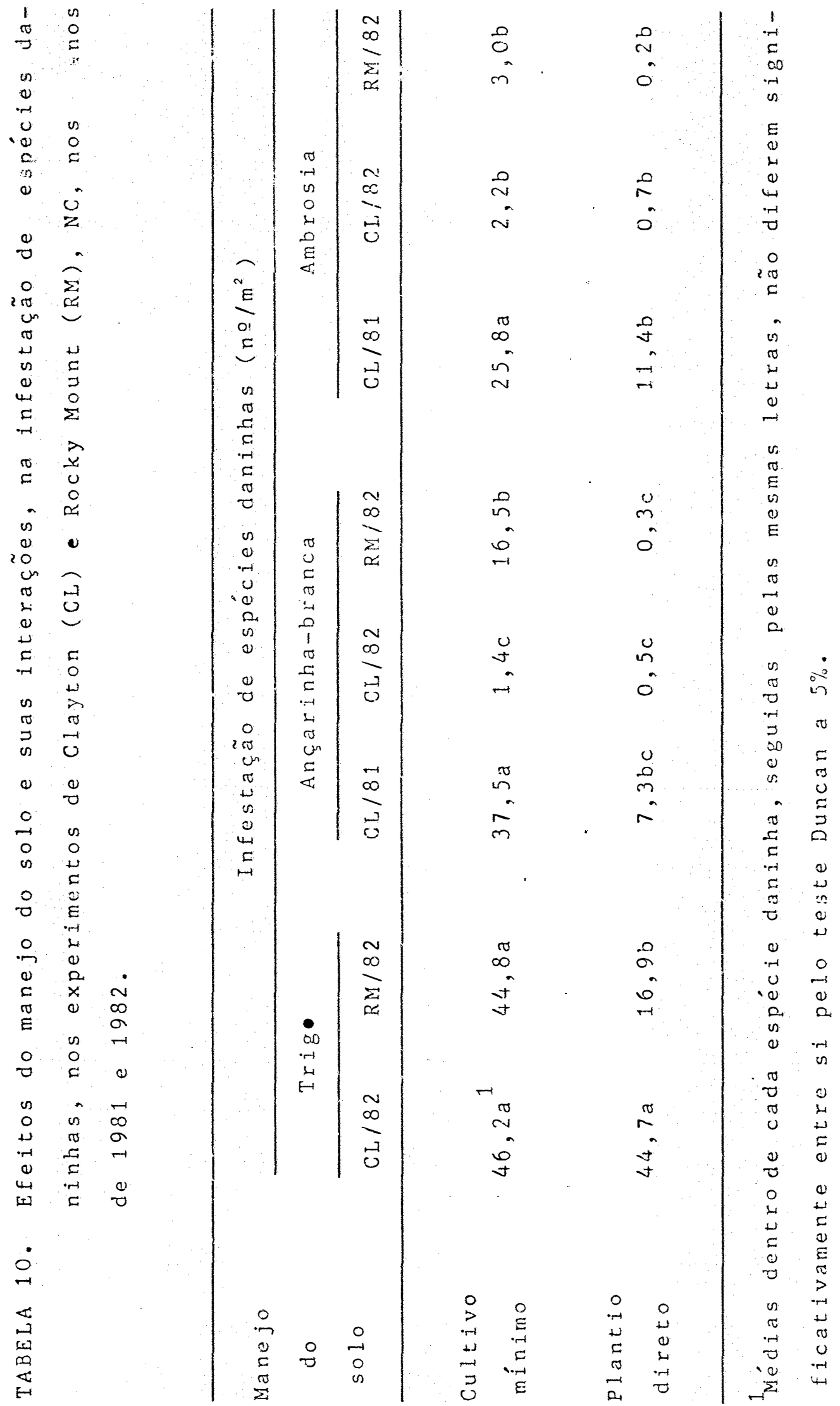


semente com a umidade do solo facllitarla a sua germinacá, tendêncla observada na Tabela 13, sem os nerbicidas residuais. Por sua vez, a ancarinha e a ambrosia na mo mudam as evidenclas anteriores de malor infestacõo no cM, sempne que ocorria uma infestacäo mals alta de plantas.

Na Tabela 1\}, os dados de interaco com locals e anos, sem os herbicidas residuals, mostram sempre uma tendência de maior infestacão nas areas do CM. Apenas as Infestacóes de ancarlnha e ambrosia forammatom no PD, en FM/B1. Supöe-se que melhores condibües de umidade do solo em Po, que antecipou a germinača da sola no po comparado com CM, deve ter proporcionado melnopes condicôes de umidade sob a resteva de trigo, para a germinaca destas duas especies, tendo sldo critica para as outras por questoes morfologicas ou fislologlcas diferentes. Por sua vez, menores infestacões no Po, pode ser o resultado da ocorrencla de sementes domentes das espeles na superficle do solo, do efelto de Iuz e temperatura efou do efelto de substancias alelopictos provenientes da resteva.

Na Tabela Te, Infestabes de caruru e de corda-de-vola, foram signlficativamente reduzldas no PD, comparado com o CM, Independente do manejo da resteva. LIEBL \& WORSHAM (1983b) obsemaram que a eliminaco do cultivo, sam o. uso de herblcidas, havia contribuldo para reduziras infestacós de carda-de-viola . GUENZI \& MCCALLA (19E8) extralram malores quantidades de acido ferulico e cumarico (substancias alelopaticas\} de solos sob cultivo minimo do que 


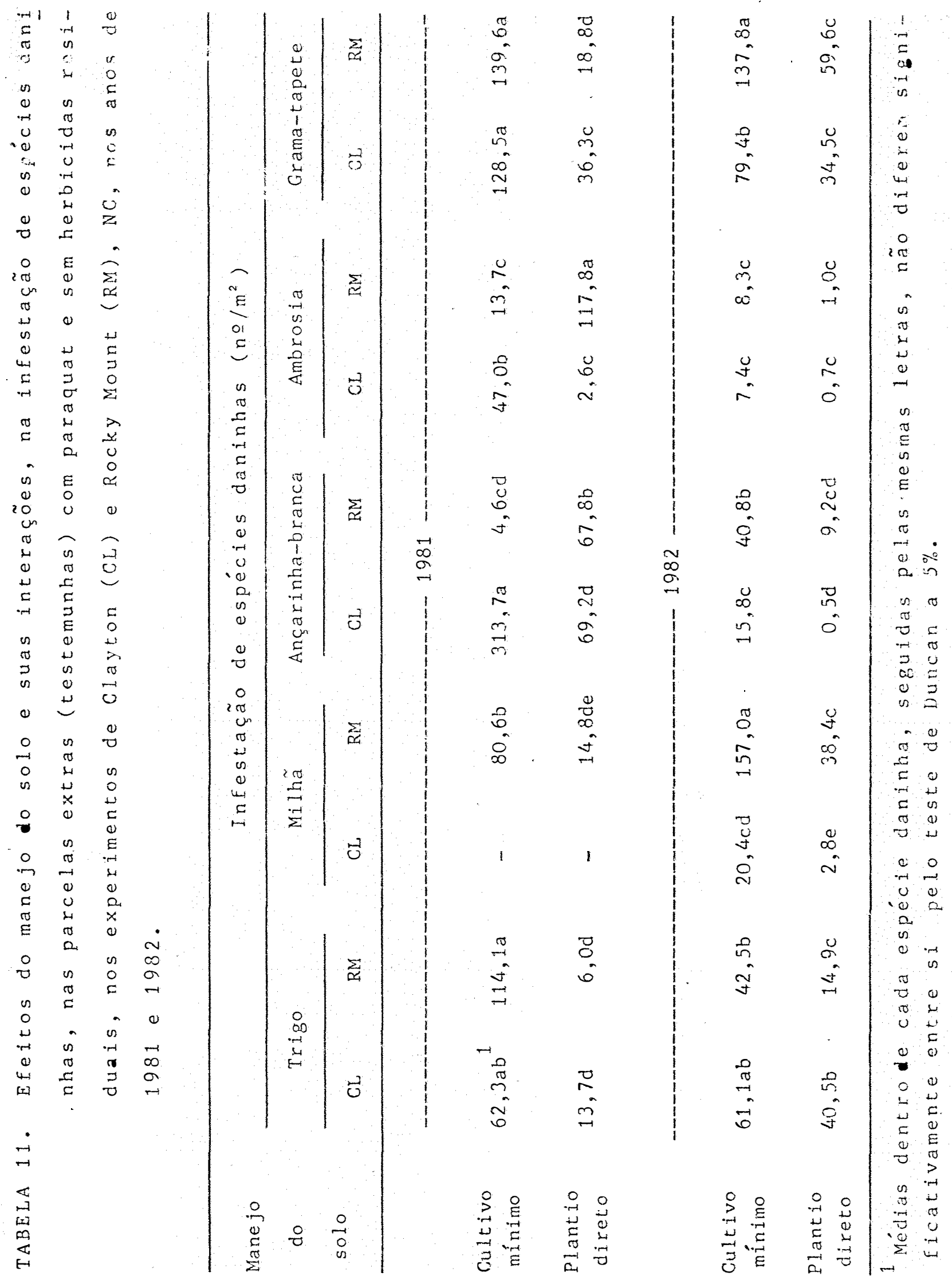


TABELA 12. Efeitos do manejo do solo, na infestação de espé cies daninhas, ros experimentos de Clayton, NC, nos anos de 1981 e 1982 .

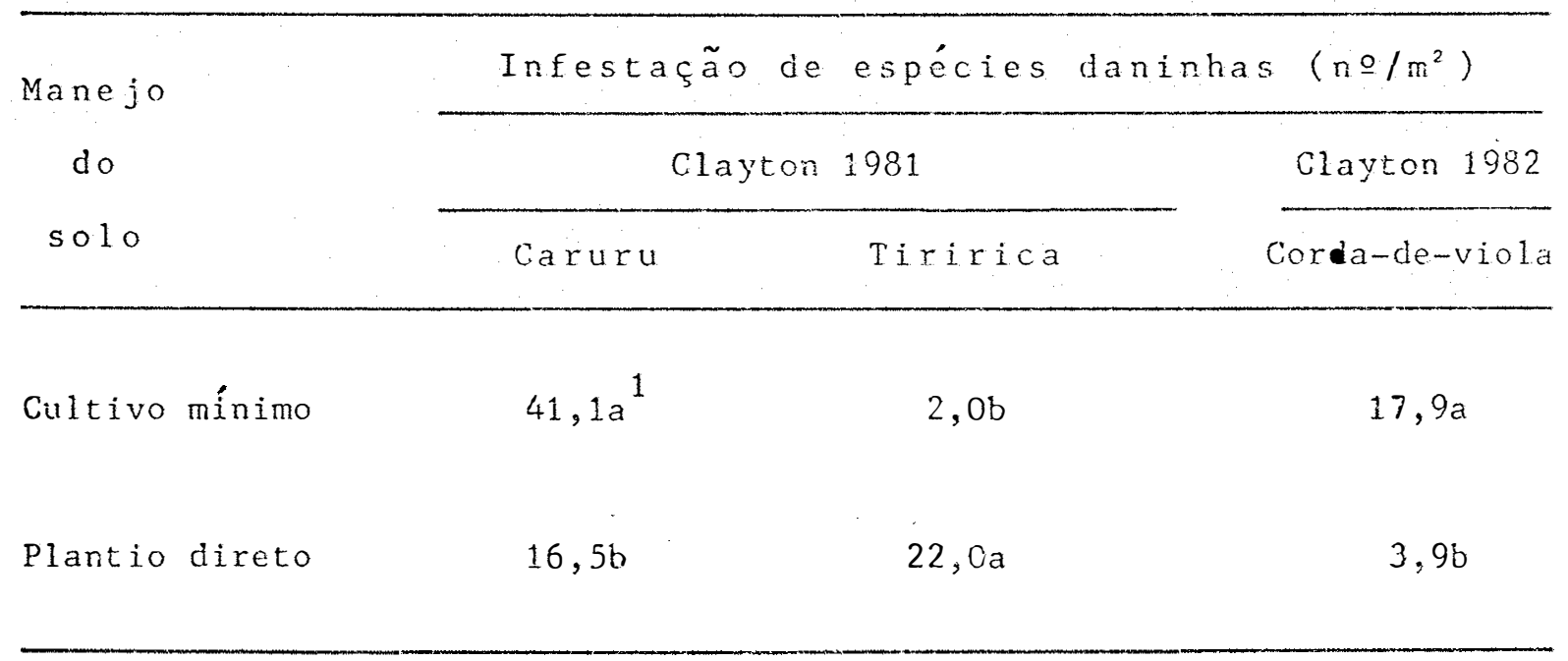

1 Médias dentro de cada coluna, seguidas pelas mesmas, letras, não diferem significativamente entre si pelo teste Duncan a. $5 \%$. 
em solo arado, o que virila a resultar na reducão de Ipomoea spp.

A tiripica mostrou resultados opostos em rela ão as outras espécies, com malores infestacós no PD, do que no CM. HOLM et a 11 (1977) observaram que a movimentacia do solo, como no CM, ao separar um tubéplulo da cadela liviamo da dominancia aploal, antes exencida sobre o mesmo. Disto poderia resultar a distribulcão de novos tubérculos simples através da camada aravel, aumentando a Infestacáo. No entanto, os tuberculos dormentes trazidos है superficie, sob condicós de tempo seco associado a altas temperaturas, apos tras dias e sol, podem ser dessecadose moptos, peduzindo a infestacão. Condloues semelhantes podem tep ocoprido no experimento em discussão, que reduzlu a intestacão da tíirica no GM, poron não afetou a espécie no PD. BULLOGK \& JEFFERY (1980) observaram que a remocão da palna do campo pela enfardadelra aumentava a tiripica no tempo, emplantio convenclonal, mas nowo sob plantio direto, o que não fol observado nas condicos dos experimentos em discussão (Tabela 7), conduzidos em diferentes la reas. Possivelmente, em plantlo convencional, com a ruptura das cadelas de bubos da tirlina as reservas acumuladas são usadas e reduzlos na poduca de novos rebentos e, com isso, tornano-se mals susceptivel aos efeltos alelopaticos da pesteva. DROST M DOLL (1980) mostrangh que extratos

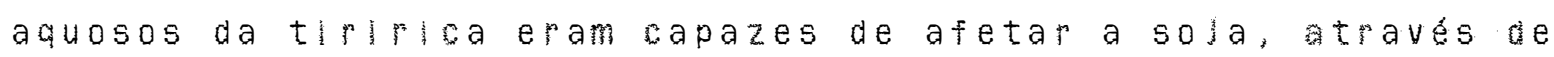
efeltos alelopaticos, não constatados a aul. 
4.3.4. Interacôes do manejo da resteva e do solo

4.1.4.1. Efeltos interativos sobre as plantas daninhas

Infestacóes de trigo, observadas em parcelas extras, apenas tratadas comparaquat (Tabela 13), foram menores em Quelmar, para CM e Po, não diferindo dos demals tratamentos de manejo da pesteva no PD: as malores infestacóes de trigo no cM, nos manejos de resteva Delxar. Remover e Remover-Repor, comparado com PD, deve-se provavelmente a enterio das sementes, melhores condifós de umidade e melhor contato com o solo para geminacão e emergencla a malores profund dades, comparado com as sementes de trigo que apenas flcaram na superflcie do solo, no PD. Elimina-se qualquer efelto alelopatico, ou de sombreamento da proprla resteva, conslderando-se que efeltos em Remover não diferiram de Deluar ou Remover-Repor a resteva. Quelmar a resteva destrulu quase toda a sementeira de trigo na superficle do solo. Segundo Moss (1981), menor umldade das sementes faclitaria a sua destrulga pelo calor.

Infestacós de ambrosia mostraram tendencias opostas ao comportamento do trigo, com malores infestacós no PD, nas combinacós com os tratamentos de manelo da restava Deixar, Remover e Remover-Repor, exceto em ouelmar. Neste tratamento com PD a meduca da lnfestaca fol devida a destrulfa da sementel ra ha superfole do solo pelo fogo. que

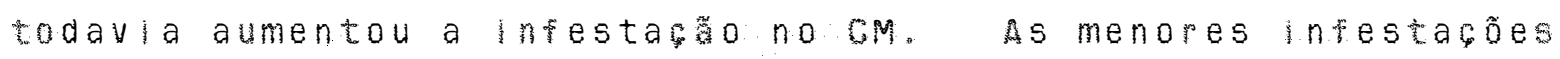
de ambrosia no CM, nos manelos de pesteva Del xar", Removere 


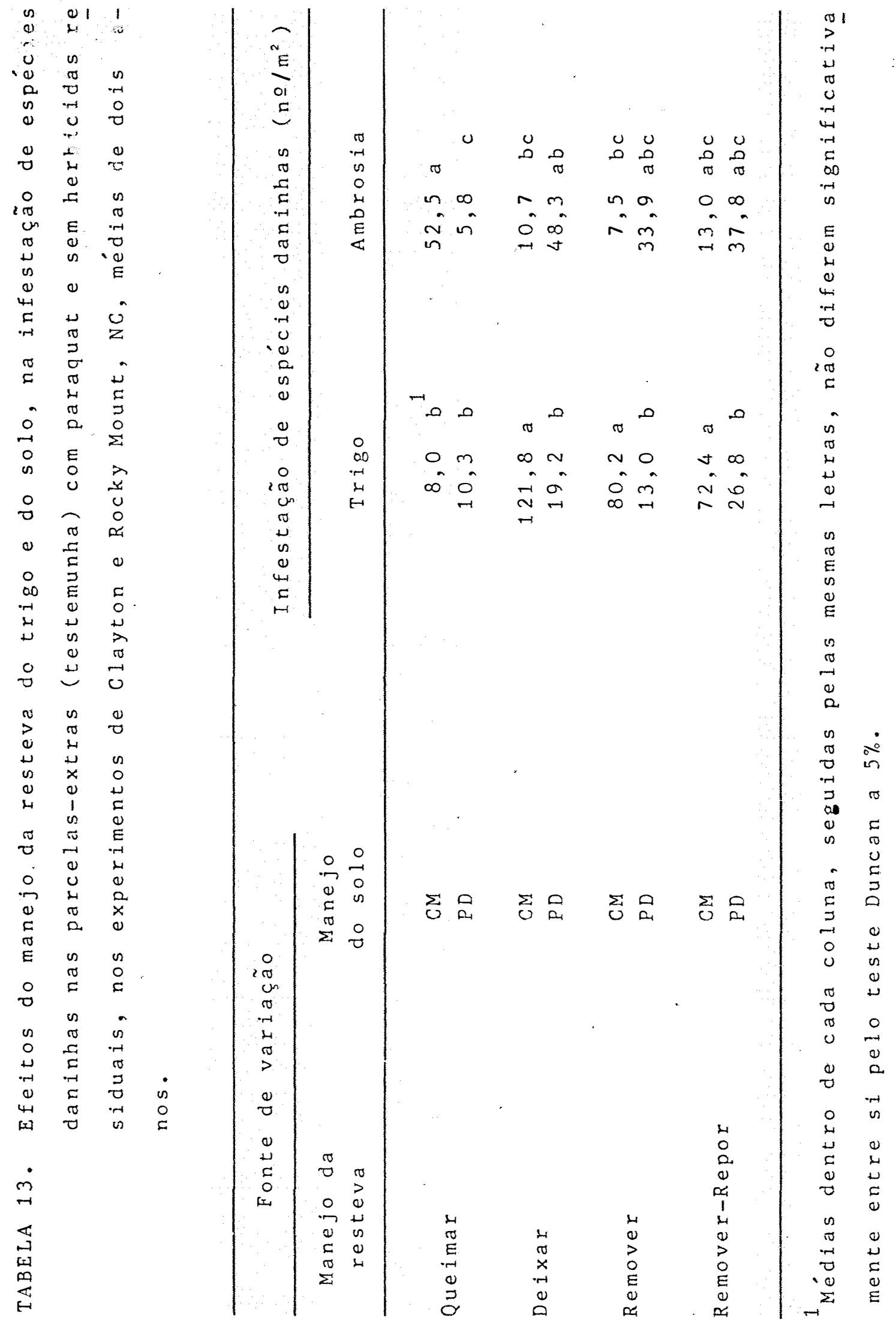


Pemover-Pepor, deve-se provavelmente ao enterrlo das sementes a malores profundidades, diflcultando a sua germinacão. Este fato contrarla as mals altas infestaboss verificadas para as demals espécies daninnas e de modo especial, nas parcelas sem os herbiclas reslduais. Esta malor infestaca de ambrosia no PD parece entäo nâ ser devida a ocorrencia de efeltos alelopaticos ou de sompreamento, que reduzimam as demals espécles, devendo-se excetuar o caruru e a tiririca. para explicar diferencas entre a ambrosia e o caruru, com semelhantes tamanhos de semente, mencionam-se aspectos de fislologia das espécias relaclonadas a menor producäo de sementes por planta da primelra em relacăo do segunda. associados a aspectos de dormencia. A malor infestacäo da ambrosia no CM, em queimar a resteva seria devida a quebra de domencia desta espécle pelo efelto do calor, temperaturado solo e penetrafáo da luz a malores protundidades. No entanto, luz no deye ser o fator de condlchonamento da especle uma vez que Delxar a resteva teria mostrado tals efeltos. o aspecto da domencia atribulda a ambrosia, como forma de sobrevivencla da espécle, pode ser explorado em Funco da menor capaclade de produca de sementes/planta e de uma malor amplitude de melos que terla para garantir a sua proliferaco em condicos menos adequadas.

4. 1.5. Efeltos dos herbiclas de manejo

4.1.5.1. Ayaliaco dos herblcidas de maneio 
Especies de plantas daninhas, infestando as áreas de experimentacão, cobriam aproximadamente 25 a $35 \%$ da superficle, nos diferentes locals e anos. especles daninnas predominando nos experimentos por ocasião da aplicacão dos herbicidas foram a ambrosla, a ancarinna-branca e o mentruz com cepa de 25 a $30 \mathrm{~cm}$ de altura, a milhã e o pantcum (Panlcum dichotomiflopum), a pesentando tres a quatro folnas; corda-de-viola, com tress a cinco folhase, a tirinica com 10 e $15 \mathrm{~cm}$ de altura. As aplicacoes dos nerblcldas de manelo Tol felta cepca de 15 dias após a colnelta do trigo. o controle das plantas daninhas fol avallado em $100 \%$ para ambos os tratamentos, paraquat e glyphosate, em avaliacoses visuals feltas dez a 14 dias após as aplicacoes dos nerbicias. Não foram observadas rebrotacós em ambos os tratamentos, nas reavaliacoes feltas uma semana mals tarde.

4.3.5.2. Efeltos da aplicaca dos nerbicldas residuals Juto com os herbicidas de manelo

4.1.5.2.1. Eteltos na produca de soja

$$
\text { Dcasionalmente, danos causados pelos }
$$

hepbloldas pre-emergentes alachlop e Inuron foram observados nas folnas simplas da sola, apos sua emergencla. Injulas de alachlor, conslstiram en deformacoes nas pontas das folnas, como resultado da peducáa da nervura principal. Inlón as de linupon, conststiram de amanelecimento garal das folnas.e. posterior morte do tecido entre as nepvuras as mesmas. As 
producoes de sola (Tabela 19), sob as comblnacón dos nepbloldas de manejo paraquat, de acou de contato, e glyphosate, sistemico, com os herbicldas puemergentes alachlor e IInuron, foram malores paracl/8\}, sob malores popula cões, não mostrando diferencas entre os tratamentos neste local nos anos de 1981 e 1982. Em RM, nos mesmos anos, as producós com glyphosate porammenores. As medias de producăo de soja (Tabela 15) Toram maiores com paraquat, que apresentou malor controle de algumas especles de tolnas laras (Tabelas 15 e 16). As menores producós com glyphosate, possivelmente sa o resultado de aplicacós sob condla ấo de tempo seco e pouca atividade das plantas. Efeltos de varlos fatores ambientais como temperatura, umidade do solo, umidade relativa, estadia de cresclmento e deficiencla de gua, Influindo na eflelencla de nerbicidas slstemicos como glyphosate, tem sido nelatados (WHLLS, 1978; KAPUSTA, 1979; AHMADI et aII1, 1980; MCWORTER \& WLL, 1980 e WITWELL et a 111,1980$)$.

4.1.5.2.2. Efeitos sobre as espacles daninhas

$0 \operatorname{trgg}$ e a ambrosia (Tabela 15) กล̃o apresentaram diferencas de controle para os hepbloidas de

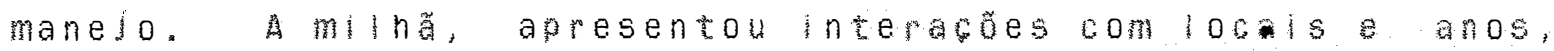
mostrando diferengas num ano com melhor controle do glyphosate e, no outro, do paraguat: a ancarinha e a gramatapete, foram melnor controlabs comparaquat do gue com glyphosate; o caruru, a tiripla e a corda-de-y|o) a (Tabela 
TABELA 14. Efeitos dos herbicidas de manejo, "mais os residuais, sobre a produção de soja, nos experimentos de clayton e Rocky Mount, NC, nos anos de 1981 e 1982 .

\begin{tabular}{|c|c|c|c|c|}
\hline \multirow{3}{*}{$\begin{array}{c}\text { Herbicidạs } \\
\text { de manejo } \\
\text { (mais residuais) }\end{array}$} & \multicolumn{4}{|c|}{ Produções de soja ( $\mathrm{kg} / \mathrm{ha})$} \\
\hline & \multicolumn{2}{|c|}{ Clayton } & \multicolumn{2}{|c|}{ Rocky Mount: } \\
\hline & 1981 & 1982 & 1981 & 1932 \\
\hline Paraquat & $1807 \mathrm{ab}^{1}$ & $1683 b c$ & $1216 \mathrm{~d}$ & $1763 \mathrm{~b}$ \\
\hline Glyphosate & $1940 a$ & $1554 \mathrm{C}$ & $976 \mathrm{e}$ & $1560 \mathrm{c}$ \\
\hline
\end{tabular}

${ }^{1}$ Médias do parâmetro de produção, seguidas pela mesma letra, não diferem significativamente entre si pelo teste Duncan a $5 \%$. 


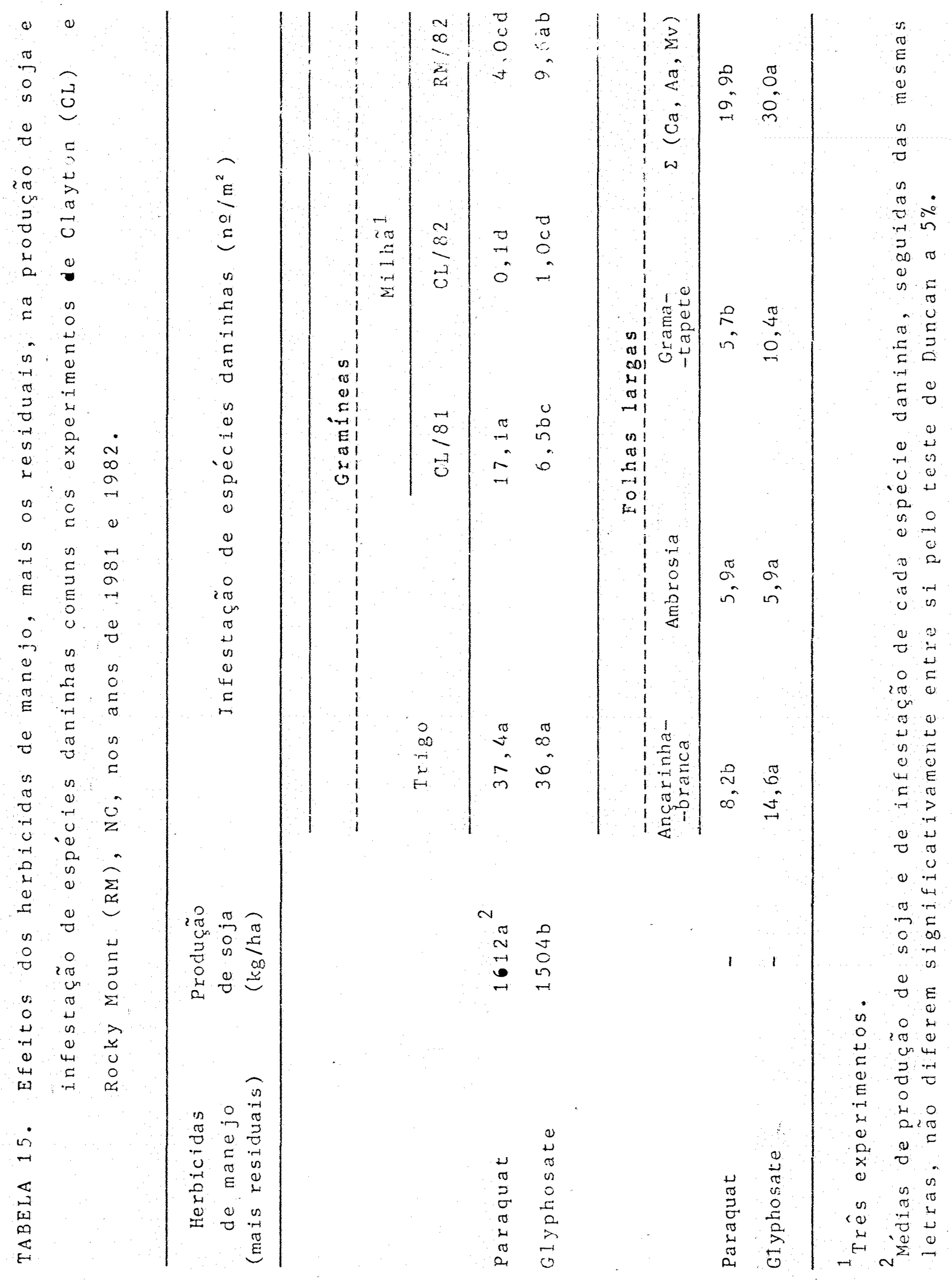


16) foram igualmente controladas pelos nembicidas.

eficiêncla dos herbicidas residuals usados pode ser constatada no controle do caruru, não se ventilcando nennum efelto no controle das especles de tirlrica e corda-de-viola. Glyphosate não fol superior ao paraquat no controle da Irifica, especie invasora perene, opondo-se aos resultados Observados por CHAPPEL (1974); ROGERS \& WORTHINGTON (1976) BULLOCK \& JEFFERY (1980). Tambem não fol constatado um controle de gramineas por tempo mals prolongado do glyphosate, Iunto com os residuals, em relaz̃o a paraquat, como observado por HARDCASTLE (1973) e WORSHAM \& LEWIS (1973), ou malores producóes, observado por WORSHAM \& LEWIS $(1973)$.

Não foram observadas interacos signiflicativas de nerbiclas com os tratamentos de manelo da pesteva ou do s010.

4.2. Herblcidas residuals no solo

4.2.1. Ensalos blologicos para restaus a a lachlor e linuron Resultados dos ensalos biologlcos conduzldos em casa-de-vegetaço, para deteção de quantldades de "estduos dos herblcidas alachlor e linumon nos experimentos de campo, são apresentados na Tabela $17 \mathrm{e}, 0 \mathrm{~s}$ padröes ue

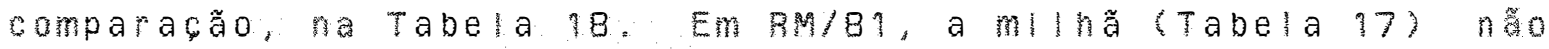

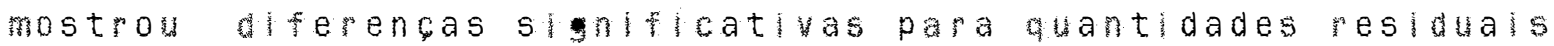
de alachlor no solo, apetado pelo manelo da resteva a do 
TABELA 16. Efeitos dos herbicidas de manejo, mais os residuais, na infestação de espécies daninhas, nos ex perimentos de Clayton, NC, nos anos de 1981 e 1982 .

\begin{tabular}{|c|c|c|c|}
\hline \multirow{3}{*}{$\begin{array}{l}\text { Herbicidas } \\
\text { de manejo } \\
\text { (mais residuais) }\end{array}$} & \multicolumn{3}{|c|}{ Infestação de espécies daninhas $\left(\mathrm{n} o / \mathrm{m}^{2}\right)$} \\
\hline & \multicolumn{2}{|c|}{ Clayton 1981} & \multirow{2}{*}{$\frac{\text { Clayton } 1982}{\begin{array}{c}\text { Corda-de- } \\
\text {-viola }\end{array}}$} \\
\hline & Caruru & Tiririca & \\
\hline Paraquat & $2,2 b^{1}$ & $6,7 a$ & $10,1 \mathrm{a}$ \\
\hline Glyphosate & $0,8 b$ & $11,5 \mathrm{a}$ & $12,2 \mathrm{a}$ \\
\hline $\begin{array}{c}\text { Paraquat sem residuais } \\
\text { (parcelas extras) }\end{array}$ & $83,5 a$ & $17,8 a$ & $10,5 a$ \\
\hline
\end{tabular}

1 Médias dentro de cada coluna, seguidas pelas mesmas letras, não diferem significativamente entre si pelo teste Duncan a $5 \%$. 
TABELA 17. Resultados de biomassa fresca do dossel de pepino, capim-miliz e sorgo, de ensaios em casa-de-vege tação, para deteç̧ão de quantidades residuais de herbicidas no solo, de experimentos a campo sob ma nejo da resteva e do solo, nos locais de Rocky Nount e Clayton, NC, em 1981 .

Biomassa fresca do dossel - \% da testemunha

Fonte de

\begin{tabular}{|c|c|c|}
\hline \multicolumn{2}{|c|}{$\mathrm{RM} / 81$} & $\mathrm{CL} / 81$ \\
\hline Mi 1 hầ & Pepino ${ }^{2}$ & Sorgo \\
\hline
\end{tabular}

Manejo da resteva

$\begin{array}{lccc}\text { Queimar } & 96,5 a^{3} & 93,0 a & 98,8 a \\ \text { Deixar } & 100,0 a & 76,8 a & 92,4 a \\ \text { Remover } & 89,8 a & 54,5 a & 90,7 a \\ \text { Remover-Repor } & 89,9 a & 56,0 a & 98,2 a\end{array}$

Manejo do solo

Cultivo mínimo

$91,8 a$

$60,2 b$

$94,5 a$

Plantio direto

$96,3 a$

$79,5 a$

$95,6 a$

${ }^{1}$ Teste para alachlor.

${ }^{2}$ Teste para linuron: pepino e sorgo (com protetor contra alachlor).

${ }^{3}$ Para cada fonte de variação, médias dentro de cada coluna, seguidas pela mesma letra, não diferem significativamente en tre si pelo teste Duncan a $5 \%$ 


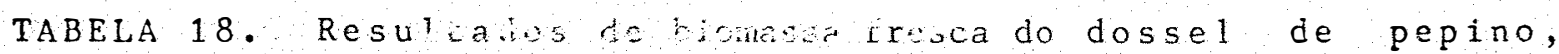
capin-milhã e sorgo, de ensaios em casa-de-vege tação, para deteção de quantidades de herbicidas residuais de alachlir e linuron.

Herbicidas (ppm)

Biomassa fresca do dossel - \% da testemunha

\begin{tabular}{ccccc} 
Alachior Linuron & Milha ${ }^{1}$ & Pepino & Sorgo $^{2}$ \\
\hline 2,0 & 0,5 & $27,0 a^{3}$ & $78,1 \mathrm{a}$ & $96,0 \mathrm{a}$ \\
1,6 & 0,4 & $37,8 \mathrm{a}$ & $84,0 \mathrm{a}$ & $100,0 \mathrm{a}$ \\
1,2 & 0,3 & $54,0 \mathrm{a}$ & $75,4 \mathrm{a}$ & $107,9 \mathrm{a}$ \\
0,8 & 0,2 & $97,3 \mathrm{a}$ & $76,8 \mathrm{a}$ & $97,4 \mathrm{a}$ \\
0,4 & 0,1 & $129,7 \mathrm{a}$ & $86,0 \mathrm{a}$ & $100,0 \mathrm{a}$ \\
0,0 & 0,0 & $100,0 \mathrm{a}$ & $100,0 \mathrm{a}$ & $100,0 \mathrm{a}$ \\
2,0 & 0,0 & $21,6 \mathrm{a}$ & $92,9 \mathrm{a}$ & $82,9 \mathrm{a}$ \\
0,0 & 0,5 & $132,4 \mathrm{a}$ & $16,5 \mathrm{~b}$ & $86,8 \mathrm{a}$ \\
\hline
\end{tabular}

${ }^{1}$ Teste para alachlor.

${ }^{2}$ Teste para linuron; pepino e sorgo (com protetor contra alachlor).

3 Médias dentro de cada coluna, seguidas pela mesma letra, não diferem significativamente entre si pelo teste de Duncan a $5 \%$. 
solo, ou interaço de ambos os fatores. Baseado nos padrões (Tabela 18 ), fez-se tentativas para determinar quantidades de alachlor no solo, indicando a presenta de cerca de 0,8 ppm de 2, 24 ppm aplicados, sem se constatar, no entanto, diferencas slgnificativas entre as blomassas fresca nas doses padrões. Peplno Gucumis satlyus $(1,)_{3} \mathrm{ov}$. Wlsconsin SMR 58 pickles (Tabela 17), também nấo mostrou diferencos significativas para uantidades residuals de linuron no solo, afetado pelo manelo da resteva, ou interacões com o manejo do solo. No entanto, pepino mostrou malor biomassa finesca do dossel em PD, commenopes teores de reslduos de linuron no solo devido a Interceptaç̃o dos herbicidas, em relaço ao CM. Neste, todas as ap|icacón de nerblcidas for am feltas após quelmar. Deixar ou Remover a resteva e passar a grade no solo, contribuindo para a ocorpencla das malores quantidades de residuos de Iinuron no solo no CM, em relacăo a PD. Neste. os hemblidas lixiylaram da resteva e alcancaram o solo, possivelmente apos suficientes chuvas, segundo LOWDER \& WEBER (1979). uma vez que a resteva no inlcio da decomposica en pouco a dsortiva (GROVER, 9971 Q WALKER \& CRAWFORD, 1968). En Queimar, a adsorca dos nepbicldas às cinzas peduz as *uantidades no solo em PD, mas na em CM, com a Incorporaca previa das cinzas (TOTH \& MILHAM, 1973 e 1975 e NIFFELER \& BLA|R, 1978). No padrăo(Tabela 18), não foram observadas dremenas significativas para as doses de linuron, combinadas com alachlor. No entanto, apenas inneron a 5 ppm reduzlu a blomassa fresca da parte a erea do pepino. Na 
mesma dose, em comblnacão com 2, o ppm de alachlor não houve reducãosigniflcativa de biomassa. Assim, observa-se que os efeltos protetores de alachlor empeplno, que não mostrou reducão na blomasa fresca, preludicou a deteccão de quantidades de I Inuron do experimento de campo.

Em CL/BI, panifum (Panlcum mellaceum L.) fol usado para detectar alachlor, mas mostrou-se vaplavel, nao permitindo a determinacão de residuos no solo. Sorgo [Sorghum blcolor (L.) Moench) (Tabela 17), com o protetor R25778 contra os efeltos de alachlor, não mostrow diferencas de blomassa fresca para manelo da pesteva e do solo, ou de suas interacôes, para o expepimento de campo, para o linuron. Tambem não foram observadas difepencas para sorgo ( $T a b e \mid a$ IB) no ensalo padrão, por ser uma espécle menos sensitiva ao Inuron, quando comparada com pepino.

4.2.2. Deteminacốes analiticas para reslduos de alachlor e I inumon

Reslduos de alachlor no solo, determinados por cromatografia gasosa (Tabela 19), não apresentaram diferencas para os tratamentos de manelo da resteva e do solo, ou suas interąồ.

Reslaus de Iinum no solo, determinado por

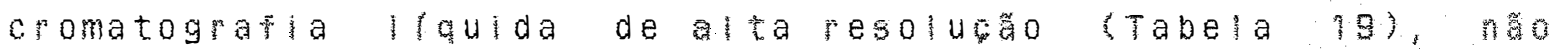
apresentam difemencas para os tratamentos de manelo da pesteva, ou suas interacos com manejo do solo, mas apresentan quantidades de reslduos significativamente 
TABELA 19. Resultados de determinação analítica de Tuantida des de residuos de alachlor e linuron no sol?, por cromatografia gasosa e líqüida, respectivamente, em experimentos de campo sob manejo da resteva e do solo, em Rocky Mount, NC, em 1982.

Fonte de Herbicidas ( ppm)

variação

\section{Manefo da resteva}

Queimar

Deixar

Remover

Remover - Repor

$$
0,48 a^{1}
$$$$
0,62 a
$$$$
0,32 a
$$$$
0,42 a
$$

$0,60 a$

$0,33 a$

$0,38 a$

$0,50 a$

\section{Manejo do solo}

$$
\begin{aligned}
& \text { Cultivo mínimo } \\
& \text { Plantio direto }
\end{aligned}
$$

$$
\begin{aligned}
& 0,48 a \\
& 0,44 a
\end{aligned}
$$

$0,60 a$

$0,30 \mathrm{~b}$

1Para cada fonte de variação, médias dentro de cada coluna, seguidas pela mesma letra, não diferem significativamente en tre si pelo teste Duncan à $5 \%$. 
maiores no $C M(0,6 p p m)$ do que no $P D(D, 3$ pm). Estes resultados concordam com aqueles obtidos no bioensalo para I Inuron, para $R M / 8\}$, em termos de malom presena sob CM. Uma tendêncla paramalores quantidades de linuron no tratamento Queimar fol observado, devido a sua adsorấa a cinzas, o que é sugerido por TOTH \& MILHAM (1973).

Muito embora o IInuron tenha apresentado menor reslduo no PD, fol neste slstema de manejo de solo que se observou menor infestacão de espécies daninhas na area experimental.

Alachlor e linuron foram recuperados das placas de vidro, em cromatografia de camada fina, em cerca de 90 * As determinacões para inuron estão em acordo com os resultados obtidos porkAHN et alli (1975). Problemas ge deteça ocono no cromatografo, prejudicaram as determinacões de alachlor, observado através do padra. Isto possivelmente ocorreu como resultado do condicionamento Imperfeito da coluna de vidro do cromatografo.

\subsection{Experlmentos em casa-de-vegetafá}

4.3.1. Efeltos da Interacalo do aclo fepulco (AF) g) yphosate (GLY) na sola

$$
\text { A altura das plantas de sola (Figura } 4 . a \text { ) }
$$

aumentou Ineamente com doses crescentes de AF, Na absucla

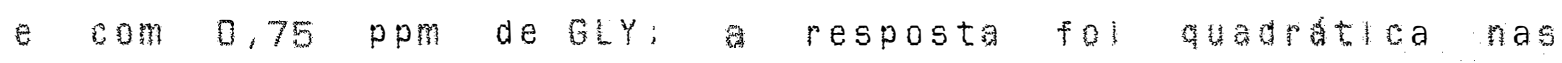
interanos de doses crescentes de AF com 1,50 e 2,25 ppm de 
GLY, resultando em aumentos adicionals de altura das plantas ate 150 ppm de AF; com a dose máxima de 3,00 ppm de GLY a fresposta ao AF fol cublca e, apenas a dose de $75 \mathrm{ppm}$ de AF pesultou em interacao significativa, aumentando a altura das plantas. os coeficientes de determinacónostram uma boa relago entre causa e efelto, em que a regressão linear explica $75 \%$ das variacoses em funca do Af, sendo mais elevados para as regressôes quadraticas (89 e $93 \%$ e cúbica (83 Aumentos de GLY (FIgura A.b) tambem resultaramem aumentos de altura das plantas de sola de modo linear nas doses de 75 e $150 \mathrm{ppm}$ de AF: a respostafol quadratica (r2= 0.90), nas interacões de GLY com 225 ppm de Af, resultando em aumentos adiclonals de altura das plantas com 0,75 ppm de GLY; os aumentos de altura, devidos a Gly como, o e 300 ppm de AF: nå foram slgniflcativos.

A blomasa fresca do dossel da sola f Figura 5. a) aumentou significativamente ate $150 \mathrm{ppm}$ de AF, em todas as combinacós com GLY, sendo reduzlda com doses malopes de AF. O coeflciente de determinaco para doses de AF pol alto $(n 己=0,80)$, o que indica que os resulados sa expl|cavels em sua malor parte pelo seu efelto. A blomassafpesca do dossel (Figuna 5.b) deciesceu, ineamente com as doses crescentes de Gly, na media te todas as combinaboes com AF. o coeficiente de deteminaca fol balxo (pe $=0,51)$.

A blomassa seca das ralzes da sola sFigura 5.a) Fol peduzlda com doses crescentes de AF comb,o ppm de GLY, apresentando um $\mathrm{n}(=0,87)$ alto. De modo semelnante, a 


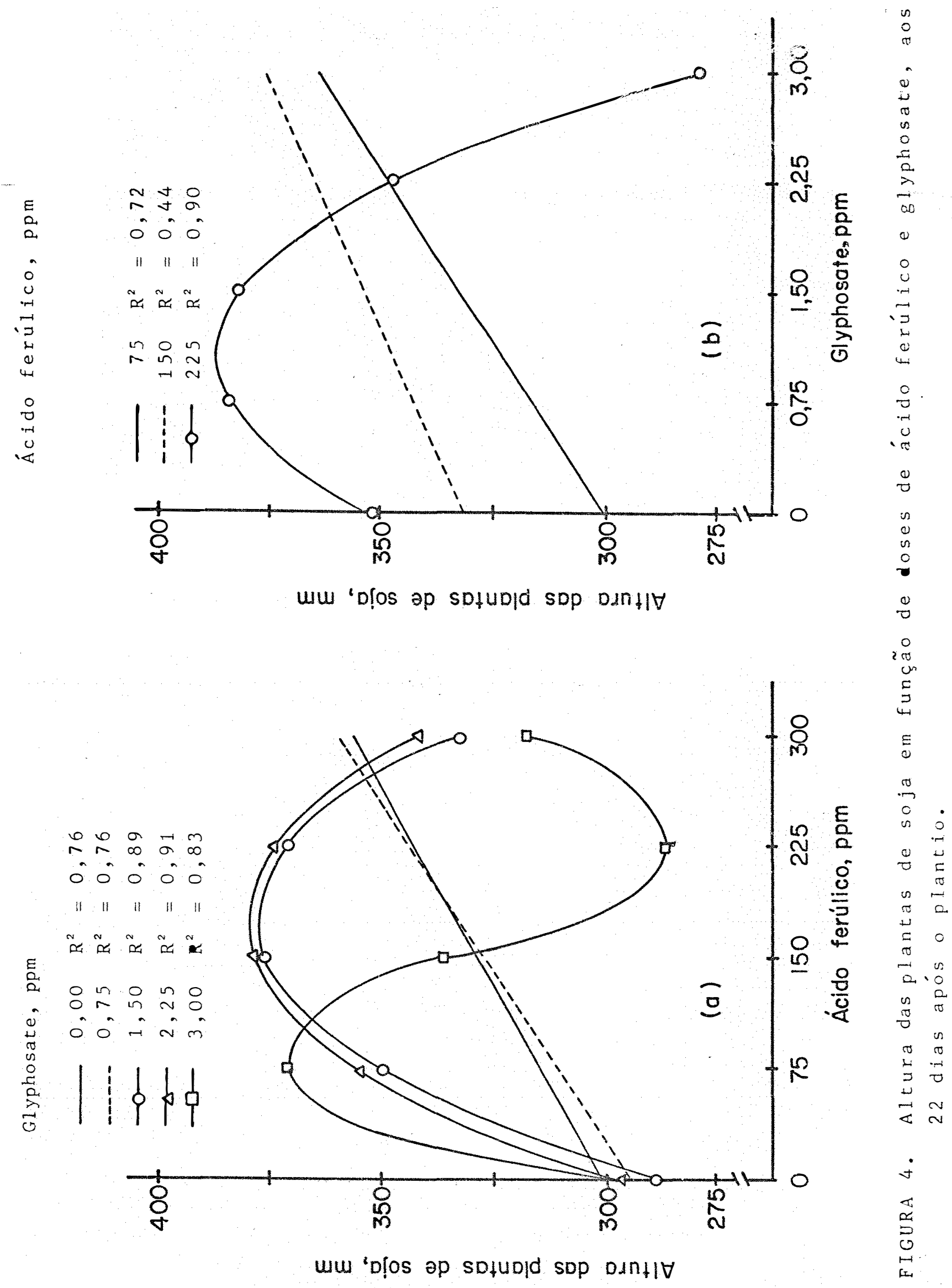




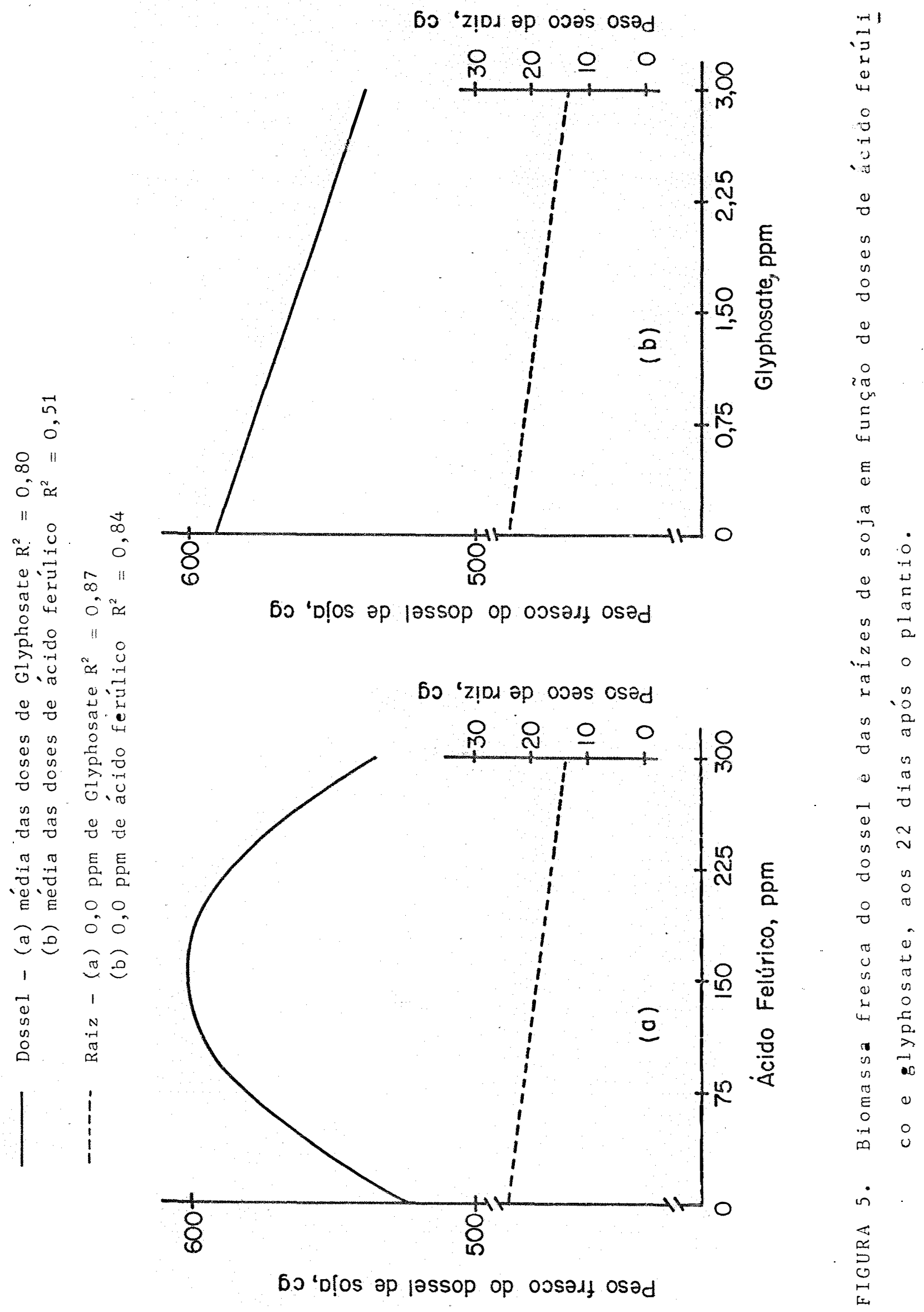


blomassa seca das ralzes da sola (Figura $5 . b\rangle$ fol reduzlda com as doses crescentes de Gly com 0,0 ppm de AF, apresentando também um pe $(=0,89)$ alto.

A estimativa dos parametros de modelos e valores de re para as discussoes antecedentes, são appesentadas no Apendice 7.

Observa-se que o AF pode produzir aumentos de altura de plantas de soja, com aumento da blomassa do dossel, mas peduzindo a biomassa das palzes a semelnanfa fe substanclas de crescimento. Por sua vez, Gly pode causar aumentos de altura das plantas de sola, com reducăo da blomassado dossel e das ralzes.

o aumento de altura das plantas de sola, causado por AF ou GLY, of uma caracteristica deselavel, significando uma vantagem competitiva por luz em relaca a as plantas daninhas. No entanto, o estlolamento da planta con reducão da blomassa do dossel poderla deixar a planta susceptryel a quebra do caule ou a a amamento. A peduga da biomassa das ralzes pode signiflicar reducão na quantida de absopbo de agua, nutrientes ou de substanclas como herbicidas. Neste caso, menores quantidades de herbicidas como alachior e Inuron serlam absorvidos pela sola, reduzindo possivels injurias, as vezes verificadas a campo. Dependendo da susceptipllidade da espécie, plantas aninhas poderlam manl restar $^{*}$ semelhantes respostas.

Exudatos de plantas tratadas com o herbicida glyphosate, absonydos por plantas de sola e millio do solo, 
mostram efeltos estimuladores, aumentando a producão de materia seca (RODRloues et al11, 1982). Este efeito Justificarla malores producos de sola em ceptos anos para glyphosate, comparado companaqut, as vezes relatado como resultado de um controle de grameneas por um peplodo mals prolongado (HARDCASTLE, 1973 e WORSHAM \& LEWIS, 1973). NO entanto, no foram obsuad a sumentos de biomassa fresca do dossel da sola devido ao glyphosate, mas sim devido ao foido ferbico. Isto opae-se aos pesultados de VoLh (1988), cula metodologla baseou-se na apllcacão de uma dose única de 500 ppm, misturado depra seca pouco antes do plantlo. por sua yez, a reducão das raizes por uma destas substancias reduziria a absorga da outra, que no caso foram aplicados a mesmo tempo. A absorcão de glyphosate serla facllitada em solos arenosos (pouco adsortivos), com suficiente umidade no solo, uma vez que a adsorcão de glyphosate as particulas do solo e elevada em funcão das suas cargas positivas be as do solo predominando as negativas), não tendo sldo observado efeltos residuals (BAIRD et al11, 1971). substanclas alelopticas, como o acldo ferilico, mostram-se capazes de afetar a germinaca e o crescimento de culturas, sendo de malor impoptancla no contpole de plantas daninhas (GuENZl B MCCALLA, 1982: PATRICK et a111, 1983: GUENZ1 et a111, 1987: KIMEER, 1973; COX, 1977; COCHRAN Et a111, 1977; COLLINS B CAVINESS, 1978: LIEGL \& WORSHAM, T983 E ALMEIOA \& RODRIGUES, 1985).

Pode-se Interir que com a ocorrancia de 
elevadas quantidades de resteva de trigo na superficle do solo e umldade adequada, com o uso de glyphosate, em plantio dipeto, resulte um posslvel aumento na altura das plantas de sola, comprovável detrimento do sistema radicular, podendo aumentar ou não a producão da cultura e o controle de plantas danintras.

4.3.2. Respostas de pepino, sola e ancarinha-oranca a Interacões de alachlor e linuron

A blomassa fiesca do dossel de plantas de pepino (Tabela 20 ), sob doses cfescentes de linuron, sem alachlor, fol signiflicativamente reduzida na dose de $0,5 \mathrm{ppm}$ de Inuron, a $25,8 \%$ da testemunha, com reducão mais acentuada alnda a, $0 \mathrm{ppm}$. Alachlop, na dose de 2,0 ppm, sem Hnuron, tambom afetou signiflcativamente a produca de bomassa fiesca do dossel, peduzindo-a a $82,5 \%$ testemunha. Reducão adicional reducão de biomassa obtlda com 0,5 ppm de IInuron, fol obsepvada na sua comblnacão com a dose de alachlor de $0,5 \mathrm{ppm}$. Combinacões de IInuron a 0,5 ppm com as doses seguintes de 1, o e 2, D ppm de alachlor Fesultaram em aumentos das biomassas. Isto, em relacáo a aplicacão de Inuron apenas, significou um aumento da blomassa de 50,4\%. por suavez, a dosede 2,0 ppm de a lachlor com a dose seguinte de 1,0 ppm de linuron, eliminou este aspecto protetor de alachlor. A proteqão observada fol mais tarde determinada ser em funcão da reducão do sistema radicular, reduzindo assim a absorgão de linuron e os seus 


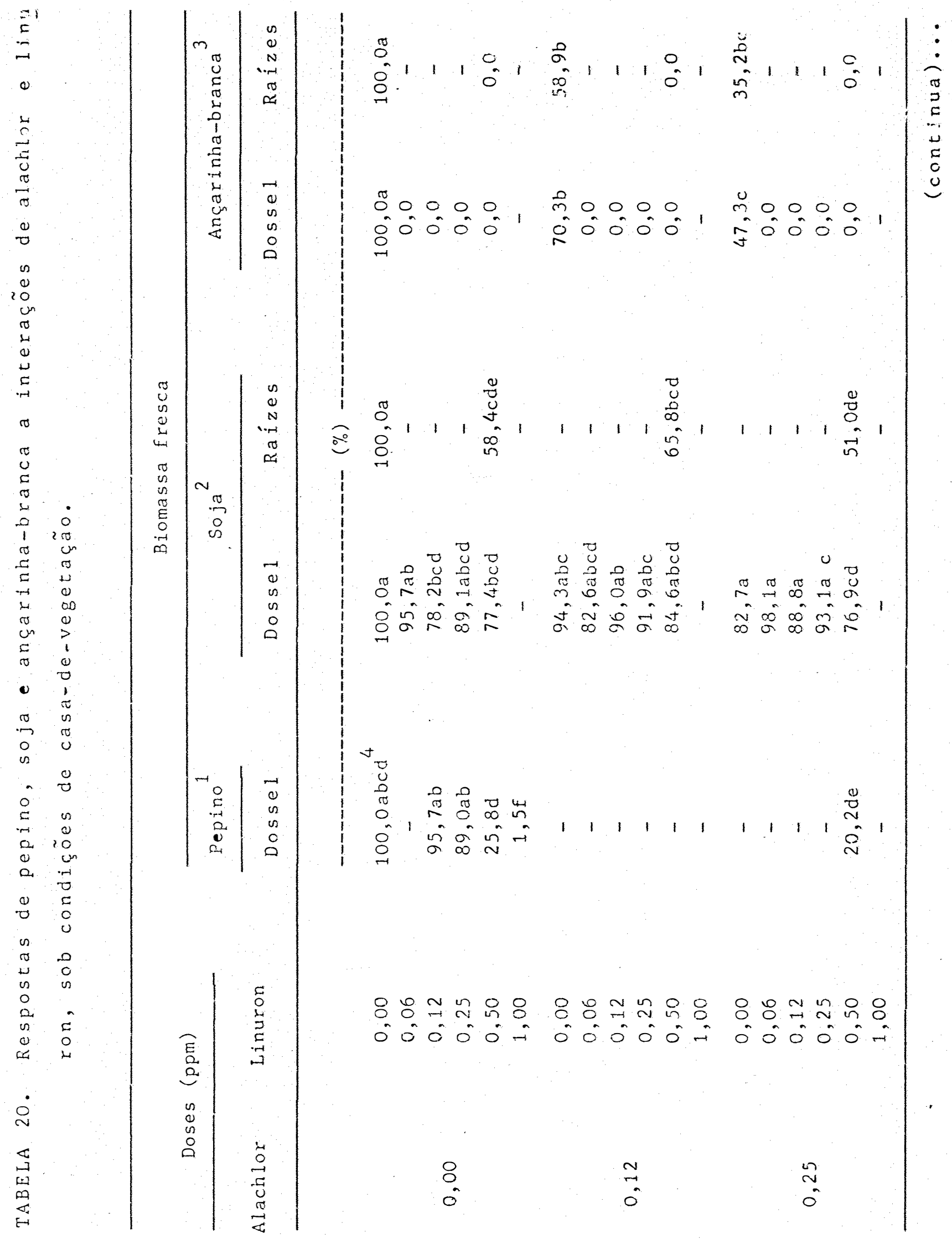




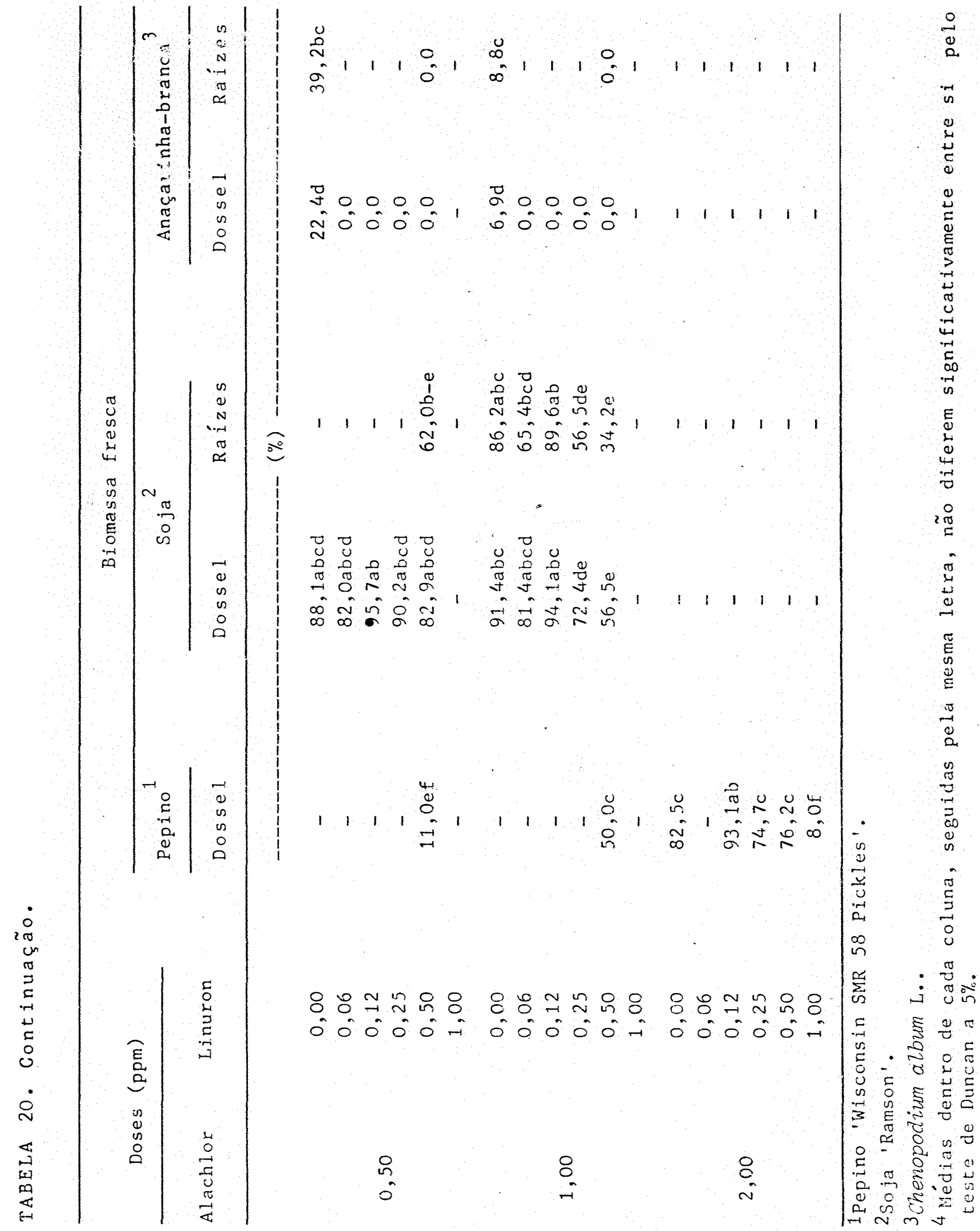


efeitos sobre pepino.

No experlmento com soja, sob doses crescentes de IInuron, a blomassa fresca do dossel da sola fol reduzlda significativamente em relacăo a testemunha (100 ppm de Iinuron, a $77,4 \%$ e, a blomassafresca das ralzes, a $58.4 \%$. Alachlor, ate a dosemalma de 1,0 ppm, sem linuron, năo apresentou reducões signiflicativas da biomassa fresca do dossel e das ralzes, flcando a $91,4 \%$ e a 8 , $2 \%$ da testemunha, respectivamente. Ao contralo de pepino, a combinaç̃ de $3,0 \mathrm{ppm}$ de alachlor com $0,5 \mathrm{ppm}$ de linuron causou reducão adicional a reducăo da biomassa şresca do dosse1, observada a 0,5 ppm de linuron. Não ocornemam efeitos adicionals significativos para as palzes.

As blomassas frescas do dossel e das ralzes de angapina-branca foram reduzldas significativamente com a dose minima de 0, 12 ppm de alachlor. Estaplanta daninha mostrou-se altamente sensfvel ao linuron, morpendo la com a dose de 0,06 ppm.

comparando-se as espectes, observa-se que sola, a espofie menos sensfvel, não toi protegla pelo alachlor contra os efeltos do Iinuron, apresentando efeltos que se somam. No entanto, efeltos protetores foram observados para pepino, uma especiemals senstuel a ambos os nepbloldas do que a sola. Nas doses testadas, a espotemals

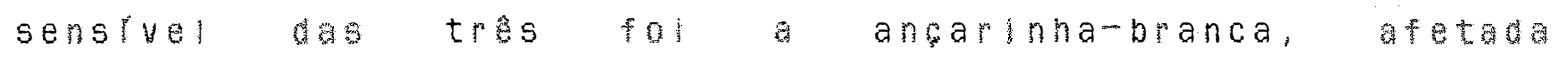
signiflcativamente pelas doses crescentes de alachlor e, näo sobrevivendo mesmo na dose minima de linuron. 
Sole e ancarinna-branca mostraram maiom senslbilidade das ralzes do que do dossel aos hapbicidas, observado através das redugôs mals acentuadas das blomassas frescas as razes do we do dosel.

$$
\text { Efeitos protetores de compostos ulmicos }
$$
contra inifilas de herbicidas, tem sido de granda valor, permitindo o uso de herbicidas eficientes sem causar danos as cuturas (WORSHAM \& LEWIS, 1973; LADLIE et aIII, 1976 LADLE, 1977). Efeitos protetores, cltados por NIFFELER ET a11 (1980) e YORK R SLFE (1981), sugerem tambem posslveis perdas de eflojếncla de nerblcidas contra espobies de plantas daninhas.

os mesultados obtidos indicam as posstvels razós para o controle de ancapinhampanca e da mantfestagão dos efeltos futotoxicos, observados na sola nos experimentos de campo, bem como reabos das plantas que podem pesultap em comportamentos varlaveis de controle de espécies daninhas.

\subsection{Experimentos em camara-de-cresclmento}

9.9.1. Absorgão de $e^{1 \frac{4}{3}}$ G-linuron e gua

A absorgão displa de colinution pela sola

(Figura b) aumentou significativamente ate o quinto dia,

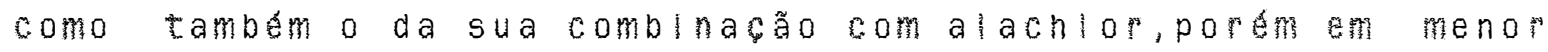
intensidade. A absorbão dispia de c-linuron pelo peplno (Figura 7) mostrou compotamento semelnante a da sola, sob concentrabão de G-inumon, quatro, e alachlop, oltovezes 


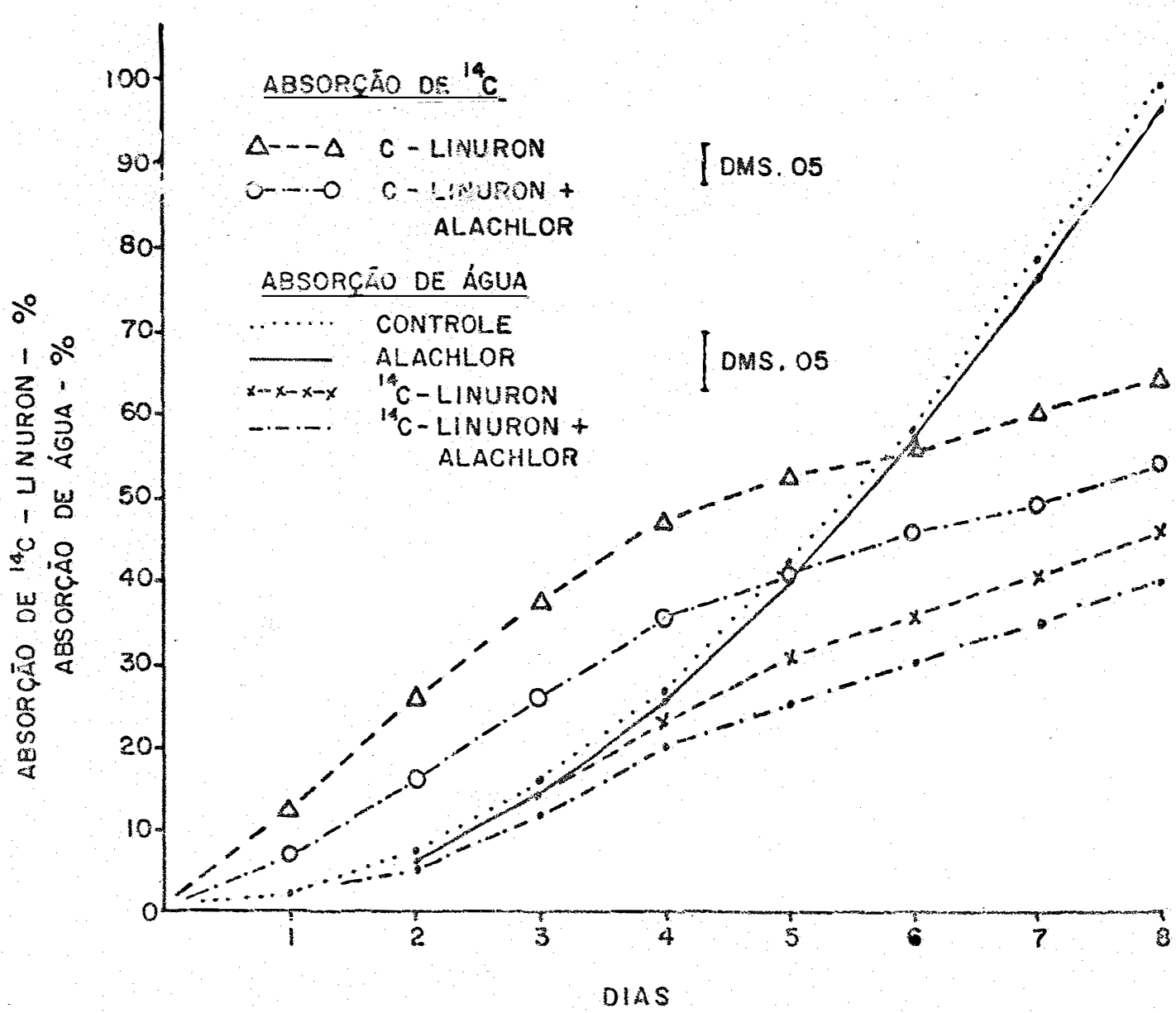

FIGURA 6. Efeitos da duração de exposição na absorção de água e radioatividade em soja 'Rainson', afós o tratamento com $0,28 \mu g / m 1$ de ${ }^{14} \mathrm{C}-1$ inuron e na sua combinação com 1, $0 \mu \mathrm{g} / \mathrm{ml}$ de alachlor. Plântulas com quatro dias na época do tratamento. DMS.05 para radioatividade $=4,95 ;$ para água $=7,2$. Percentagens para valores máximos de radioatividade $=8.843 \mathrm{dpm}$ e, para água $=223,7$ m1. Equivalentes de radioatividade de ${ }^{14} \mathrm{C}-1 \mathrm{i}-$ nuron adicionados à solução nutritiva das rázes de 422.172 dpm. 


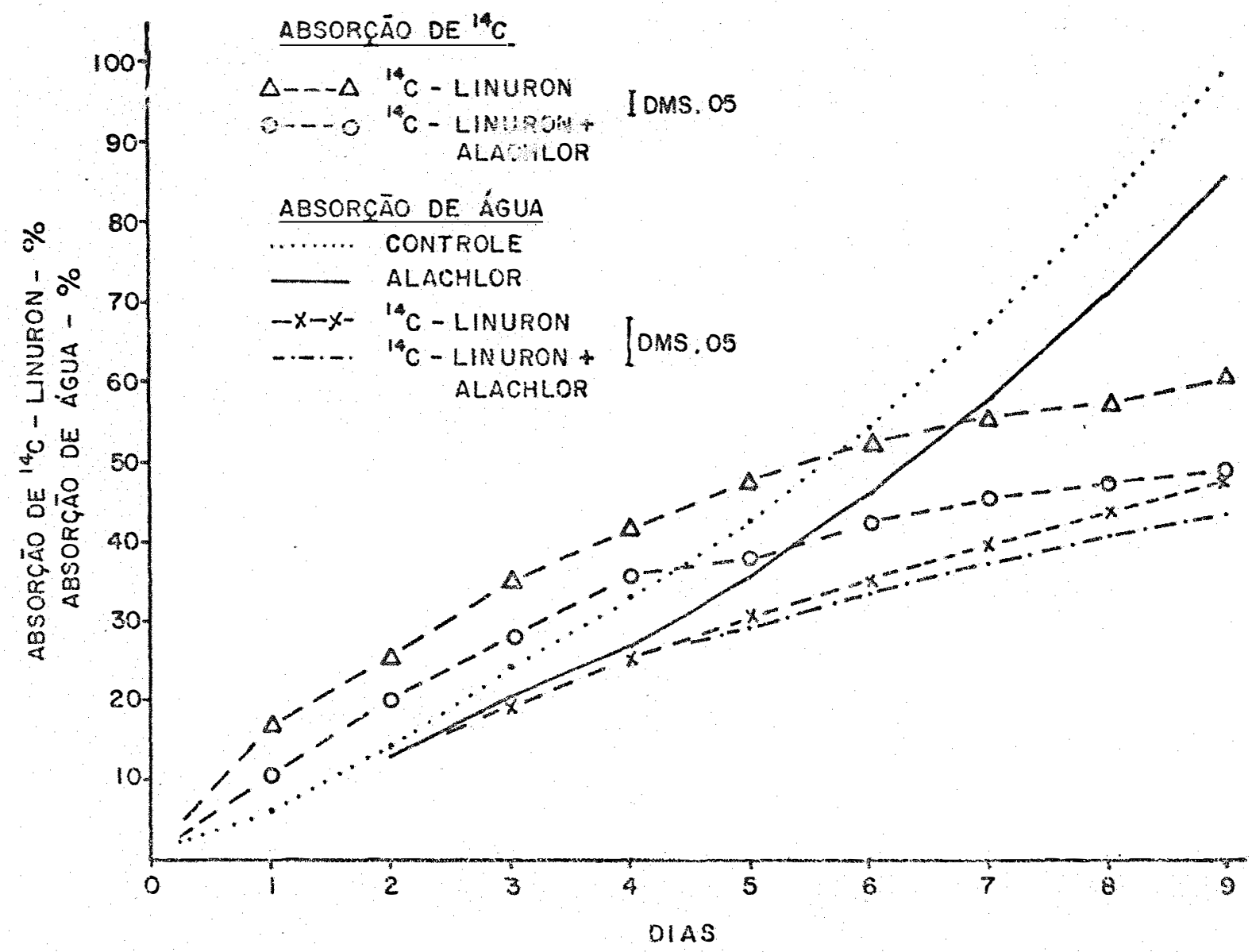

FIGURA 7. Efeitos da duração de exposição na absorção de água e radioatividade em pepino 'Wisconsin SMR 58 Pickles', após tratamento com $0,08 \mu g / m l$ de ${ }^{14} \mathrm{C}-1$ inuron e na sua comóinação com $0,12 \mu \mathrm{g} / \mathrm{m} 1$ de alachlor. Plân tulas com três dias de idade na época do tratamento. DMS.05 para radioatividade $=3,21$; pará́gua $=6,1$. Percentagens para valores máximos de radioatividade $=2.252 \mathrm{dpm}$ e, parágua $=179,5 \mathrm{ml}$. Equivalentes de radioatividade de ${ }^{14} \mathrm{C}-1$ inuron adicionados à solução nutritiva das ráizes de 112.605 dprn. 
menores.

A absorcão diaria de a gua pela sola (Figura b) aumentou significativamente a partir do quato dia nos tratamentos testemunha e alachlor. os aumentos não foram signiflcativos para c-linuron e sua comblnaca com alachlor, ambos apresentando comportamentos similates. No entanto, devido comblnacão de alachlor como c-linuron a absorcão de agua tendeu a ser menor. A absorqão diaria de igua pelo pepino (figura 7) mostrou comportamento semelhante ao da sola. o tratamento com alachlor comparado com a testemunha reduzi mais a absorcão de ăgua em funcão da reducão das ralzes (Tabelas 21 e Z2), sendo malor no pepino do que na sola.

As absoriones cumulativas de c-linuron em dpm/plantaldia, para a sola podem ser descritas pelas seguintes equacöes:

$y=-0.5+33.940,9 x-2.091,6 x^{2}$, com re $=0.87 \mathrm{e}$

$y=-0,2+25.426,9 x-1.194,2 x$, com re $=0,86$

e para pepino

$\gamma=-0,1+6.098,0 x-282,5 x^{2}$, com re $=0,89 \mathrm{e}$

$y=-0,2+5.558,0 x-272,0 x^{2}, \operatorname{com} r 2=0,89$

19

para os tratamentos c-linuron e comblnacão com o alachlor, respectluamente.

A absorcão de 19 c-linuron e agua apresentaram um coeflciente de correląão $r=0,96$ na sola, e $r=0,79$ no pepino. Este alto grau de correlacão na sola, mostra que a absorgão de c-linuron governada pela absorqão de faga, 
parecendo ser passiva, conforme fol observado por NASHED \& ILNICKI (1970), em tres diferentes espécles. o comportamento do IInuron, destemodo, é algo oposto daquele de $3-(p-<p-$ clopofenoxi)-(fenil)-1-1-dimetl|uréa (cloroxuron), relatado por Gelssbiliter etalit (1970)*, para outro composto da mesma fam/11a.

4.4.2. Blomassa fresca de partes da planta

Cotllédones e hipocotilo da sola (Tabela 21) não apresentaram diferencas signiflcatluas de blomassa entre os tratamentos. o alachlor não causou diferencas de blomassa em qualquer parte da planta em relacão testemunha. Esta e alachlor apresentaram majores blomassas para as folnas, eplótilo e palzes quando comparados como colinuronso e comblnado como alachlor, mostrando assim, os efeltos de fitotoxidez do IInuron. Os cotilédones e o hipocotilo, não foram afetados no seu metabolismo pelos nepblcidas, não acarretando diferencas significativas de blomassa. As folnas simples e as palzes mostraram os efeltos do linuron através da reducão da sua biomassa, sendo acentuados com a presenca do alachlor: isto não fol observado como alachlor sozinho.

Resultados de blomassa fresca das partes de pianta de pepino (Tabela 22 ) mostraram diferengas entre tratamentos para as folnas, cotilédones, hipocotilo e ralzes. o alachlor comparado com a testemunha, neduzlu a

WGE|SB|HLER, H.G.; HASELBAGK, G.; AEBI, M.; EBNER, L. We d Research, 3:181-394, 1963. 
TABELA 21. Biomssa fresca das partes de planta da soja 'Ramsion' sob efesto do ${ }^{14} \mathrm{C}-1$ inuron a $0,28 \mathrm{ppm}$, a lachlor a 1,0 ppm combinac̃ão de ambos.

\begin{tabular}{|c|c|c|c|c|c|c|}
\hline \multirow{3}{*}{ Tratamento } & \multicolumn{6}{|c|}{ Parte da planta - biomassa fresca (g) } \\
\hline & \multicolumn{2}{|c|}{ Follhas } & \multirow{2}{*}{$\begin{array}{l}\text { Cotilé } \\
\text { dones }\end{array}$} & \multicolumn{2}{|c|}{ Caule } & \multirow{2}{*}{ Raízes } \\
\hline & $\begin{array}{c}\text { Compos } \\
\text { tas }\end{array}$ & Simples & & $\begin{array}{l}\text { Epicó } \\
\text { tilo- }\end{array}$ & $\begin{array}{c}\text { Hipocó } \\
\text { tilo }\end{array}$ & \\
\hline Testemunha & $1,149 a B^{1}$ & $1,061 \mathrm{a} \quad \mathrm{BC}$ & $0,872 \mathrm{aC}$ & $0,958 \mathrm{a} \mathrm{BC}$ & $0,817 a C$ & $1,913 \mathrm{a} \quad \mathrm{A}$ \\
\hline Alachior & $1,227 a B$ & $1,058 \mathrm{a} \quad \mathrm{BC}$ & $0,919 \mathrm{aCD}$ & $1,034 \mathrm{BC}$ & $0,797 \mathrm{aD}$ & $1,896 a$ A \\
\hline${ }^{14} \mathrm{c}-1$ inuron & $0,402 \mathrm{BD}$ & 0,532 b CD & $1,014 \mathrm{aA}$ & $0,683 \mathrm{bB}$ & $0,790 \mathrm{aB}$ & $0,743 \cup \mathrm{EC}$ \\
\hline \multicolumn{7}{|l|}{${ }^{14} \mathrm{C}-1$ inuron } \\
\hline + alachlor & $0,321 \mathrm{bDE}$ & $0,242 \mathrm{cE}$ & $0,920 \mathrm{aA}$ & $0,601 \mathrm{bBC}$ & $0,805 \mathrm{AB}$ & $0,520 \mathrm{COD}$ \\
\hline
\end{tabular}

DMS. $(0,05)=0,215$

${ }^{1}$ Médias seguidas pela mesma letra minúscula, na coluna, e maíscula, na linha, não diferem entre si pelo teste DMS ao nível de $5 \%$. 
TABEla 22. Biomassa Eresca das partes da planta de pepirij 'Wisconsin SMR 58 Pickles' sob efeito de ${ }^{14} \mathrm{C}-1$ inuron a $0,08 \mathrm{ppm}$, alachlor a $0,12 \mathrm{ppm}$ e combinação de ambos.

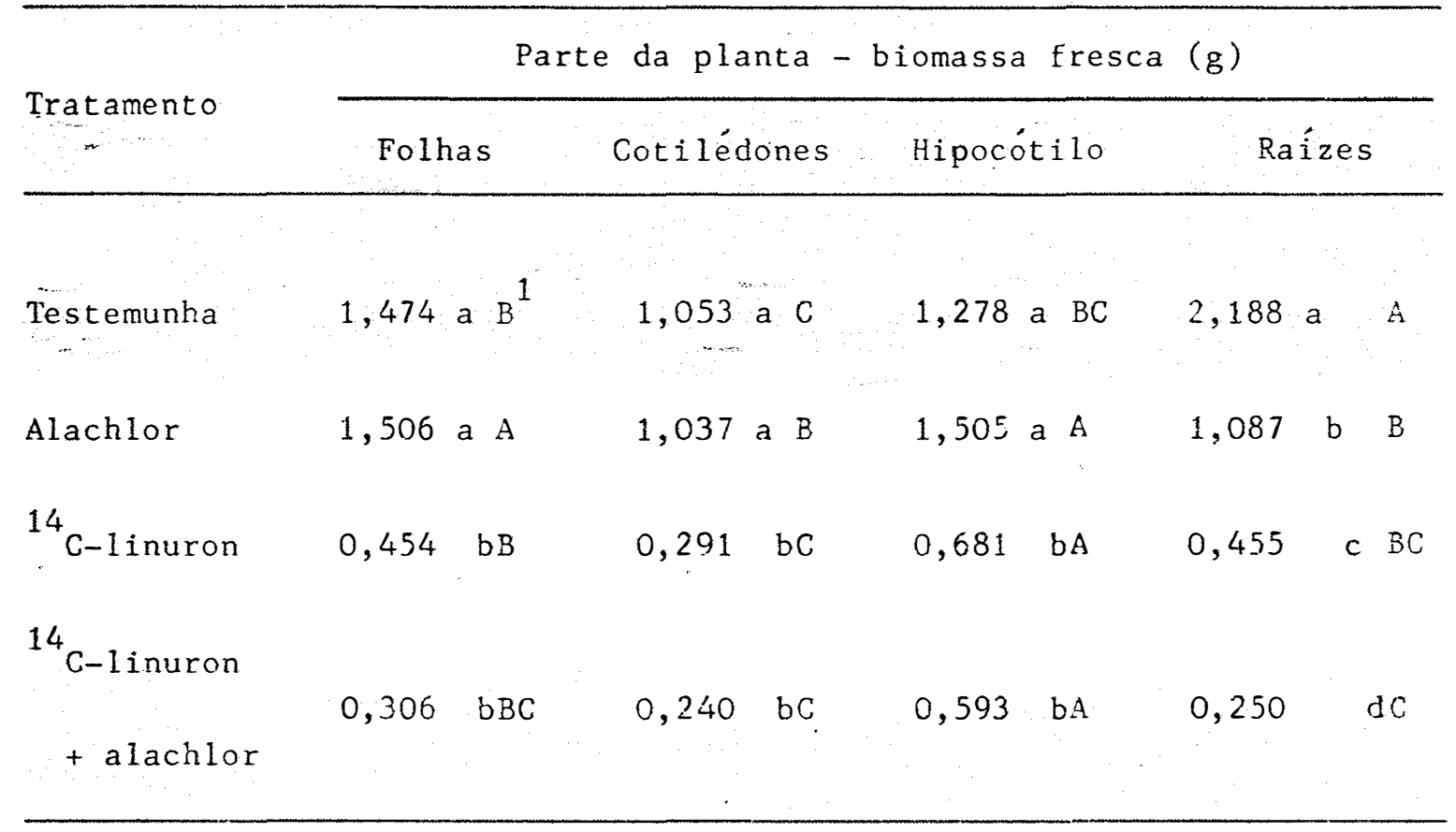

$\operatorname{DMS}(\mathrm{C}, 05)=0,204$

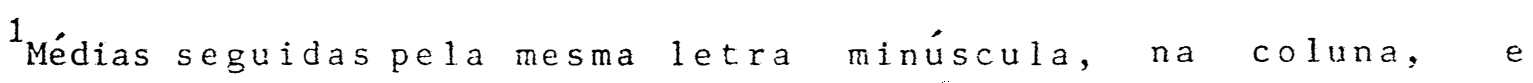
maiúscula, na linha, não diferem entre si pelo teste DMS ao nível de $5 \%$. 
blomasa do sistema radicular. Nennuma outra direrenca afetou todas as partes da planta, reduzindo suas blomassas; combinado com o alachlor, form aumentados os efeltos negativos nas ralzes. olferente da sola, as blomassas dos cotiledones e do hipocotilo do pepino foram reduzidas por efeitos fitotóxicos do Inuron. Estes efeltos distintos devem estar associados diferencas de metabolismo e fislologia das duas especies, que manifestam diferentes graus de sensibllidade a linuron. Fol observado ainda, que as plantas tratadas pelo alachlor apresentavam a cor das folnas e cotiledones mals verdes, devido possivelmente a maior producão elou concentracão de clorofila.

os resultados de biomassa do dossel das plantas opore-se nipotese formulada de que a presenca do alachlor contrarla parclalmente os efeitos do linuron, quando aplicados em mistura. Este comportamento fol observado para peplno, não se veriflcando o mesmo na sola. o momento da aplicacão dos produtos, que na casa-de-vegetacão fol no plantio e, no experimento em discussão, tres a quatro dias após a germinacão, pode ter contriburdo para a manifestacão das diferencas. con esta protelacão, as plantulas apresentaram um slstema radicular mals desenvolvido, com melnores condicões para absorvero linuron, cula absorcão seria reduzlda, sob condicóes de ralzes inibidas pelo alachlor. Semeinantes efeitos fitotóxicos de inibicão pelo tpiflupalin e reducões nas absopones do metribuzin am sola, 
foram observadas por LADLIE (1977). Fato importante a considerar é a resposta diferenclal das especies em termos de metabolismo e fistologia. Como la fol observado no experimento anterior com sola (ftem A.3.2\}, a mesma apresentou pespostas diferentes daquelas apresentadas por peplno, ou sela, não nouve protegão do alachlor contra os efieltos do Iinuron ha sola, mesmo aplicando os produtos por ocasião do plantio.

Em termos próticos, especies daninhas sensivels aos nerbicldas alachlor e linuron, em mistura de tanque, podem apresentar ou não os ereltos platados para pepino no estálo iniclal de crescimento, dependendo de condicões ambientais favoravels ou nä a atividade dos mesmos.

4.4.3. Dlstribulcão da radloativldade na planta

4.4.3.1. Contagem por cintilagão l quida

14

A distin mostrou difencas signiflcativas de concentracão entre os 14

tratamentos de c-linuron, semou como alachlor, dentro das paptes da planta como follas compostas, cotilebones. epicotilo, nipocotilo e matzes. No entanto, malor concentracão do c fol observada nas folnas simples, sendo signiflcativamente malor na sua combinacão como alachlor. A malor concentracoa de c-radioativo nas follhas simples están em concorancia com os sinals de fitotoxicidade do inuron, 
TABELA 23. Distriluição do ${ }^{14}$ c-total em extrato de metanol em partes da planta de suja 'Ramson', após a aplicação de $422.172 \mathrm{dpm}$ de equivalentes do ${ }^{14} \mathrm{C}-1$ inuron só e em combinação com o alachlor.

\section{Partes da planta}

Tratamento (dias) $\quad \begin{gathered}\text { Tempo } \\ \end{gathered}$

${ }^{14}$ C. $\mu g / g$ de biomassa fresca ${ }^{1}$

${ }^{14} \mathrm{C}$-1inuron $\quad 8 \quad 4,622 a \mathrm{~B}^{2} 12,991 \mathrm{~b} A \quad 2,923 \mathrm{aBC} \quad 0,913 \mathrm{aC} \quad 0,620 \mathrm{aC} \quad 2,304 \mathrm{aBC}$

${ }^{14}$ C-Iinuron

+ alachlor

$8 \quad 4,976 a B \quad 30,909 a A \quad 2,824 a B C \quad 1,044 a C \quad 0,710 a C \quad 2,404 a C$

DMS. $(0,05)=2,429$

${ }^{1}$ Corrigido para ${ }^{14}$ C-total absorvido pelas plantas, por tratamento.

${ }^{2}$ Médias seguidas pela mesma letra minúscula, na coluna, e maiús cula, na linha, não diferem entre si pelo teste DMS ao nível de $5 \%$. 
com ocorrencla de amarelecimento internerval na superficie e posterior morte do tecido. As folnas simples acumularam 53,3 14

e 72, $1 \%$ do c-total, na ausencla e presenca do alachlor. respectivamente.

A distribulcão do ${ }_{14}^{14}$ C em peplno (Tabela 24) apresentou malop concentracão do c nos cotlledones do que nas folnas, por isso sendo mals susceptruel, comparado coma sola. Não foram observados efeltos adicionals do alachlor. As folnas tenderam a apresentarmalor concentracão do 0 na 14

combinacão de c-linuron com o alachlor. os cotilédones acumularam 77,4 e $B 2,8 \%$ do c-total, na ausancla e presen do alachlor, respectivamente. A presenca do alachlor fez com que houvesse um atraso no surgimento das primeiras folnas, mais verdes.

Ds resultados de distoloulo da radoatividade na planta mostram que o efelto de reducão da biomassa fresca, observada nos cotlledones do pepuno não nos a sola, esta placlonado commalores quantidades do ${ }^{14}$ nos cotiledones, enquanto que na sola lsto ocorre nas follas simples.

Menores concentracoes do 19 nas plantas no 19

tratamento com G-linuron, pepresenta maior blomassafresca de soja e peplno, malor absorcão de agua e menor absorgo de 19 c-linuron da solucão nutritiva.

Quantidades do 19 remanescente nos tecidos das plantas foram malores com collnuron do que nas suas comblnacồes como alachlor (Apênalce B). 
TABELA :4. Distribuição do ${ }^{14}$ c-total em extrato de metanol eñ partes da plani: de pepino 'Wisconsin SMR 58 Pickles', após a aplicação de 112.605 dpm de equivalentes do ${ }^{14} \mathrm{C}-1$ inuron só e em combinação com o alachlor.

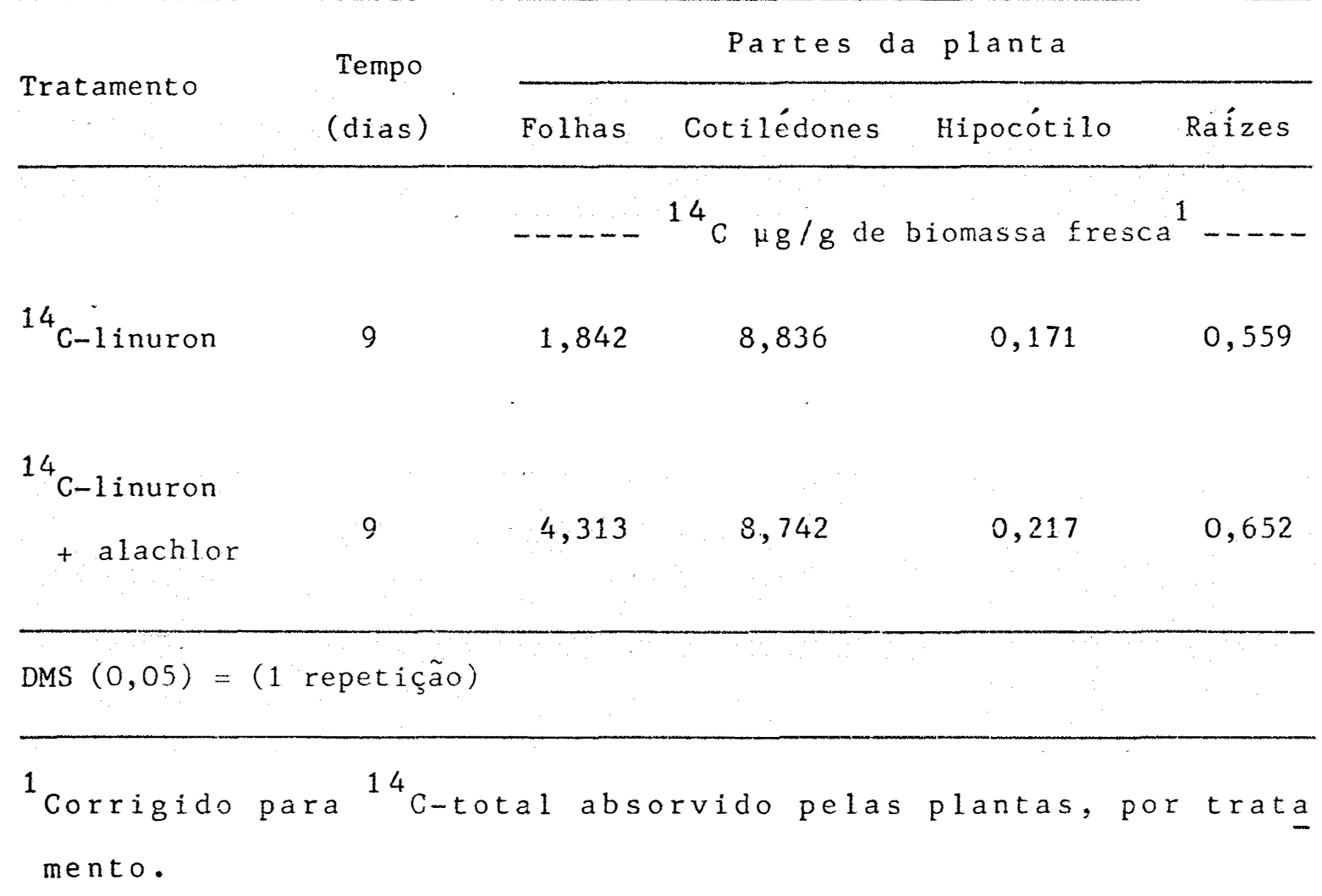


4.4.3.2. Autoradlografia

Ralo-x da planta de sola, para c-linuron

(Figura 8) e da sua combinacão com o alachlor (Figura 9 ) do pepino (Figura 10), inculindo amos os tratamentos, năo mostraram contrastes evidentes para identificar partes da planta com malor concentracão da padoatividade, para confirmar os dados de contagem por cintilacalo llaulda, com excecão da combinacoúo do c-linuron como alachlor, na sola. onde contrastes mais acentuados, correspondendo a malores 19

concentracoes de G são observados. Pouca evidêncla pode ser constatada na reducão do desenvolvimento das ralzes devido ao a) achlon.

4.9.9. Metabolitos de C-linuron e distribulcöo na planta 19

o ploo padrão do c-inuron, posicionado por varpedura da placa de CCF, e apresentado na Figura 11. Metabolitos de co-linuron, em numero de cinco, foram identificados em sola e pepino. para os tratamentos so e combinado com alachlor (Flguras 12 a 15). os posslveis metabolitos, segundo a bibllografia, distribudos numa escala de referencla (Rf) a partir da orlgem na placa te cromatografia seriam: (A) na or $1 \mathrm{gem}$, metabolitos conjugados de Inuron com B-b-glucosidios e proteinas, os mals polares:

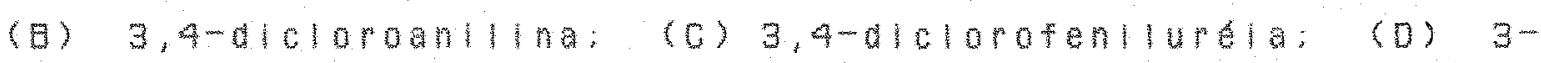
$(3,4-d) c$ torotent1)-1-metoxiurela e, (E) 3-(3,4-diclorotent1)1-metoximetilurela, ou inuron. No entanto, saguno GEISSBIHHER et ali (1975), o componente (B) tem sido 
19

FIGURA B. Distribulgểo do C emsola 'Ramson', aos outo d as após a sua aplicacóo (autoradografla). 


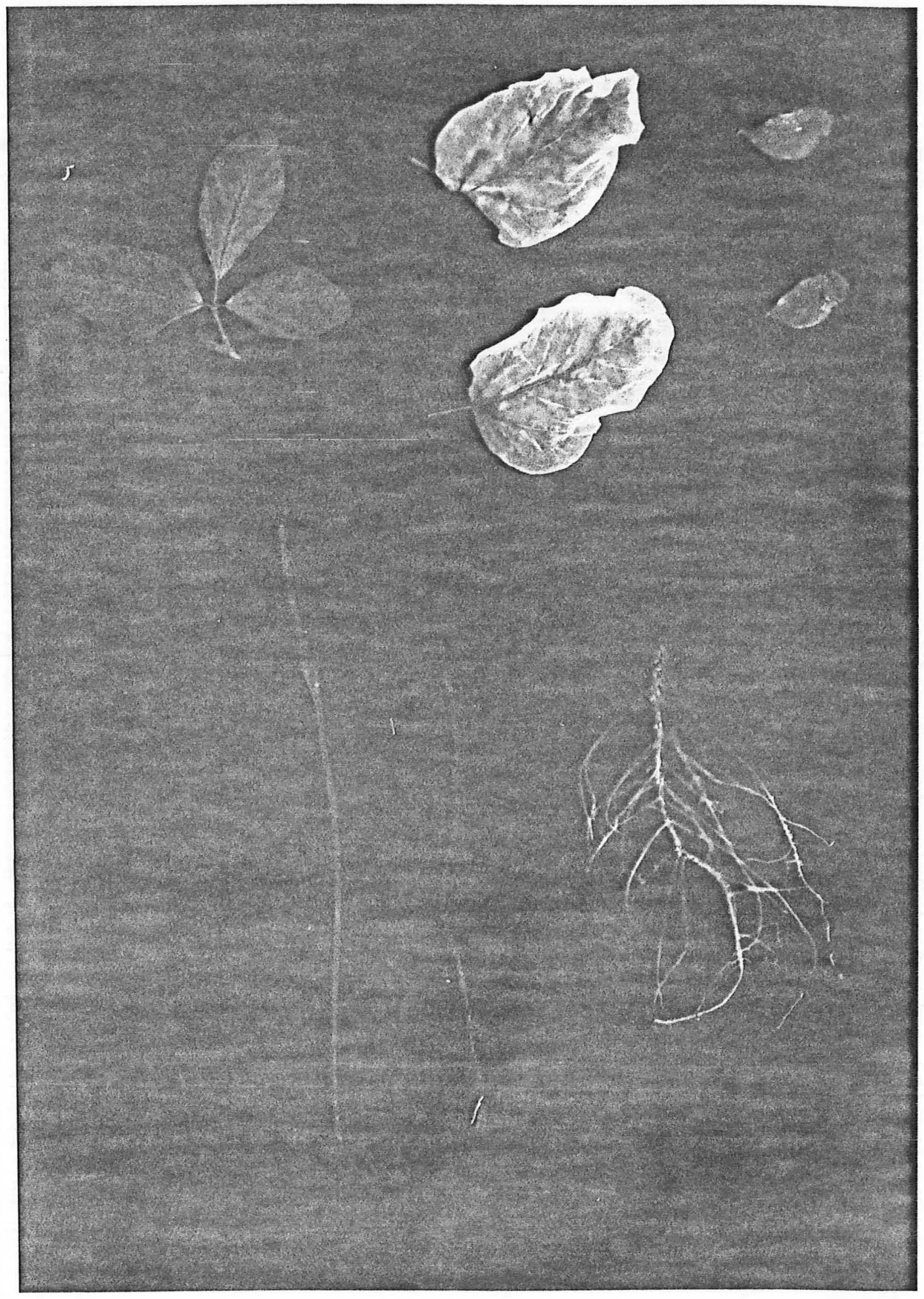


19

FIGURA 9. Distribulgäo do C em sola 'Ramson', aos olto dias apos a sua aplicacão em combinacăo com o alachlor (autoradiografla). 


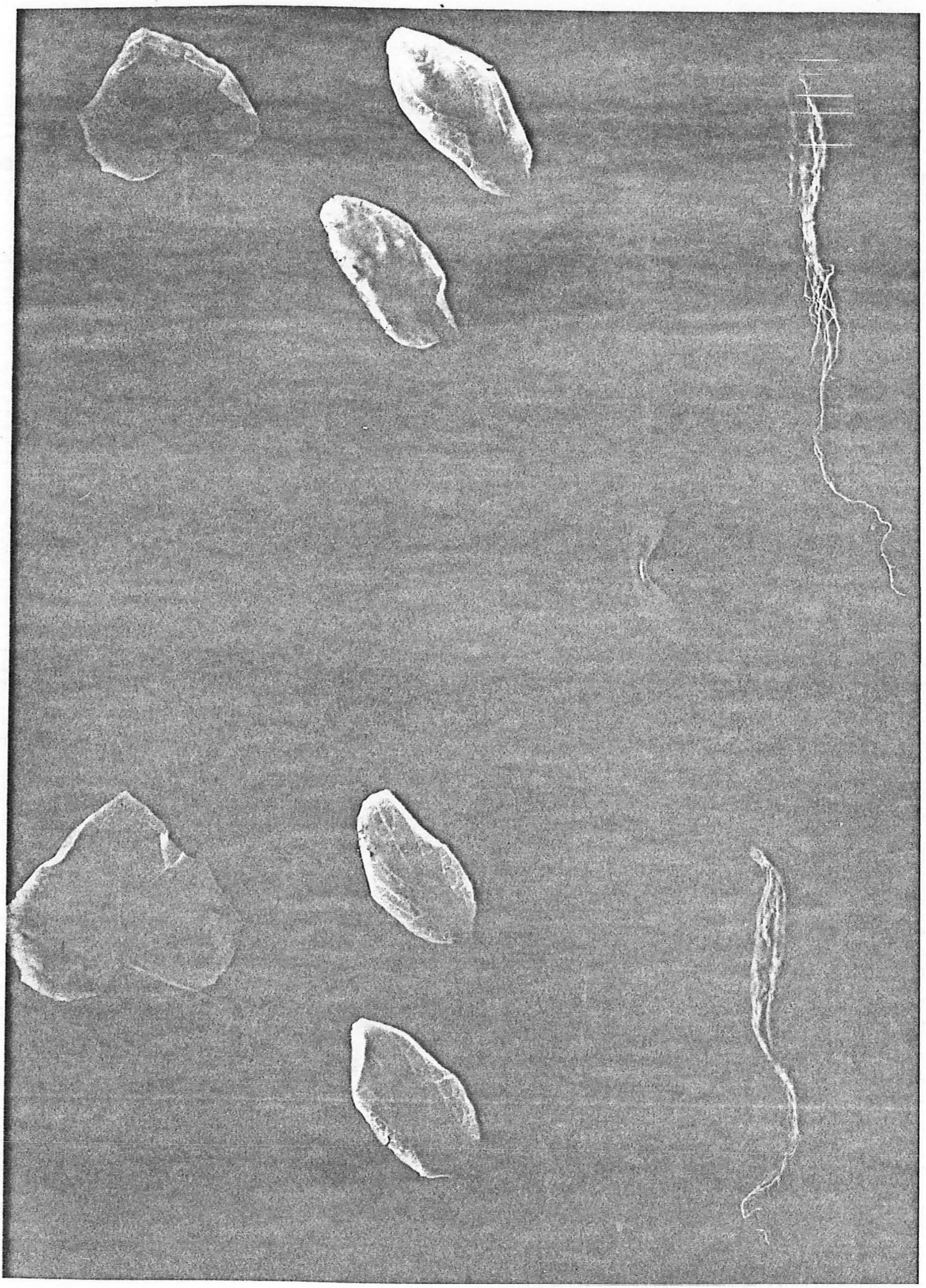


14

FIGURA 10. DIstribuifáa do C em pepino 'Wisconsin SMR 58 PIckles', aos noves dias após a sua aplicafão. Planta superior: 94 inuron. Planta inferior: 14

c-linuron em comblnacão com o alachlor (autoradografia). 


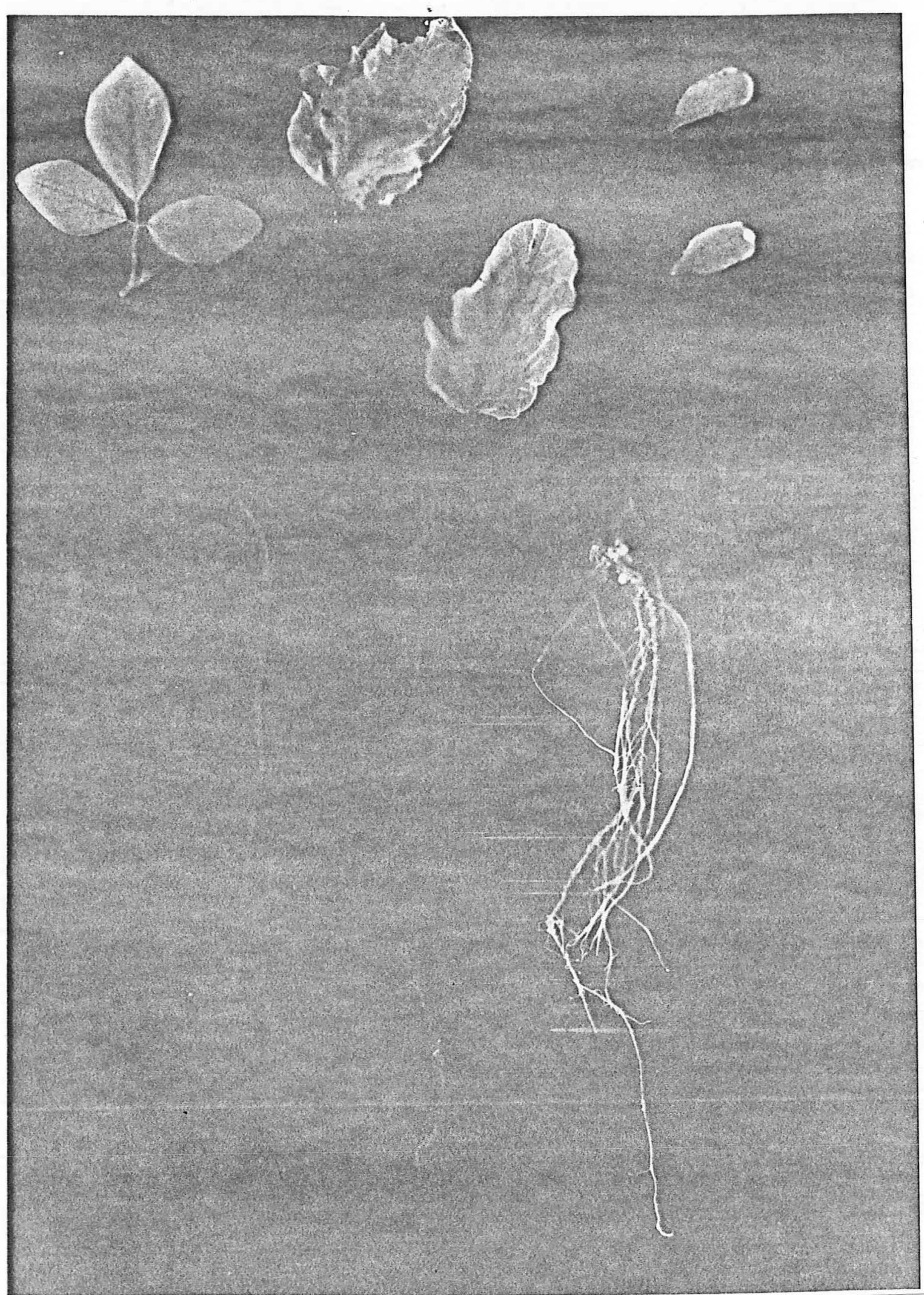




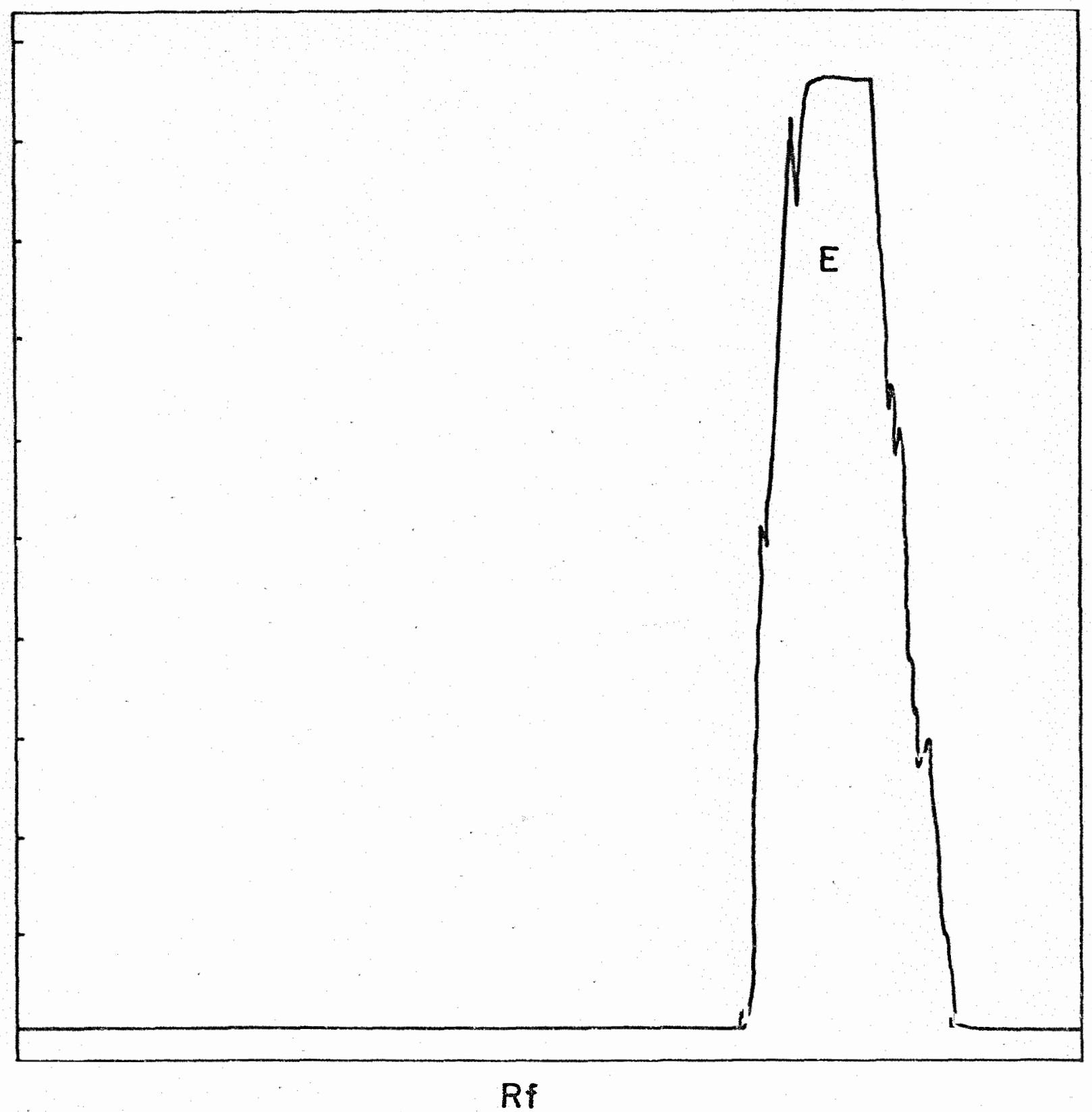

FIgURA 11. Análise de ${ }^{14}$ C-1inuron por cromatografia em camada fina (CCF), revelado em solução de benzeno/acetona a $(2: 1, \quad v / v)$. 


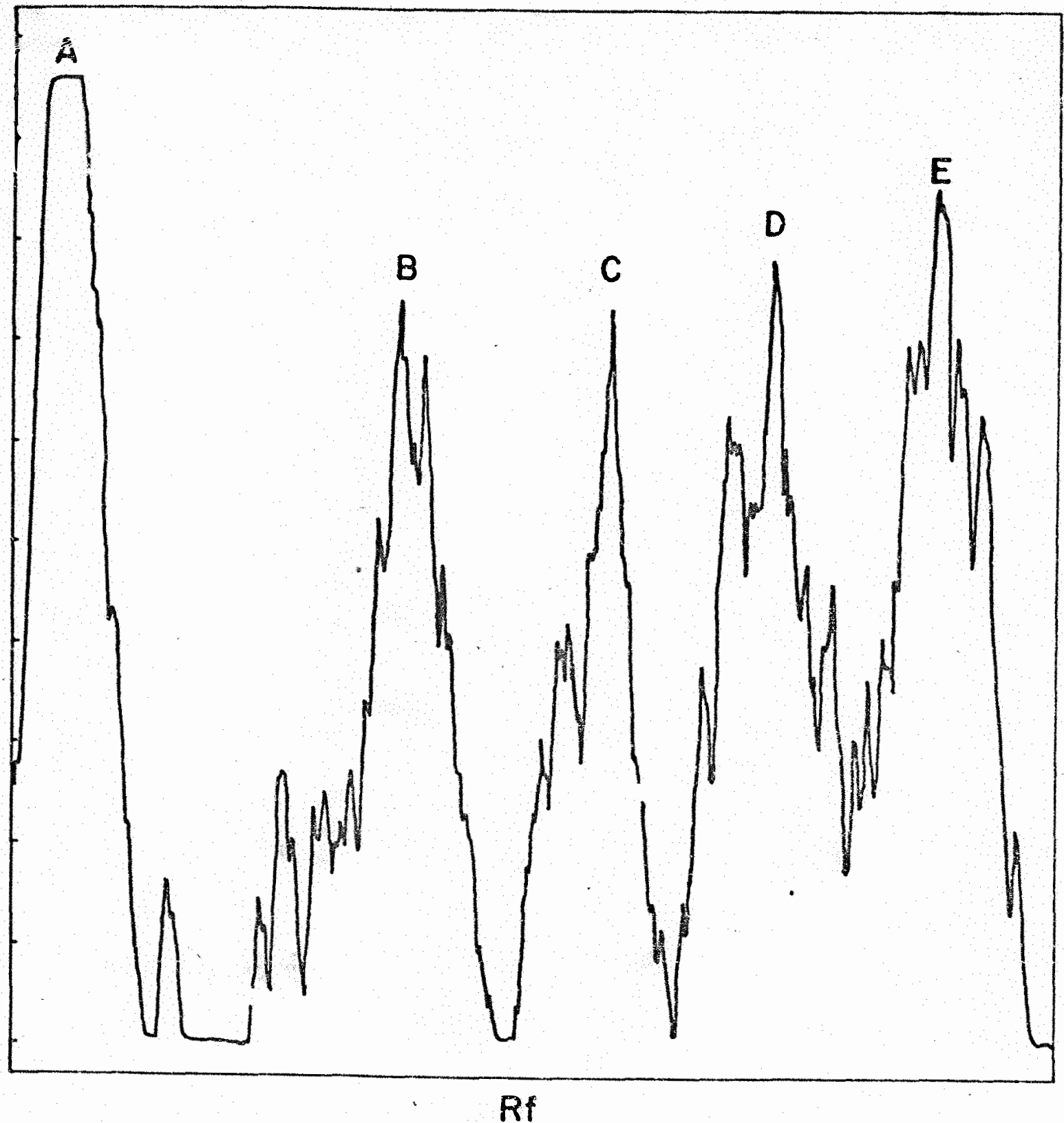

FIGURA 12. Análise por CCF de metabólitos de linuron, extraí dos das folhas simples de soja 'Ramson', aos oito diás após a aplicação do ${ }^{14}$ C-linuron e revelado em solução benzeno/acetona $(2: 1, v / v)$. A e B $=$ conjugados de linuron; $C=$ feniluréia; $D=$ metoxi linuron e, $E=1$ inuron. 


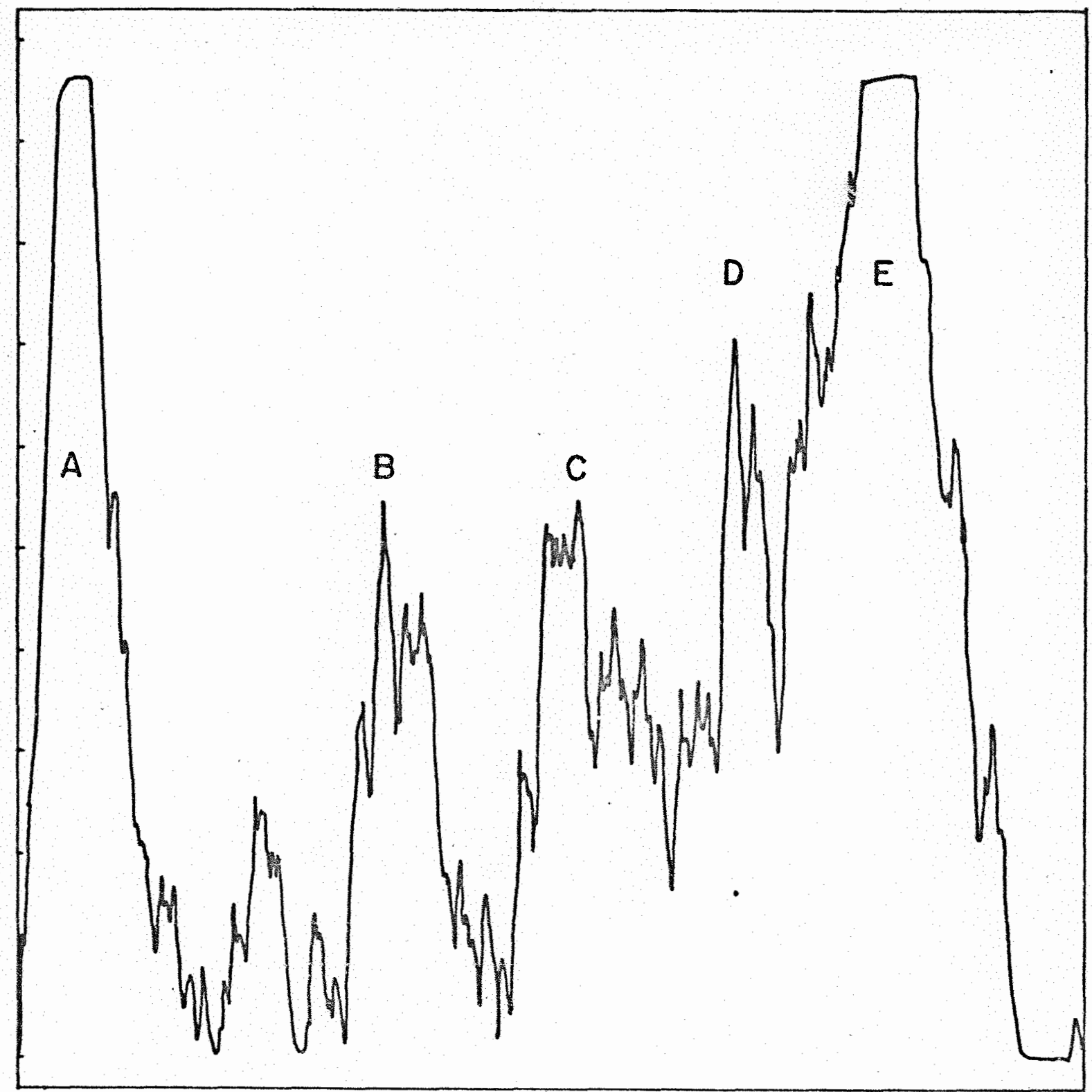

\section{Rf}

FIGURA 13. Análise por CCF de metabólitos de linuron, extrá dos das folhas simples de soja 'Ramson', aos oito dias após a aplicação do ${ }^{14}$ C-linuron em combinação com o alachlor e revelado em solução de benzeno/acetona $(2: 1, \mathrm{v} / \mathrm{v})$. $\mathrm{A}$ e $\mathrm{B}=$ conjugados.de $1 \mathrm{i}$ nuron; $C=$ feniluréia; $D=$ metoxilinuron e, $E=$ linuron. 


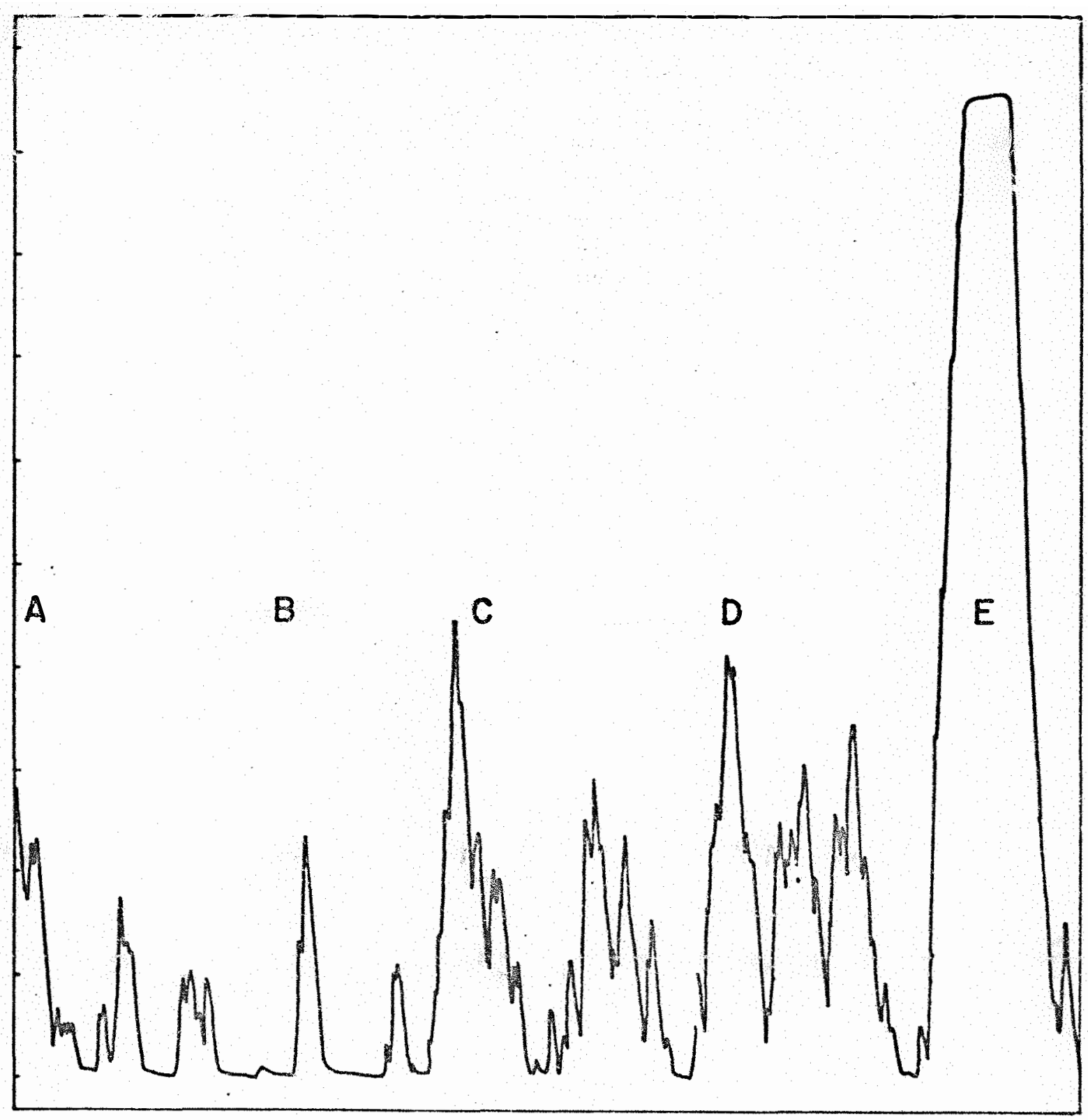

Rf

FIGURA 14. Análise por CCF de metabólitos de linuron, extrá dos dos cotilédones de pepino 'Wisconsin SMR 58 Pickles', aos nove dias após a aplicação do ${ }^{14} \mathrm{C}-$ - Iinuron e reveliado em solução de benzeno/acetona $(2: 1, v / v)$. A e $B=$ conjugados de Iinuron; $C=$ feniluréia; $D=$ metoxilinurone, $E=$ linuron. 


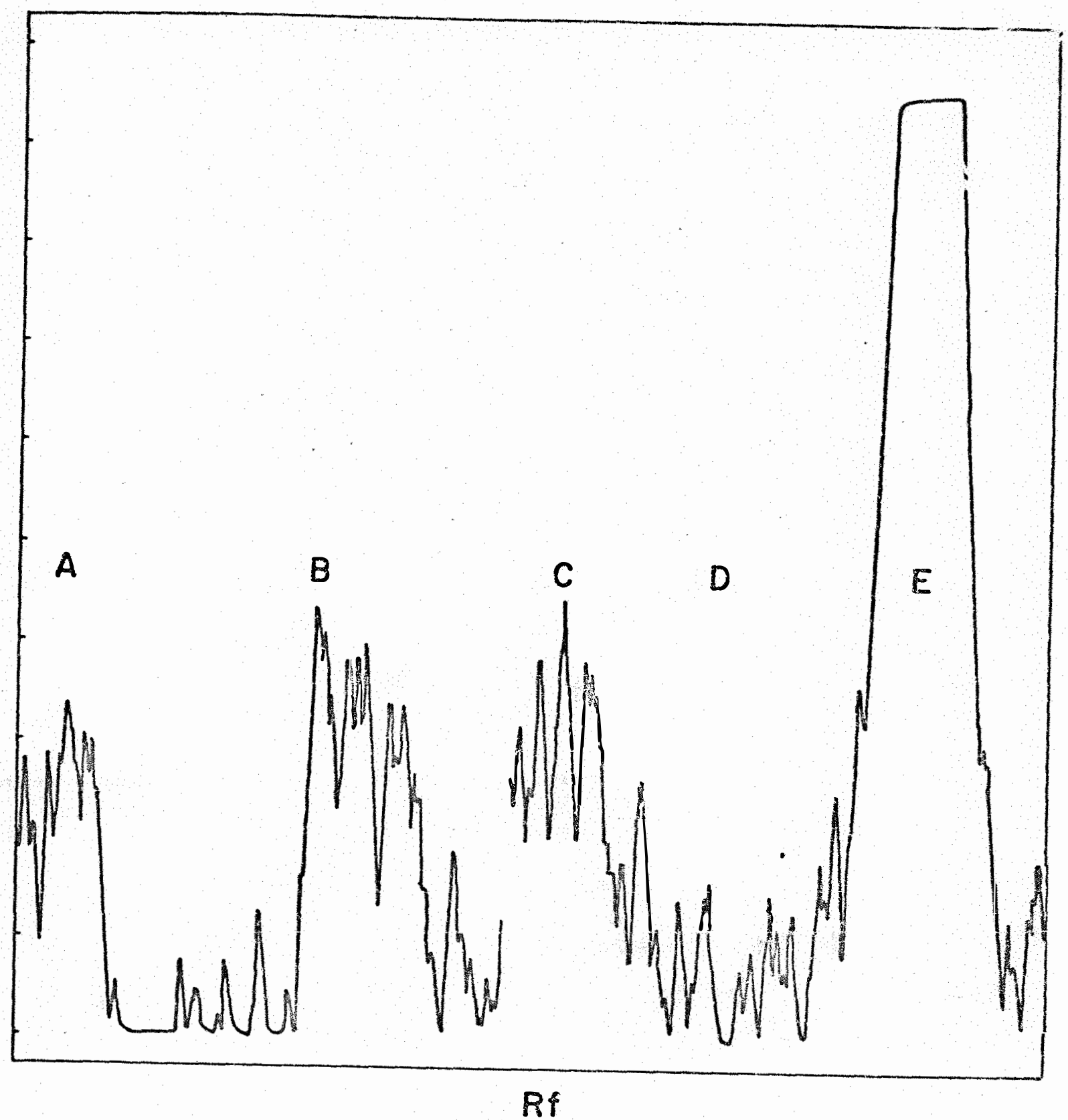

FIGURA 15. Análise por CCF de metabólitos de linuron, extraí dos dos cotilédones de pepino Wisconsin SMR 58 Pickles', aos nove dias após a aplicação do ${ }^{14} \mathrm{C}-$ - linuron em combinação com o alachlor e revelado em solução de benzeno e acetona $(2: 1, v / v)$. A e $B=$ conjugados de linuron; $C=$ feniluréia; $D=m e$ toxilinuron e, $E=$ linuron. 
d $\mid f Y c \| l$ de observar, talvez devido a uma pápla transformacão posterlor da amina arombtica. Por sua vez, LEE \& FANG (1973), Ind cam na mesma sequencla para monuron co mesmo grupo das fenllurblas), a ocorpencla de complexos polipeptidicos, sem Indicarem a ocorpencla da anllina entre as varlas formas de conjugados identificados. Uma vez que ocorrem razoavels quantldades da substâncla 8 serão mantidas as denominacốa de conjugados $A$ e $B$.

os resultados obtidos com as raspagens de porcoses das placas de cromatografla e da tecnica de cIntllaç̃o luqulda, mostraram diferencas de radioatlulade para as diferentes quantidades destes metabolitos (Tabelas 25 e 28). Malores quantidades do linuron alterado foram observadas na soja do que em pepino. Estas quantidades do 14

6-linuten metabollzado foram de 79, 2 e 80,0 \%, na sola (Tabela 25) e, de 20,8 e 19,5\%, empelno (Tabela 28), no tratamento com ${ }^{9} \mathrm{c}-1$ inuron $e$ na sua combina alachlor, respectivamente.

Na sola (Tabela 25) a peduç̃o de $19,2 \%$ nas 19

quantidades do c-linuron metabolizado (linuron alterado), na sua combinaça com o alachlor, Indica um efelto adiclonal a fitotoxicidade na presenca deste fotimo, tendendo a reduzir a biomassa fresca das partes da planta e aumentar significativamente a concentracão de o nas șolnas simples. Não foram observadas diferencas signiflcatlyas dentro de cada metabulito entre os tratamentos herblcidas. No entanto, malores quantidades de c-linuron não alterado tenderam 


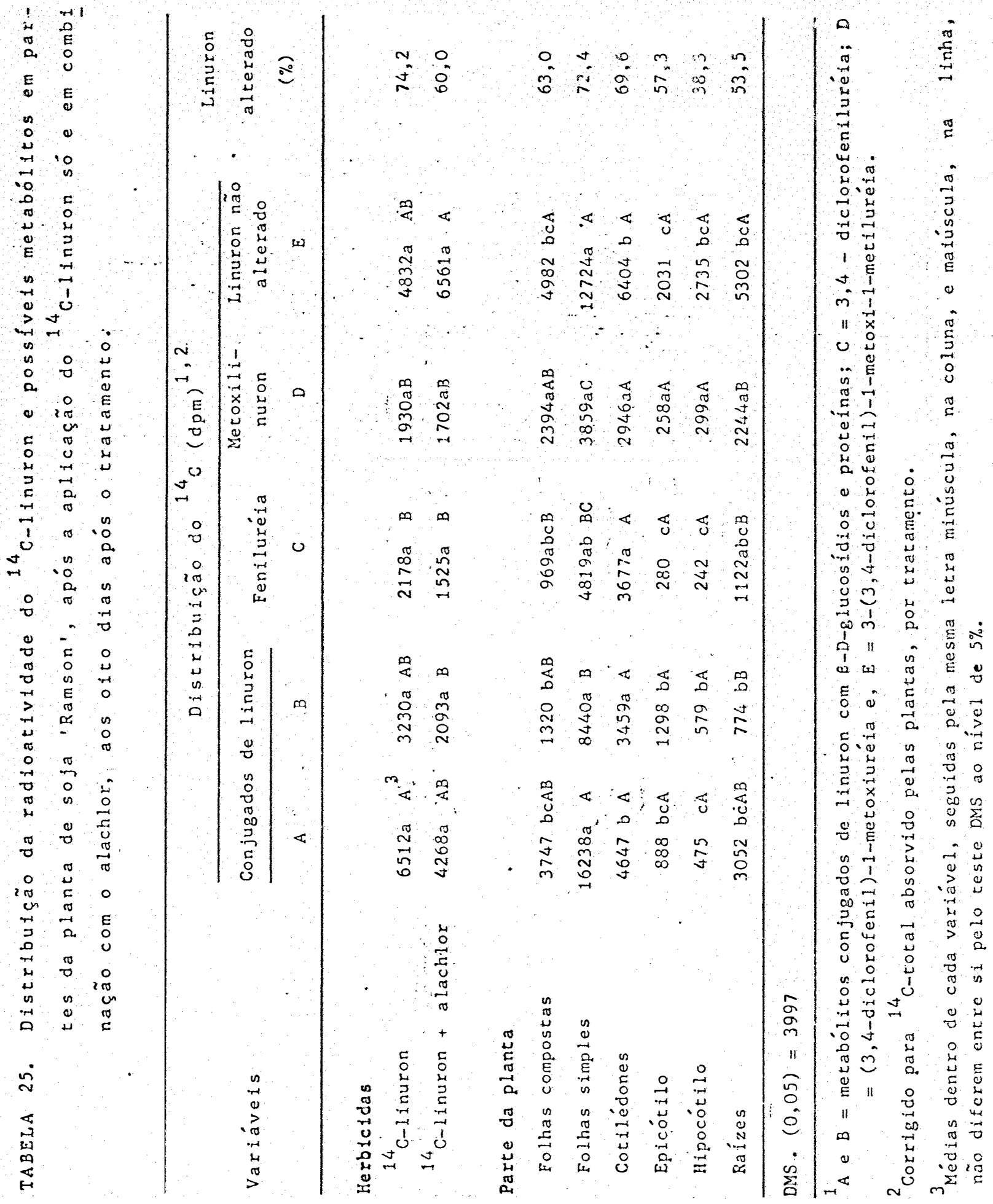


ocoprer na comblnacia com o alachlor, com a reducấo dos conlugados de Iinuron.

Por parte de planta, maiores quantidades de 14 c-linuron e metabolitos foram observadas nas folhas simples da soja, apresentando a malor porcentagem do mesmo metabolizado, $72,4 \%$ Malores quantidades do metabolito conjugado A, seguldo pelo conlugado B, foram obsepvadas nas folnas simples. As ralzes, como principal ponto de entrada de materiais na planta, acumularam $10,8 \%$ do material radloativo, metabolızando $53,5 \%$ do mesmo.

Em pepino ( $T$ abela 26 ), as quantidades do ${ }^{14}$ Inuron metabolizado (IInuron alterado) foram semelhantes em ambos os tratamentos herbicidas, havendo no entanto, como na sola, uma tendencia a ocorrermenor biomassa fresca das plantas na sua combinacáo com o alachlor e um aumento ge ${ }^{4}$ nas folnas. As quantidades de c-linuron náo a terado foram semelnantes, representando cera de $80 \%$ do total.

Por parte de planta, malores quantidades do 19 c-linuron e metabolitos foram observadas nos cotiliedones, diferlndo da sola e apresentando apenas $18,3 \%$ do collnuron metabollzado. As rafzes acumularam 1,4 g do material radloativo, metabolizando $43,7 \%$ do mesmo.

Nas comparabões entre as duas espécies, observa-se que na sola, a espécle mals resistente aos efeltos do Inturon, ocorreu maror absorbáa do G-linuron e malor grau de metabolizacão na região de acumulacăo do que em pepino, a espole mals susceptivel. SMITHet a H (1966) 


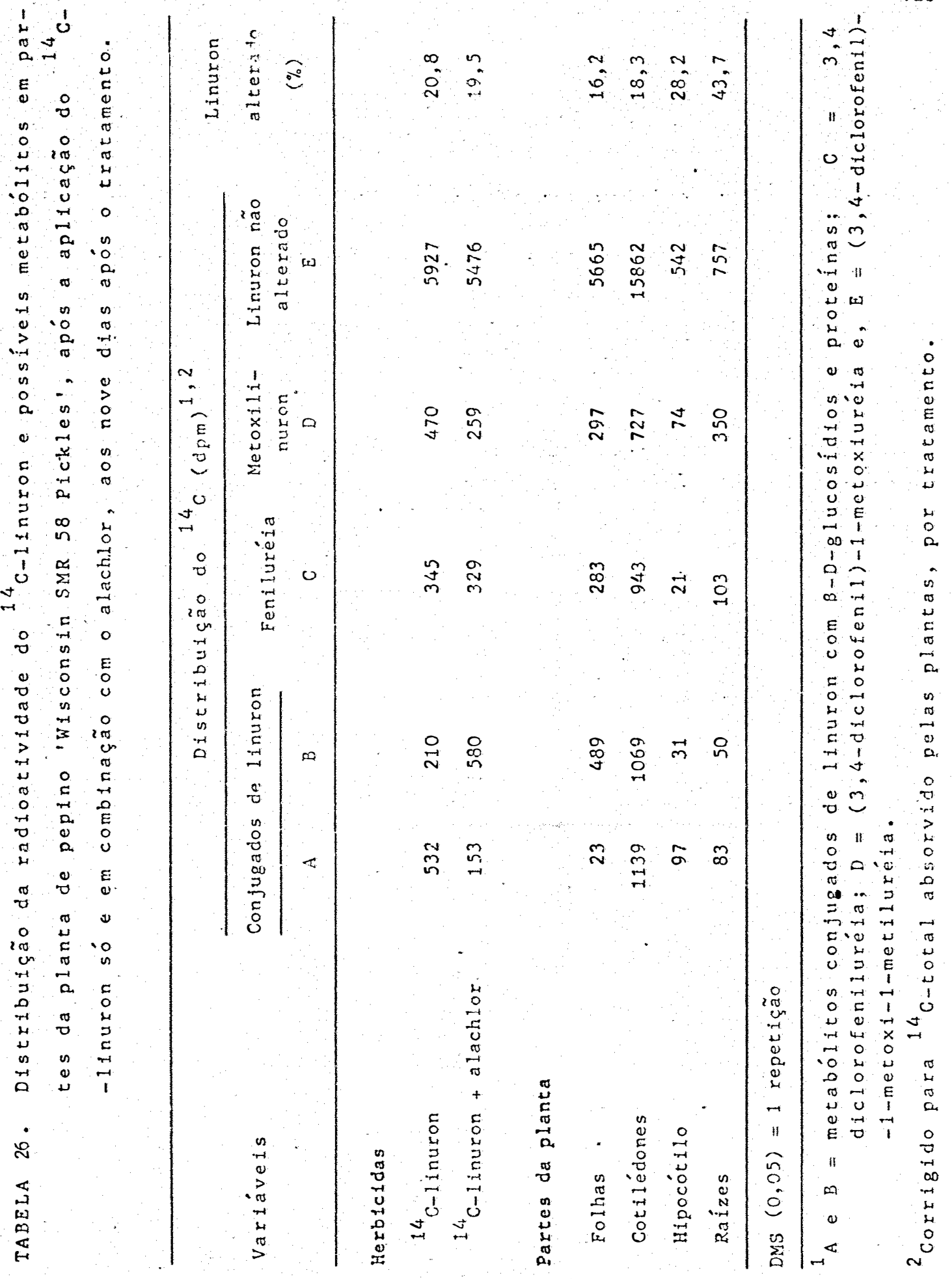


mostraram que especies resistentes podiam contrabalancan injurlas de alachlor a a borv-lo em meneres quantidades, ou mesmo em malores quantidades, do que especies susceptivels. HOGUE \& WARREN (1968) mostrapam que o grau de metabolizacăo do Hnuron e importante em espécles de plantas mals resistentes, bem como o local de acumulacão. A Importancla do grau de metabollzacão em relacão aos efeltos fltotóleos foram tambóm observados por coley (1985) e por POSEMOND et a $111(9975)$.

4.4.5. Distribuicão do 9 e metabolitos na solucão nutritiva 4.4.5.1. Distribulcão do 9 em extratos de água e cloroformio

Extratos de cloroformio dos melos de cultura da soja (Tabela 27 ) não mostraram diferencas significativas de radioatividade entre c-inuron e sua combinacão como alachlor. Tambem na foram observadas diterencas significativas para pepino, nem mesmo papa os extratos de radioatividade em bgua. Diferencas significativas foram observadas para os extratos a sola em a a a sendomalor a radioatividade observada em o-ingund do que na sua combinacão com o alachlor. No tratamento $0-1$ inuron, na 19 sola, o c da solucão nutritiva mostrou valores mals balxos nos extratos de clopoformio que solublliza substânclas näo 14

polares, como o c-linuron, tólco, nãometabołizados, e malores em água rque solublliza substincias polares, como 
TABElA 27. Distribuição do ${ }^{14}$ C-total em extratos de clorofórmio eágua, nas soluções nutritivas de soja 'Ramson' e pepino 'Wisconsin SMR 58 Pickles', tra tados com ${ }^{14}$ C-1inuron e combinação com alachlor.

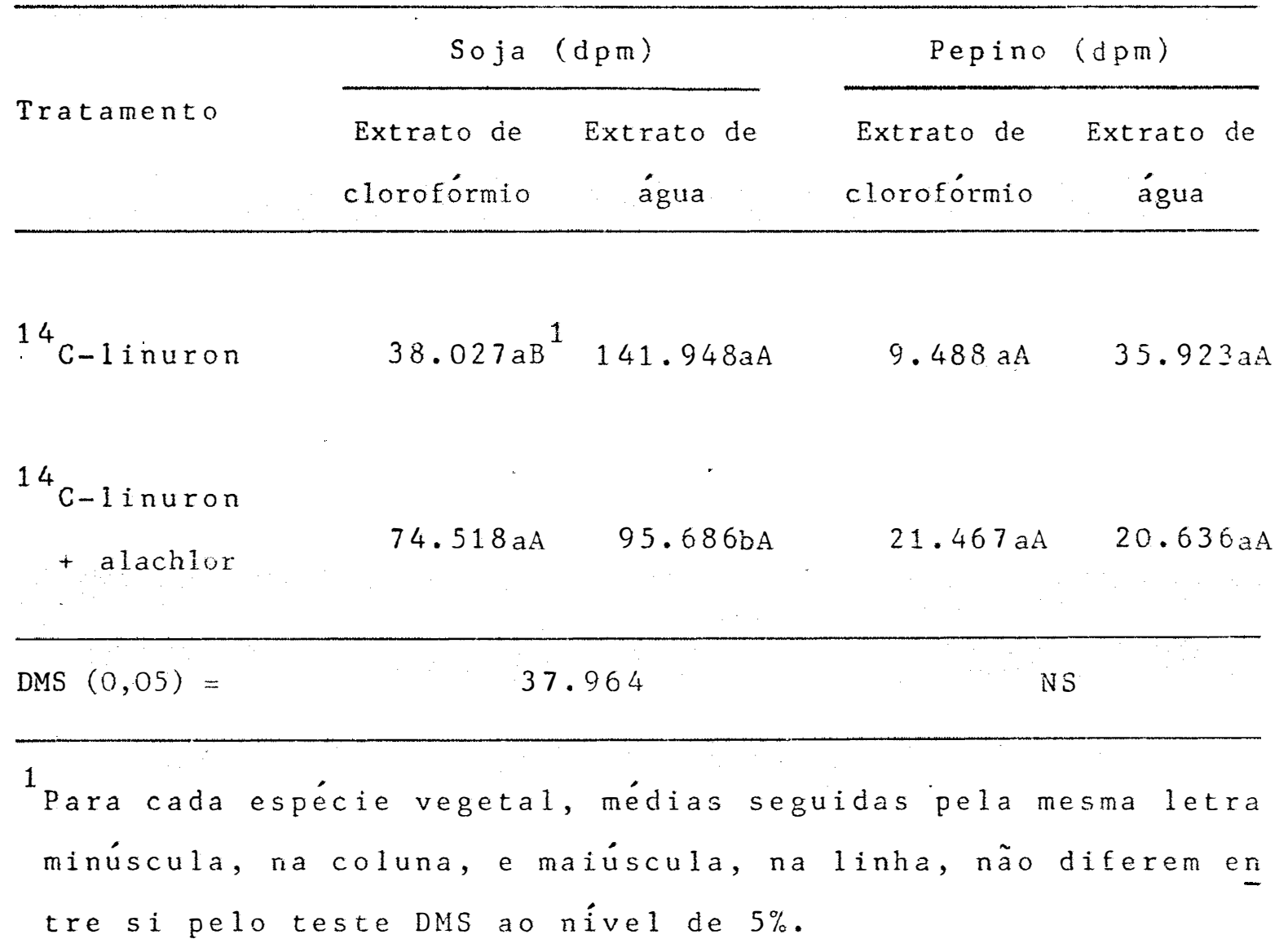


94

metabolitos conjugados de G-ilnuron com glucostalos ou prote(nas, não tóx|cos), tendendo a ocorrer o mesmo para 0 pepino. 0 acréscimo do alachior a ${ }^{14}$ c-linuron tendeu a aumentap as quantidades do ${ }^{14} \mathrm{c}$ no extrato de cloroformio, reduzindo-o no extrato em agua. Isto indica um aumento de fitotoxlcldade, causado pela reducão da metabolizacão do ${ }^{-\infty}$ IInuron pela planta.

19

4.4.5.2. Metabolitos de c-linuron na solucão nutpitiva

possiveis metabolitos de $\$ 4-1 i n u r o n$ e respectivas quantidades soluvels em cloroformo e agua, encontrados nas solucốcs nutritivas, são apresentados para sola (Tabela 28$)$ e para pepino (Tabela 29 ).

Na sola (Tabela 28$),$ extratos de clopofómlo 14

appesentaram malores quantidades do c-linuron não alterado 14

no tratamento c-linufon com o alachlor do que no tratamento 14

com c-linuron só. Em ambos os tratamentos foram observadas 14

maiores quantidades do c-llnupon não alterado, em relacão aos demals metabolitos. Extratos em agua apresentaram 14 malores quantidades do C-linuron alterado, conlugado A, no 4

tratamento c-linuron do que na sua combinacão com 0 achlon. Em ambos os extratos, exlundo-se o metabolito predominante, os demals apresentaram-se quase que iqualmente distributas, em quantidades multo inferlores.

No pepino (Tabela 29 ), as consideraföess feltas para a soja aplicam-se de modo geral tambem para esta especie, apresentando quantidades de metabolitos do 19 


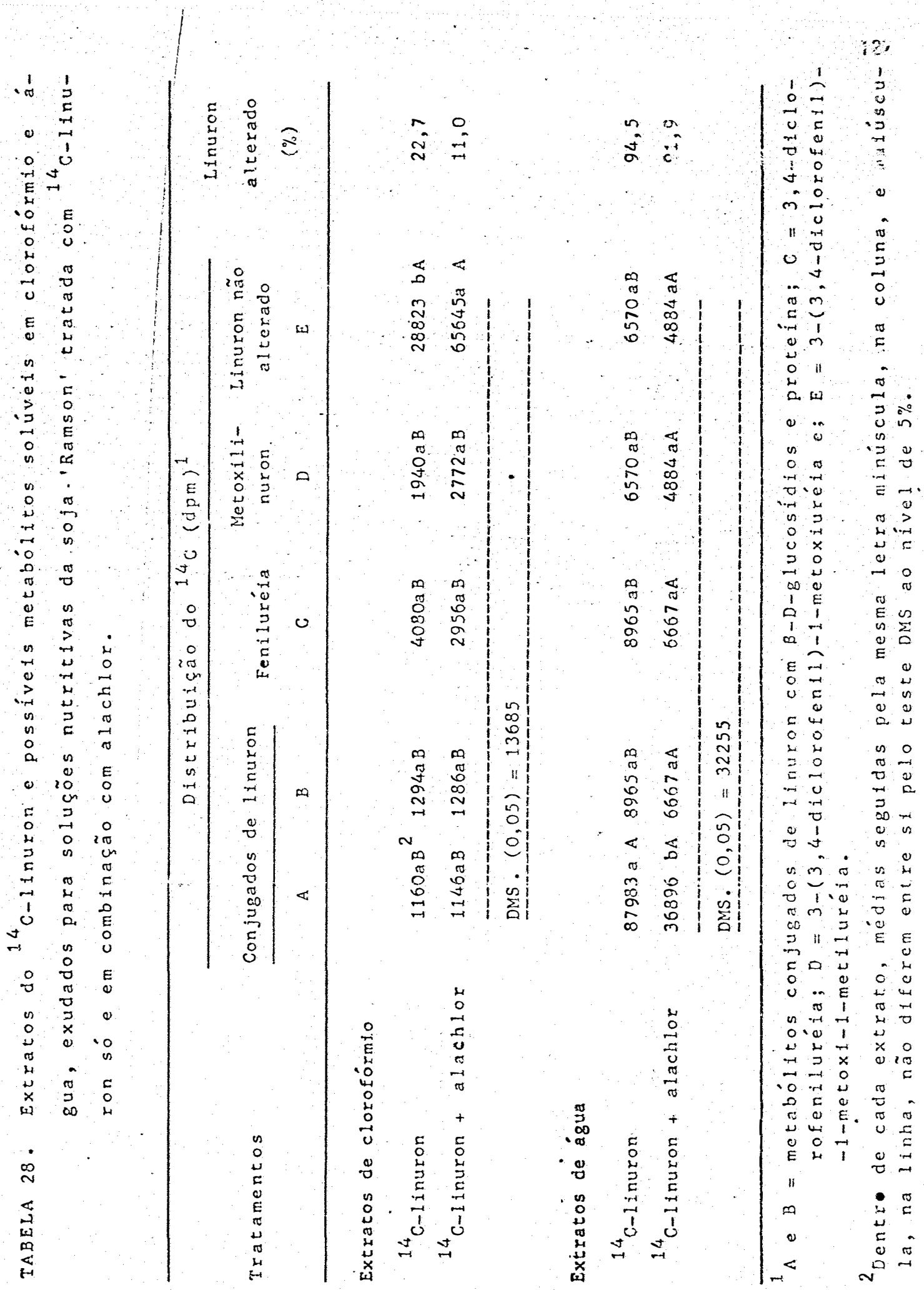




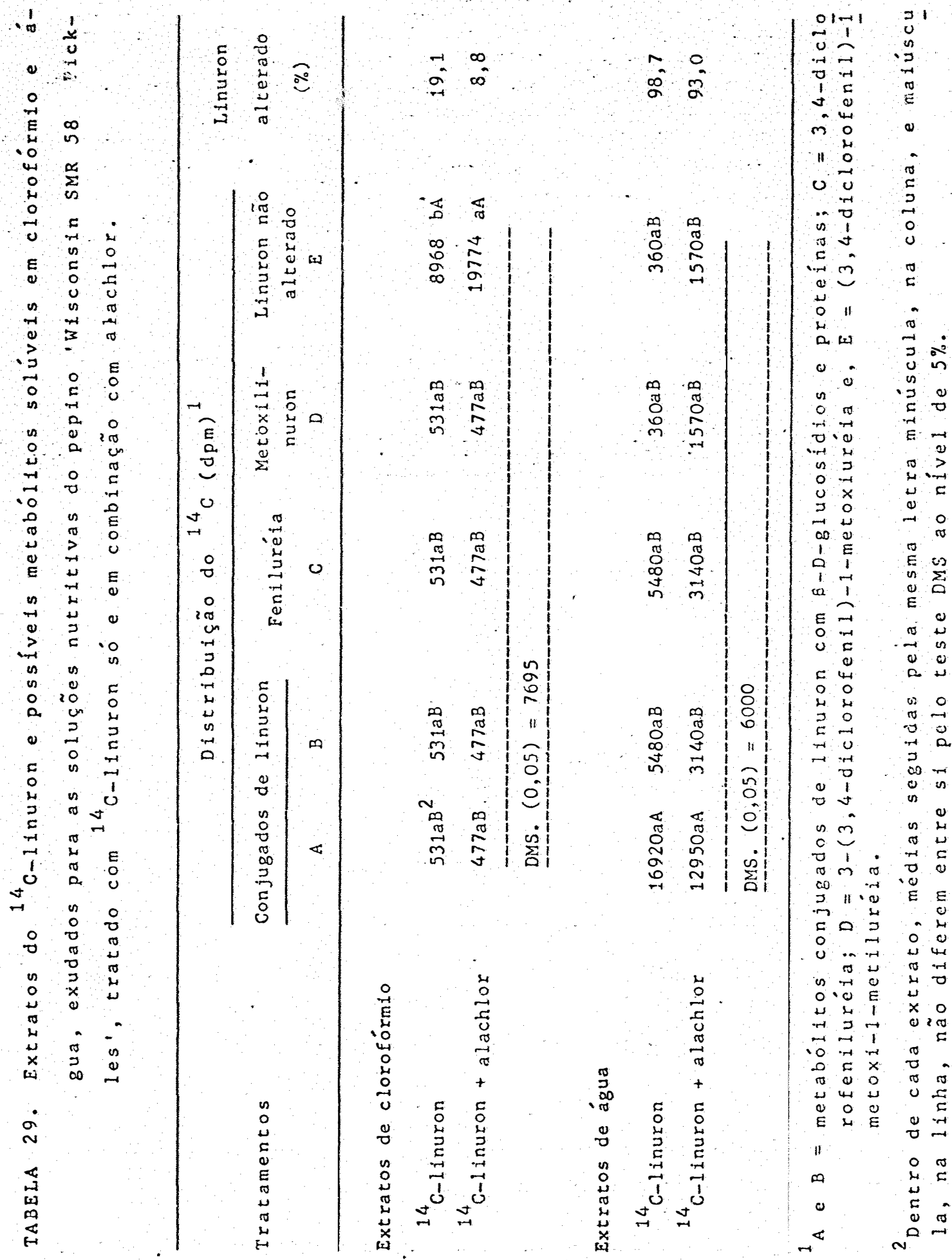


I inuron proporclonalmente menores, em funcão de menores doses usadas no experimento.

Como fol visto no item anterior (Tabela 27), 1.4

tanto na sola como no pepino, sob o efelto do tratamento cInuron, ocorreram menores quantidades do 0 nos extratos de cloroformlo do que em gar. que tenderam a aumentar com

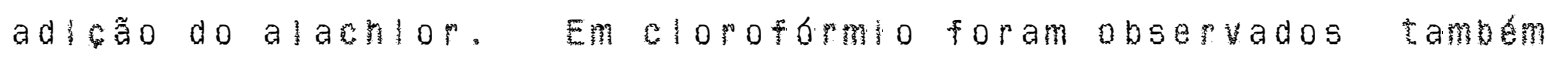
19

malores quantidades de G-linuron não alterado, que tendeu a aumentar ainda mals com a adläo do alachlor. Na agua observa-se malores quantidades de conlugados de linuron em ambos os tratamentos. Menor grau de metabollzacão do $C^{4}-$ Inuron ou aumento do cutotal no extrato de cloroformio, no caso, significa aumento de fitotoxicidade à planta.

Estes resultados, obtidos em solucão nutpitlva, podem dar-nos indicacões sobre a susceptibllidade das respectivas especles de plantas em funcão das quantidades 14

de G detectadas e graus de metabolizacão, veplficadas nos respectivos extratos, considerando-se as respectivas quantidades dos produtos adiclonadas às solucôs nutritivas.

Nas condicós do experimento, a aplicaco dos herbicldas tres e quatro dias após a geminacio da sola ou de pepino, năo permitlu observar os efeltos de protecso do alachlor contra os efeitos fitotoxicos do linuron, obervados previamente para pepino em casa-de-vegetacan, nas aplobcos por ocasião do plantlo. 
A caracterizacáo da fitotoxidez do linuron nas plantas, menor em sola do que em pepino, pode ser felta do

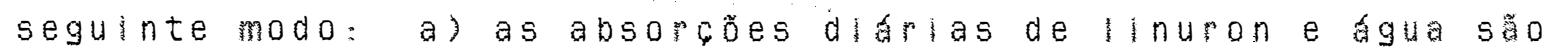
reduzidas progressivamente: b) ocore malor absoräo do Iinuron na soja do que em pepino; c) reducão da biomassa de partes de planta, excetuando-se os cotiledones e o hipocotilo, na sola; d) malop acumulacão do hepbicida nas folnas simples, na sola, e nos cotilladones, empepino; e) malon grau de metabolizacão do linumon na sola do que em pepino, com reducão em ambos quando adlcionado o alachlon.

Sob condlióes de campo é posslvel que combinacós de nerbicidas, como as a linurone alachlor, sob yarladas condicós ambientals por ocasião da germinacão, possam fazer com que a planta de sola seja proteglda contra as Injurlas de um deles, ou a contraplo, aumentados os seus efeitos fitotokicos. por outrolado, os efeltos das combinacies dos herblcidas nas espécies daninhas e das condicoses ambientals por ocasião da sua germinacão, tamberm podem ser no sentido de aumentar o seu espectro de controle, ou reduzto- 10. 


\section{CONCLUSOES}

A andise e discussa tos dados obtidos nos diferentes experimentos conduzidos permitem as segulntes conclusôes:

a) as pioducos de soja, sob diferentes manejos da resteva de tpigo e do solo, tivetam compoptamentos Iguals com populacón de 50 a com cerca de 25 platas/m na Hhas Reducós slgnificativas de populaso e produba de sola ocorperam com a que ina da pesteva em pertodo seco de lantio e, com a permanencia da resteva, em solocom alto teor de umidade:

b) ha evidencias de que a interara da mesteva de trigo e glyphosate, em sola, aumenta a altura das plantas e a blomassa do dossel e reduz a bionassa das ratzes:

a) as combinacós de paraquat e glyphosate com a mistura de alachlop e linuron controlaram digltarla sangulnalls, chenopodlum album, Ambrosla artemlsilfolla, Mollugo vertlclllata e Amaranthus spp., mas na controlaram cyperus esculentus, lpomoea spp. e Trlticum aestivum;

a) as infuras do inum em pantas podem sem reduzidas por alachlor, ao afetarem as palzes das mesmas, aepentieno das espesies e combinacos de doses:

e) espstes menos susceptivels a 


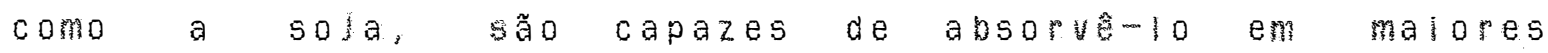
quantidades, devido a metabolizacao do produto em malor grau: f) maín consentracão de cinuron e seus metabólitos ocorrepam nas rolnas simples; na sola e, nos cotiledones, no pepino;

9) os residuos do hepbicida inumon no solo folam malores em CM do que em po, onde são parcialmente interceptados pela resteva;

h) a infestacão det. aestivum fol peduzida com a quelma da resteva: maiopes uniestacoes fopam observadas com a permanência da pesteva em CM;

1) a quelma da pesteva pesultou na quebra de dormancia de A. artemislifolla, de sementes nã destrulas pelo calor no solo, aumentando a sua infestacác. Esta Tol reduzida com a ueima en peplodo seco de plantio. Malopes infestacöes foram observadas tambén con a permanência da resteva ou remogão a parte celfada, em PD:

j) infestacöes de o. sangulnalis a M. vertlclllata foram reduzidas por eneltos alelopaticos elou de sombreamento, com a permanencla da pesteva na supefieledo solo, o que não ocorreu com Amaranthus spp. e c. esculentus;

k) Infestacöes de 0. sangulnalls e M. vertacllata foram aumentadas com a guelma da pesteva de trigo, na a

3 o controle das espácies daninhas, com ou sem alachion e linupon, fol malor empo do que em gm, ondo

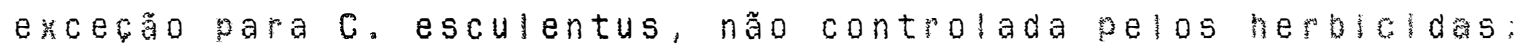


m) a Infestacão de lpomoea spo. fol reduzlda em PD: houve também evidancia de redufão com a permanencla da pesteya da cultivar de trigo usada. 


\section{LITERATURA CITADA}

AHMADI, M.S.; HADERLIE, L.C.; WICKS, G.A. Effect of stage and water stress on barnyardgrass (Echincchloa crus-galli) control and on glyphosate absorption and translocation. Weed Sci., Champaign, 28:277-282, 1980 .

ALMEIDA, F.S.; OLIVEIRA, V.F.; RODRIGUES, B.N. Influência do sistema de preparo do solo na atuação dos herbicidas. In: CONGEESSO BRASILEIRO DE HERBICIDAS E PLANTAS DANINHAS, 14, Campinas, 1982. Resumos. Campinas, Soc. Bras. Herb. Ervas Dan. 1982. p.20-2.

ALMEIDA, F.S. \& RODRIGUES, B.N. Plantio Direto, p.341-99. In: Guia de Herbicidas: Contribuição para o uso adequado em plantio direto e convencional. Londrina, IAPAR, 1985. $468 p$.

ALMEIDA，F.S.; RODRIGUES，B.N.; VIDAL，R.A.; LEITE，C.R.F. Subsidio para o estudo do desempenho da cobertura morta na densidade de infestação das culturas de verão, em plantio direto. In: CONGRESO BRASILEIRO DE HERBICIDAS E PLANTAS DANINHAS, 16, Campo Grande, 1986. Resumos. Campi nas, Soc. Bras. Herb. Ervas Dan., p.13. 
ALMEIDA, F.S.; RODRIGUES, B.N.; VOSS, M.; TETE, C.R. • : feitos alelopáticos e de competi气̃ão da B. plantaginea na soja. In: CONGRESSO BRASILEIRO DE HER;ICIDAS E PLENTAS DANINHAS, 16, Campo Grande, ia86 Resumos. Campinas, Soc. Bras. Herb. Ervas Dan., 1986. p.5-6.

Alves, P.L.C.A.; PITElli, P.A.; DAMIÃOFILHO, C.F.; MALHEIROS, E.B. Estudo dos efeitos inibitórios do caruru (Amaranthus retroflexus) sobre. a germinação e desenvolvimento de plântulas de pepino (Cucumis sativus). In: CONGRESSO BRASILEIRO DE HERBICIDAS E PLANTAS DANINHAS, 16, Campo Grande, 1986. Resumos. Campinas, Soc. Bras. Herb. Ervas Dan. $1986 . \quad p \cdot 3$.

ANDERSON, W.P. Weed Science: Principles, 2ed. New York, West Publishing Co., 1983. $655 \mathrm{p}$.

BANKS, P.A. \& ROBINSON, E.L. Effect of straw mulch on preemergence herbicides. In: SOUTHERN WEED SCIENCE SoCIETY, 33, Hot Springs, 1980. Proceedings. Champaign, Weed Sci.Soc.Am., 1980, p.286.

BAIRD, D.D.; UPCHURCH, R.P.; HOMESLY, W.B.; FRANZ, J.E. Introduction of a new broad spectrum post-emergence herbicide class with utility for herbaceous perennial weed control. In: NORTH CENTRAL WEED SCIENCE CONFERENCE, 26, 1971. Proceedings. Champaign, Weed Sci. Soc. of Am., 1971 . p. $64-8$. 
GEir, j.i. \& KOEPPE, D.F. Noncompetitive effects of giant foxtail on the growth of corn. Agron. J., Madison, $64: 321-325,1972$.

BHOWMIK, P.C. \& DOLL, J.D. Allelopathic activity of redroot pigweed (Amaranthus retroflexus L.) and yellow foxtail (Setaria glauca (L.) Beauv.) residues on corn and soybeans. In: SOUTHERN WEED SCIENCE SOCIETY, 35, Atlanta, 1982 a. Proceedings, Champaign, Weed Sci. Soc. of Am., 1982 . $\mathrm{p} .65$.

BHOWMIK, P.C. \& DOLL, J.D. Corn and soybean response to allelopathic effects of weed and crop residues. Agron. J., Madison, 74:601-606, 1982 b.

BOQUET, D.J. \& WALKER, D.M. Influence of irrigation, seedbed preparation and seed treatment on double-cropped soybeans. In: LOUSIANA STATE UNIVERSIY. Annual Progress Report. 1981. Baton Rouge, 1981. p.1-262.

BULLOCK, F.D. \& JEFFERY, L.S. Weed control in no-tillage soybean-wheat double cropping system. In: SOUTHERN WEED SCIENCE SOCIETY, 33, Hot Springs, 1980. Proceedings. Champaign, Weed Sci. Soc. of Am., 1980. p.43.

CHAPPEL, W.E. No-tiliage studies in soybeans, corn and vegetables. In: SOUTHERN WEED SCIENCE SOCIETY, 27 , Atlanta, 1974. Proceedings. Champaign, Weed Sci. Soc. of Am., 1974. p.100-8. 
CARRINGER, R.D.; DIFCK, C.: EUGH, I.. E Effect of R-25.778 on EPTC metabclism in corn (zea mays). Weed Sci., Champaign, 26:167-17i, 1978 .

CHANCELLOR, R.J. Dormancy in weed seeds. Outlook on Agriculture, Yarnton, $11: 87-93,1982$.

COCHRAN, V.L.; ELLIOT, L.F.; PAPENDICK, R.I. The production of phytotoxins from surface crop residues. Soil Sci. Soc. Am. J., Madison, 41:

COLBY, S.R. Herbicide metabolism: N-glycoside of amiben isolated from soybean plants. Science, Washington, $150: 619-620,1965$.

COLLINS, F.C. \& CAVINESS, C.E. Growth of soybeans on wheat straw residue. In: AMER. SOC. AGRON : CROP SCI. SOC. AMER. \& SOIL SCI. SOC. AMER., 70, Chicago, 1978 . Agronomy Abstracts. Madison, Amer. Soc. Agron., 1978 . p. $92-3$.

Cox, R.W. Factors affecting the growth and yield of double cropped soybeans. Arkansas, 1977. 89p. (Mestrado-Universidade de Arkansas).

DEAL, M.N. \& HESS, F.D. An analysis of the growth inhibitory characteristics of alachlor and metolachlor. Weed Sci... Champaign, 28: $168-175,1980$. 
Drosi. E.C. \& DOLL, J.D. The allelopathic effect of yellow nutsedge (Cyperus esculentus) on corn ( 2ea mays) and scybeans (Glycine max). Weed Sci., Champaign, $\underline{28}: 229 \ldots 233,1980$.

ERBACH, D.C. \& LOVELY, W.G. Effect of plant residue on herbicide performance in no-tillage corn. Weed Sci., Champaign, $\underline{23}: 512-515,1975$.

FOLONI, L.L. \& ZAGATTO, A. Influência do preparo do solo nos sistemas convencional, reduzido e plantio direto na eficiência de alaclor + atrazine no controle de plantas daninhas e na produção do milho. In: CONGRESSO BRASI LEIRO DE HERBICIDAS E PLANTAS DANINHAS, 15, Belo Horizonte, 1984. Resumos. Campinas, Soc. Bras. Herb. Ervas Dan., $1984, \mathrm{p} .69$.

FRENCH, C.M. \& SANTELMANN, P.W. Herbicide systems for double cropping of no-tillage soybeans. In: SOUTHERN WEED SCIENCE SOCIETY, 31., New Orleans, 1978 . Proceedings, Champaign, Weed Sci. Soc. of Am., 1978 . p. 60 .

GEISSBUHLER, H.; MARTIN, H.; VOSS, G. The substituted ureas. In: KEARNEY, P.C. \& KAUFMAN, D.D. Herbicides: Chemestry, Degradation and Mode of Action. New York, Marcel Dekker, Inc., 1975. p.209-291. 
GOREN, R. The effect of fluometuron on the thhation citrus leaves. Weed Res., Osney Mead, 9:121-135, 1969.

GORTNER, W.A. \& KENT, M.J. The coenzime requirement and enzime inhibitors of pinneapple indolacetic acid oxidase. J. Biol. Chem., Baltimore, 233:731-735, 1958 .

GROVER, R. Adsorption of picloran by soil coloids and various other adsorbents. Weed Sci., Champaign, $\underline{19}: 417-418,1971$.

GUENZI, W.D. \& MCCALLA, T.M. Inhibition of germination and seedling development by crop residues. In: SOIL SCIENCE SOCIETY, 26, 1962. Proceedings. Madison, Soil Sci. Soc. of Am., 1962. p.456-8.

GUENZI, W.D. \& MCCALLA, T.M. Phytotoxic substances extracted from soil. In: SOIL SCIENCE SOCIETY, 30 , 1966. Proceedings. Madison, Soil Sci. Soc. of Am., 1966. p. $214-6$.

GUENZI, W.D. \& MCCALLA, T.M. Phenolic acids in oats, wheat, sorghum, and corn residues and their phytotoxicity. Agron. J., Madison, 58:303-304, 1966 .

GUENZI, W.D.; MCCALLA, T.M.; NORSTADT, F.A. Presence and persistence of phytotoxic substances in wheat, oat, corn, and sorghum residues. Agron. J., Madison, 59:163-165, 1967. 
HARDCASTLE, W.s. Weed control in conventional, non-tille and stable bed plantings of soybeans. In: SOUTHERN WEED SCIENCE SOCIETY, 26, New Orleans, 1973. Proceedings. Chanaign, Weed Sci. Soc. of Am., 1973 . p.88.

HOGUE, E.J. \& WARREN, G.F. Selectivity of linuron on tomato and parsnip. Weed Sci., Champaign, 16:51-54, 1968 .

HOLM, L.G.; PLUCKNETT, D.L.; PANCHO, J.V. ; HERBERGER, J.P. The World Worst Weeds: Disbribution and Biology. Honolulu, East-West Center, Univ. Press of Hawaii. 1977. 320 .

HUNT, T.W.; MONACO, T.J.; SHEETS, T.J. Residue and efficacy studies of alachlor of cabbage and soil. Amer. Soc. Hort. Sci., Alexandria, 105:929-932, 1980 .

KAPUSTA, G. Seedbed, tillage, and herbicide influence on soybean (Glycine $\max$ ), weed control and yield. Weed Sci., Champaign, 27 :520-526, 1979 .

KHAN, S.U.; GREENHALGH, R.; COCHRANE, W.P. Determination of linuron residue in soil. Bull. Environ. Contamination and Toxicology., New York, 13:602-610, 1975 .

KIMBER, R.W.L. The effect of time of rotting of straw from some grasses and legumes on the growth of wheat seedlings. Plant and Soil., The Hague, 38 $\underline{38}$ 347-361, 1973 . 
LADLIE, J.S. Effect of trifluralin and metrituzin combinations on soybean tolerance to metribuzin. Need Sci., Champaign, 25: $88-93,197 \%$.

LADLIE, J.S.; MEGGIT, W.F.; PENNER, D. Effect of pH on metribuzin activity in the soil. Weed Sci., Champaign, 24: $505-507,1976$.

LEAVIT, J.R.C. \& PENNER, D. Protection of corn (Zea mays) from acetanilide herbicidal injury with the antidote R-25.778. Weed Sci., Champaign, 26:653-659, 1978 .

LEE, S.S. \& FANG, S.C. Metabolism of monuron in excised leaves of corn and bean plants. Weed Res., Osney Mead, $\underline{13}: 59-66,1973$.

LIEBL, R. Allelopathic supression of certain weeds in no-till cropping systems. In: SOUTHERN WEED SCIENCE SOCIETY, 35, Atlanta, 1982. Proceedings. Champaign, Weed Sci. Soc. of Am., 1982. p.316.

LIEBL, R.A. \& WORSHAM, A. D. Inhibition of pitted morming glory (Ipomoea lacunosa L.) and certain other weed species by phytotoxic components of wheat (Triticum aestivum L.) straw. J.Chem. Ecol., New York, 9: $1027-2043,1983 \mathrm{a}$. 
LIEBL, R.A. \& WORSHAM, A.D. Tillage and alcheftects on morning glory (Ipomoea spp.) arjectain other weed species. In: SOUTHERN WEED SCIENCE SOOLET, 36, Bilaxi, 1983b. Proceedings, Champaign, Weed Sci. Soc. of Am., 1983. p. 405-14.

LOWDER, S.W. \& WEBER, J.B. Atrazine retention by crop residues in reduced tillage systems. In: SOUTHERN WEED SCIENCE SOCIETY, 32, Boston, 1979. Proceedings. Champaign, Weed Sci. Soc. of Am., 1979. p.303-7.

MICKIETA, R.; ILNICKI, R.D.; JUSTIN, J.R. Weed control in double crop soybeans with herbicides applied alone and in combination with paraquat or glyphosate. In: NOTHEASTERN WEED SCIENCE SOCIETY, 31, 1977. Proceedings. Champaign, Weed Sci. Soc. of Am., 1977 . p.61-9.

McCALLA, T.M. \& HASKINGS, F.A. Fhytotoxic substances from soil microorganisms and crop residues. Bacterial Rev. Baltimore, 28:181-207, 1964 .

McWhORTER, T.N.J. \& WILLS, G.D. Translocation of ${ }^{14}$ C-GIyphosate in soybeans (Glycine max) and Johnsongrass (Sorghum halepense). Weed Sci., Champaign, 28:113-118, 1980 .

MOSS, S.R. Some effects of burning cereal straw on seed viability, seedling establishement and control of Alopecurus myosuroides Huds. Weed Res., Osney Mead, 20: $271-276,1981$. 
NOpir.t. TAD', F.d. \& MCCALLA, T.M. Microbial induced phytotoxicity in stubble mulched soil. Soil Sci. Soc. Arer., Madison, 32:241-245, 1968 .

NASHED, R.B. \& ILNICKI, R.D. Absorption, distribution and metabolism of linuron in corn, soybean, and crabgrass. Weed Sci., Champaign, 18:25-28, 1970 .

NORSTADT, F. A. \& MCCALLA, A. Microbial populations in stubble mulched soil. Soil Sci., Rutgers, 107:188-193, 1969 .

NYFFELE, A. \& BLAIR, A.M. The influence of burnt straw residues on soil compactation on chlortoluron and isoproturon activity. In: BRITISH CROP PROTECTION CONFERENCE-WEEDS, 14, Brighton, 1978. Proceedings. Craydon, British Crop Protection Council, 1978 . p. $113-119$.

NYFFELER, A.; GERBER, H.R.; HENSLEY, J.R. Laboratory studies on the behavior of the herbicide safener CGA-43 089. Weed Sci., Champaign, 28:6-10. 1980 .

PAPENDICK, R.I. \& MILLER, D.E. Conservation tillage systems in the Pacific Nothwest. J. Soil Conserv., Baltimore, 32: 49-56, 1977 . 
PAtík, Z.A. \& KOCH, I. W. Inhibition of respiration, germination, and growth by substances arising during the decomposition of certain plant residues in the soil. Can. S. Botary, Ottawa, 36:621-647, 1958 .

PATRICK, Z.A.; KOCH, L.W.; TUSSON, T.A.; SNYDER, W.C. Phytotoxic substances in arable soils associated with decomposicion of plant residues. Phytopathology, Lancaster, 53:152-161, 1963 .

PATTERSON, D.T. Effects of allelopathic chemicals on growth and physiological responses of soybeans (Glycine max). Weed Sci., Champaign, 29:53-59, 1981 .

PATTERSON, M.S. \& GREENE, R.C. Measurement of low energy beta-emitters by 1 iquid scintillation counting of emulsions. Ana1. Chem., Washington, 37:854-857; 1965 .

PHILLIPS, R.E.; THOMAS, G.W.; BLEVINS, R.L. No-Tillage. Research: Research Reports and Reviews. Lexington, University of Kentucky - Coll. Agric. and Agric. Exp. Sta., 1980 . $151 \mathrm{p}$.

PINTO, H. \& CORBIN, F. T. Absorption and translocation of tetrafluron in cotton (Gossypium hirsutum), jimsonweed (Datura stramonium), peanut (Arachis hypogeae), and prickly sida (Siảa spinosa). Weed Sci., Champaign, $\underline{28}: 557-565,1980$. 
Pl:TAAR. AR, ; BARNES, J.P.; DeFRANK, J. Components of Weed Control in no-tillage sustems. In: SOUTHERN WEED SCIENCF SOCIETY, 35, Atlanta, 1982. Proceedings. Champaign, Weed Sci. Soc. of Aner., 1982, p.66.

RODRIGUES, J.J.V.; WORSHAM, A.D.; CORBIN, F.T. Exudation of glyfosate from wheat (Triticum aestivum) plants and on interplanted corn (2ea mays) and soybean (Glycine max). Weed Sci., Champaign, 30:316-320, 1982 .

ROGERS, C. \& WORTHINGTON, J.P. Evaluation of glyphosate in no-till double crop soyoeans using varying volumes and pressures. In: NORTH CENTRAL WEED SCIENCE CONFERENCE, 31 , 1976. Proceedings. Champaign, Weed Sci. Soc. of Am., $1976 . \quad p .32$.

ROSEMOND, J.M.; ZORNER, P.S.; WITT, W.W.; OLSON, G.L. Absorption and translocation of linuron in Nimblewill and Kentucky bluegrass. In: SOUTHERN WEED SCIENCE SOCIETY, 28, Memphis, 1975. Proceedings, Champaign, Weed Sci. Soc. of Amer., 1975 . p.343.

SANFORD, J.O.; MYHRE, D.L.; MERWINE, N.C. Double cropping systems involving no-tillage and conventional tillage. Agron. J., Madison, 65:978-982, 1973 .

SMITH, G.R.; PORTER, C.A.; JAWORSKI, E.G. Uptake and metabolism of ${ }^{14}$ C-labeled a-cloroacetamides by germinating seeds. In: AMERICAN CHEMICAL SOCIETy MEETING, 52, New York, 1966. Proceedings. New York, Amer. Chem. Soc., 1966 . p. 121 . 
SMITH, J.W. \& SHEFTS.T. Rete, discribution and metaboliam of noruron and diuron by several plants. J.Agric. Food Chem. Easton, 15:577-581, 1967 .

SOMODY, C.N.; MICHIETA, R.W. ; ILNICKI, R.D. Glyphosate and paraquat in combination with herbicides for weed control no-till double crop soybeans. In: NORTHEASTERN WEED SCIENCE SOCIETy, 32, New Orleans, 1978 . Proceedings. Champaign, Weed Sci Soc. of Amer., 1978. p.52-5.

STEINSIEK, J.W. \& OLIVER, L.R. Effect of wheat straw and ash on field activity of preemergence herbicides. In: SOUTHERN WEED SCIENCE SOCIETY, 32 , Bostón, 1979. Proceedings. Champaign, Weed Sci. Soc. of Amer., 1979 . p. 312 .

STEINSIEK, J.W.; OLIVER, L.R.; COLLINS, F.C. The effect of phytotoxic substarices from wheat straw on selected weeds: In: SOUTHERN WEED SCIENCE SOCIETY, 33, Hot Springs, 1980. Proceedings. Champaign, Weed Sci. Soc. of Amer., 1980. p.65.

STONE, J.E.; BLUNDELL, M.J.; TANNER, K.G. The formation of allelopathic substances in wheat plants. Can. J. Chem., Ot tawa, 29: $734-745,1951$.

STRANG, R.H. \& ROGERS, R.L. A microradiographic study of ${ }^{14}$ C-diuron absorption by cotton. Weed Sci., Champaign, $19: 355-362,1971$. 
STUCKY, J.M.; MONACO, T.J., WOESHAH, A.D. Identifying seedin, and rature weeds common in the Southeastern United States. Raleigh, NGARS \& NCAES/NCSU, 1980 197p.

SWANSON, C.R. \& SWANSON, H.R. Metabolic fate of monuron and diuron in isolate leaf discs. Weed Sci., Champaign, $16: 137-143,1968$

THILSTED, E. \& MURRAY, D.S. Effect of wheat straw on weed control in no-till soybeans. In: SOUTHER WEED SCIENCE SOCIETY, 33, Hot Springs, 1980. Proceedings. Champaign, Weed Sci. Soc. of Amer., 1980 . p.42.

TOTH, J. \& MILHAM, P.J. Burning reduces. herbicides effect. Agr. Gaz., NSW, 84:62, 1973 .

TOTH, J • \& MILHAM, P.J. Activated carbon and ash-carbon effects on the adsorption and phytotoxicity of diuron. Weeds Res., Osney Mead, 15:171-176, 1975 .

TRIPP , T.N.; BANKS, P.A.; HAMMEL, J.E.; MCBRIDE, J.F. The effect of tillage systems on sicklepod interference with soybeans. In: SOUTHERN WEED SCIENCE SOCIETY, 36, Biloxi, 1983. Proceedings, Champaign, Weed Sci. Soc. of Amer., 1983 . p. 417-8.

TYLER, B.H. Paraquat's role in no-tillage crop production in the Southeastern United States. In: SOUTHERN WEED SCIENCE SOCIETY, 22, 1969. Proceedings. Champaign, Weed Sci.Soc. of Amer., 1969. p.117-23. 
VEDOATO, R.A. WILES, T.L. Estudo integrado de plantio direto, cultivo minimo e controle de ervas daninhas em soja/ trigo - Norte do Paraná. In: SEMINÁRIO BRASILEIRO DE HER BIC. DAS E PLENTAS DANINHAS, 11, Londrina, 1976. Campinas, Soc. Bras. Herb. Ervas Dan., 1976. p.97.

VIDAL, R.A.; ALMEIDA, F.S.; MIZOKAMI, M.M. Efeito alelopático de extratos de capim-marmelada (Brachiaria plantaginea) no crescimento inicial de algumas culturas. In: CONGRESSO BRASILEIRO DE HERBICIDAS E PLANTAS DANINHAS, 16, Campo Grande, 1986. Resumos. Campinas, Soc. Bras. Herb. Ervas Dan., 1986. p.6.

Voll, E. Efeitos do ácido ferúlico em interações com densidades de soja (Glycine max (L.) Merr. cu. Bragg) e caruru (Amaranthus retroflexus L.). In: CONGRESSO BRASILEIRO DE HERBICIDAS E PLANTAS DANINHAS, 16, Campo Grande, 1986. Resumos. Campinas, Soc. Bras. Herb. Ervas Dan., 1986. p. ?.

YORK, A.C. \& SLIFE, F.W. Interaction of buthidazole and acetanilide herbicides. Weed Sci., Champaign, $\underline{29}: 461-468,1981$.

WALKER, A. \& CRAFORD, D.V. The role of organic matter in adsoption of triazine herbicides by soils. In: Isotopes. and Radiation in Soil Organic Matter Studies. In: INTERNATIONL SYMPOSIUM OF ATOMIC ENERGY AGENCY, 2 , Viena, 1968. Proceedings. Viena, Atomic Energy Agency, 1968 . p. $91-108$. 
WALKER, A. \& ZIMBDAHL, R.L. Simviat:s of the perstence of atrazine, linixon and metolachlor in soil at different sites in the USA. Weed Res., Osney Mead, 21:255-265, 1981 .

WEED SCIENCE SOCIETY OF AMERICA. Alachlor. Linuron. In: HERBICIDE HANDBOOK , 4 ed • , Champaign, 1983 . $515 \mathrm{p}$.

WHITWELL, T.; BANKS, P •; BASLER, E •; SANTELMANN, P.W. Glyphosate absorption and translocation in bermudagrass (cynodon dactylon) and activity on horsenettle (Solanum carolinense). Weed Sci., Champaign, 28:93-96, 1980 .

WILLIS, G.D. Factors affecting toxicity and translocation of glyphosate in cotton (Gossypium hirsutum). Weed Sci., Champaign, 26 $2609-513,1978$.

WORSHAM, A.D. \& LEWIS, W.M. No-tillage corn and soybeans with glyphosate. In: SOUTHERN WEED SCIENCE SOCIETY, 26 , New Orleans, 1973. Proceedings. Champaign, Weed Sci. Soc. of Amer. 1973. p.43. 
7. APÊNDICE 
APENDICE 1. Chuvas, em mm, ocorridas em Rocky Mount e Clayton, NC, nos aros do 196 e 1982.

Rocky Mount

Dat a

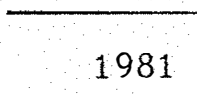

Junho Julho

2
3
4
6

10

11

12

13

14

15

16

17

18

19

20

21

22

23

24

25

26

27

28

29

30

31
1982

Junho Julho
Clayton

1981

1982

Junho Julho Junho Julho

$\begin{array}{llll}1,5 & 2,3 & 6,4 & 8,1\end{array}$

$\begin{array}{llll}2,5 & 15,0 & 0,0 & 0,0\end{array}$

$\begin{array}{llll}0,8 & 27,4 & 0,0 & 0,8\end{array}$

$\begin{array}{llll}0,0 & 9,7 & 26,7 & 10,7\end{array}$

$0,0 \quad 0,0 \quad 0,0 \quad 5,1$

$20,3 \quad 2,3 \quad 26,2 \quad 0,0$

$0,0 \quad 0,0 \quad 0,0 \quad 4,6$

$\begin{array}{llll}0,0 & 0,0 & 0,0 \quad 0,0\end{array}$

$\begin{array}{llll}0,0 & 0,0 & 10,7 & 0,0\end{array}$

$\begin{array}{llll}0,0 & 0,0 & 8,6 & 12,7\end{array}$

$\begin{array}{llll}0,0 & 0,0 & 13,7 & 6,1\end{array}$

$\begin{array}{llll}4,1 & 0,0 & 0,0 & 0,0\end{array}$

$\begin{array}{llll}0,0 & 0,0 & 6,9 & 0,0\end{array}$

$\begin{array}{llll}0,0 & 0,0 & 1,0 & 5,6\end{array}$

$0,0 \quad 0,0 \quad 0,0 \quad 0,5$

$0,0 \quad 6,6 \quad 3,0 \quad 0,0$

$0,3 \quad 0,5 \quad 5,1 \quad 0,0$

$\begin{array}{llll}1,8 & 0,0 & 0,3 & 0,0\end{array}$

$1,0 \quad 0,0 \quad 9,7 \quad 0,0$

$0,3 \quad 0,0 \quad 0,0 \quad 0,0$

$0,0 \quad 21,1 \quad 0,0 \quad 0,0$

$0,0 \quad 0,0 \quad 0,0 \quad 0,0$

$0,5 \quad 0,0 \quad 1,0 \quad 24,6$

$0,0 \quad 0,8 \quad 30,7 \quad 0,5$

$\begin{array}{llll}3,0 & 7,4 & 0,0 & 0,0\end{array}$

$0,0 \quad 0,0 \quad 0,0 \quad 0,0$

$0,0 \quad 0,0 \quad 4,3 \quad 0,0$

$0,3 \quad 0,0 \quad 14,0 \quad 0,0$

$0,5 \quad 3,0 \quad 0,0 \quad 12,2$

$\begin{array}{llll}0,3 & 7,1 & 10,2 & 0,8\end{array}$

$12,2 \quad 10,2$

$-\quad 0,0$

$-\quad 9,7$

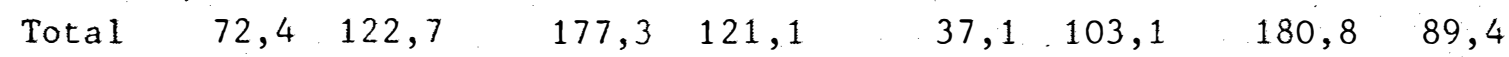

${ }^{1}$ Data de plantio. 
APÊNDICE 2. Análise da variância para produçóes de soja obtidas em experimentos de campo, nos locais de Clayton ${ }^{1}$ Rocky Mount, NC, nos anos de 1981 e 1982 .

\begin{tabular}{|c|c|c|c|}
\hline Fonte de variação & $\begin{array}{c}\text { Graus } \\
\text { de } \\
\text { liberdade }\end{array}$ & $\begin{array}{l}\text { Soma dos } \\
\text { quadrados }\end{array}$ & $\begin{array}{l}\text { Teste } \\
\text { F.0 } 5\end{array}$ \\
\hline Local-Ano (LO-ANO) & 3 & $20.894 .767,45$ & $*^{2}$ \\
\hline$B 10 \cos (B L) \quad(L O-A N O)$ & 11 & $16.978 .426,98$ & \\
\hline Resteva (R) & 3 & $1.543 .539,05$ & \\
\hline $\mathrm{R} * \mathrm{IO}-\mathrm{ANO}$ & 9 & $10.013 .652,21$ & $\star$ \\
\hline$B L * R(L O-A N O)$ & 33 & $4.522 .974,64$ & \\
\hline Cultivo do solo(C) & 1 & $50.087,10$ & \\
\hline$C *$ LO-ANO & 3 & $870.621,02$ & \\
\hline $\mathrm{C} * \mathrm{R}$ & 3 & $209.479,69$ & \\
\hline $\mathrm{C} * \mathrm{R} * \mathrm{LO}-\mathrm{ANO}$ & 9 & $620.676,79$ & \\
\hline $\mathrm{BL} * \mathrm{C} * \mathrm{R}(\mathrm{LO}-\mathrm{ANO})$ & 44 & $5.209 .915,90$ & \\
\hline Herbicidas $(\mathrm{H})$ & 1 & $702.423,31$ & $*$ \\
\hline $\mathrm{H} * \mathrm{LO}-\mathrm{ANO}$ & 3 & $1.357 .922,35$ & $*$ \\
\hline $\mathrm{H} * \mathrm{R}$ & 3 & $394.505,74$ & \\
\hline $\mathrm{H} * \mathrm{R} * \mathrm{LO}-\mathrm{ANO}$ & 3 & $1.077 .630,63$ & \\
\hline $\mathrm{H} * \mathrm{C}$ & 1 & $13.801,40$ & \\
\hline $\mathrm{H} * \mathrm{C} * \mathrm{LO}-\mathrm{ANC}$ & 3 & $357.133,60$ & \\
\hline $\mathrm{H} * \mathrm{R} * \mathrm{C}$ & 3 & $351.941,55$ & \\
\hline $\mathrm{H} * \mathrm{R} * \mathrm{C} * \mathrm{LO}-\mathrm{ANO}$ & 9 & $1.715 .676,11$ & \\
\hline $\mathrm{BL} * \mathrm{H} * \mathrm{R} * \mathrm{C}(\mathrm{LO}-\mathrm{ANO})$ & 88 & $10.175 .428,85$ & \\
\hline
\end{tabular}

1 Clayton, ano 1982 , com três repetições.

${ }^{2}$ Significativo ao nível de probabilidade de $5 \%$. 
APÊNDICE 3. Análise da variância pra popolaçóes de soja obtidos em experimentos de campo, nos locais te ciayton (CL) e Rocky Mount (RM), NC nos anos de 1981 e 1982 .

\begin{tabular}{|c|c|c|c|c|c|}
\hline \multirow{3}{*}{$\begin{array}{c}\text { Fonte } \\
\text { de } \\
\text { variação }\end{array}$} & \multirow{3}{*}{$\begin{array}{c}\text { Graus } \\
\text { de } \\
\text { liberdade }\end{array}$} & \multicolumn{4}{|c|}{ Soma dos quadrados } \\
\hline & & \multicolumn{2}{|c|}{ Rocky Mount } & \multicolumn{2}{|c|}{ Clayton } \\
\hline & & 1981 & 1982 & 1981 & 1982 \\
\hline Blocos (BL) & 3 & 72,80 & 22,59 & 33,89 & 200,79 \\
\hline Resteva (R) & 3 & $1.481,42 *^{1}$ & 23,69 & 35,53 & $147,38 *$ \\
\hline $\mathrm{BL} \div \mathrm{R}$ & 9 & 77,14 & 46,16 & 69,23 & 68,48 \\
\hline Cultivo (C) & 1 & $260,02 *$ & 0,78 & 1,20 & 2,34 \\
\hline$C * R$ & 3 & 81,05 & 6,03 & 9,05 & 36,61 \\
\hline$B L \quad(R * C)$ & 12 & 121,69 & 34,38 & 51,56 & 37,10 \\
\hline
\end{tabular}

${ }^{1}$ Teste-F significativo ao nivel de probabilidade de $5 \%$. 


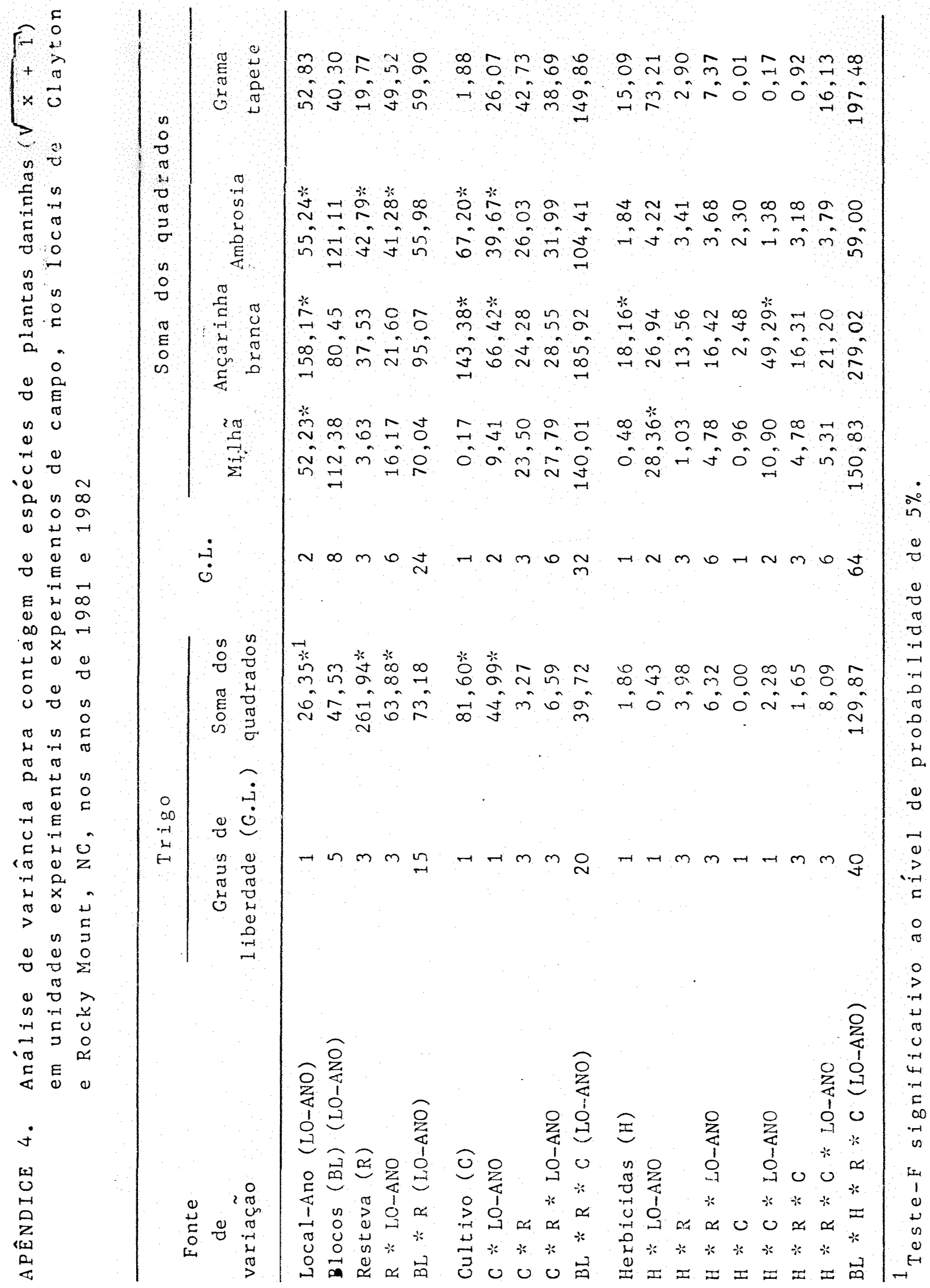




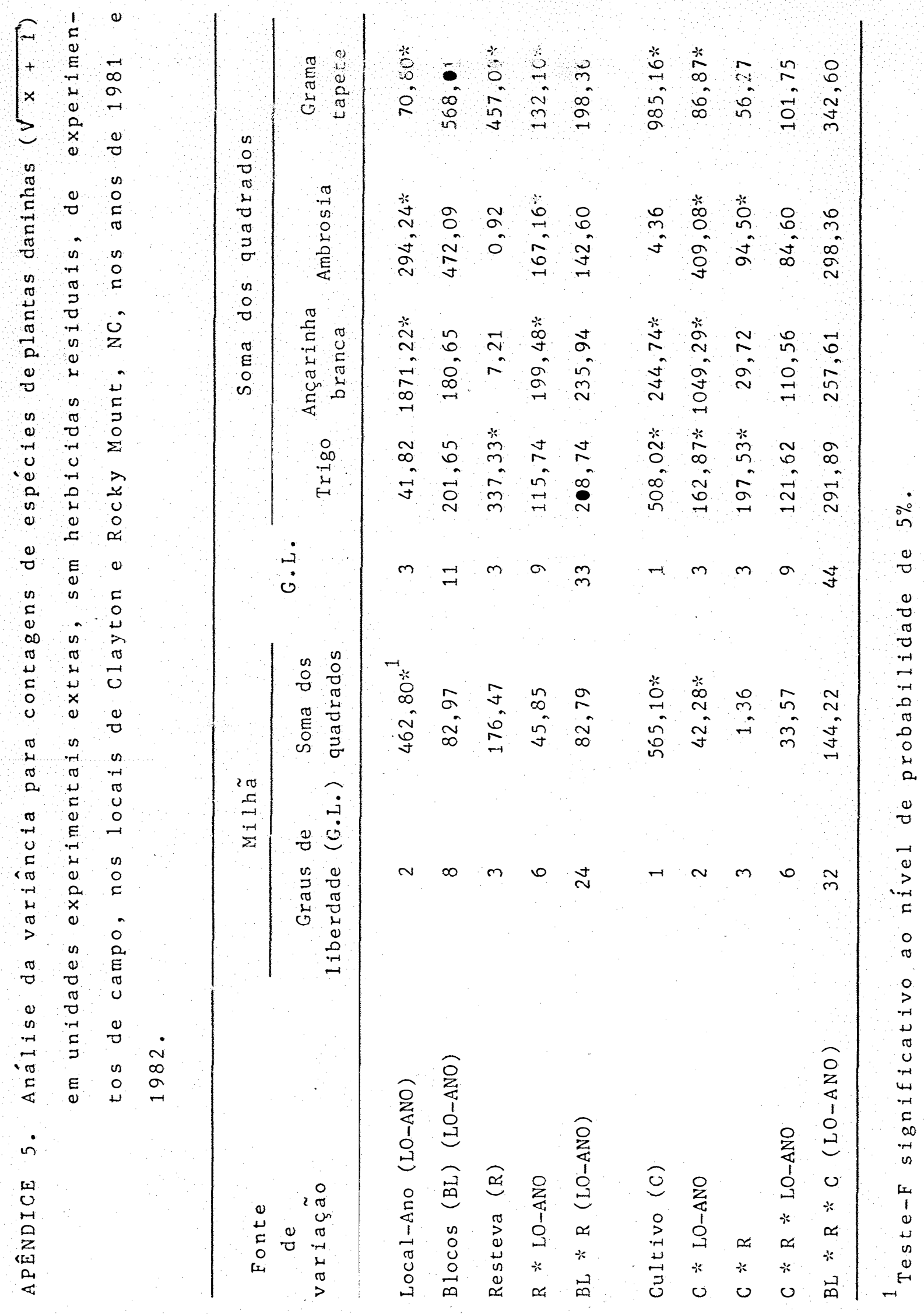




$$
\begin{aligned}
& \text { E } \\
& \text {. }
\end{aligned}
$$

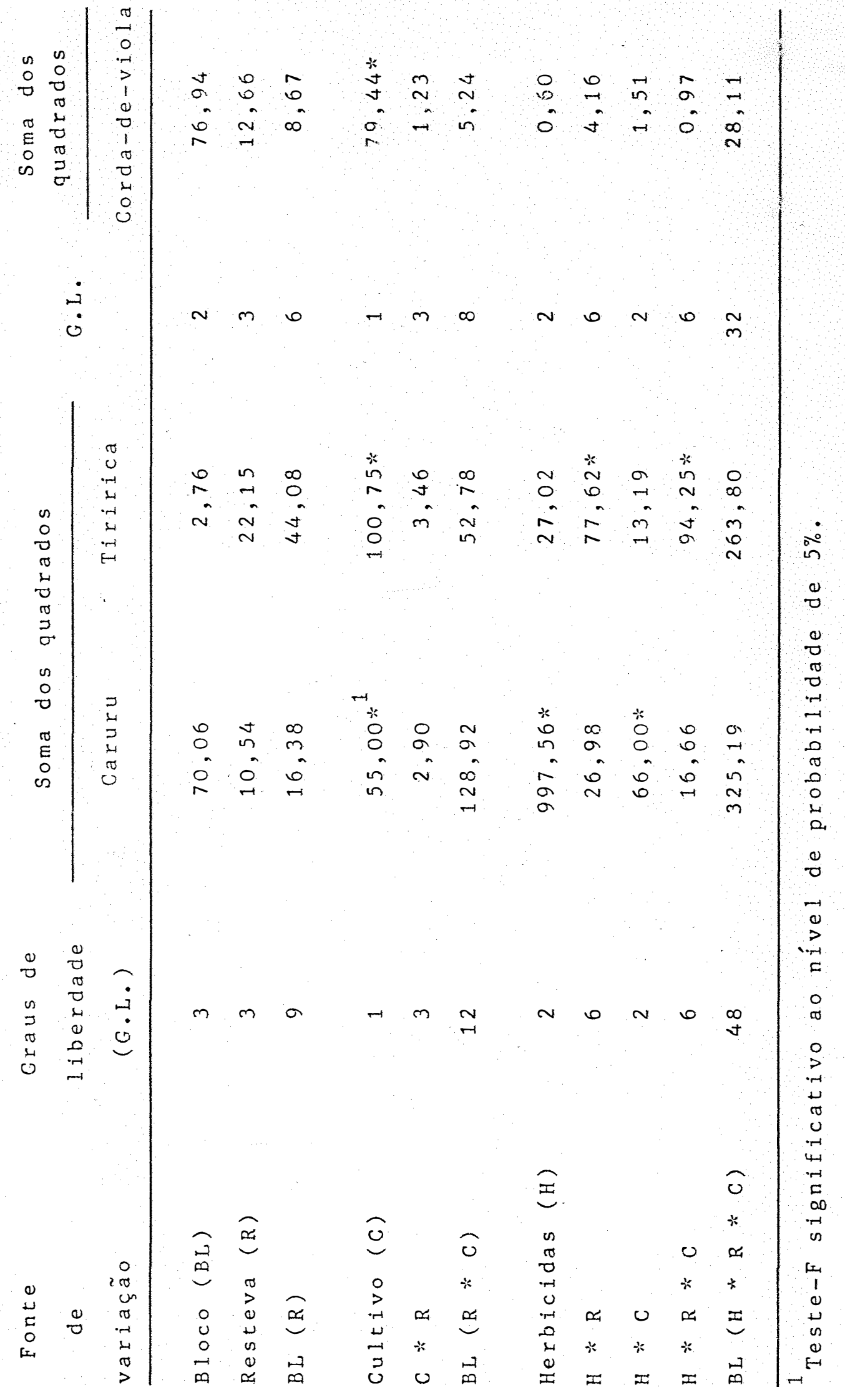

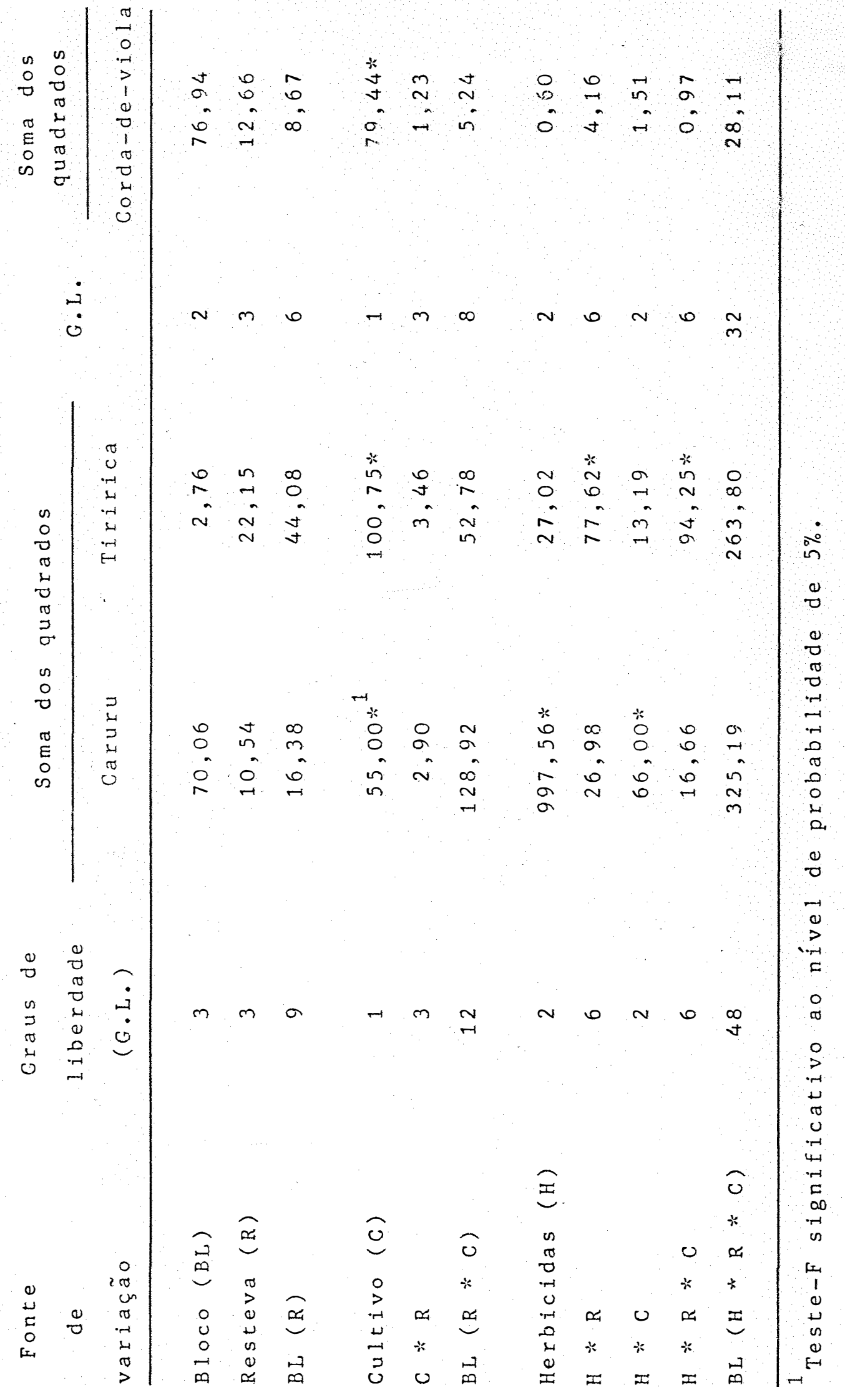

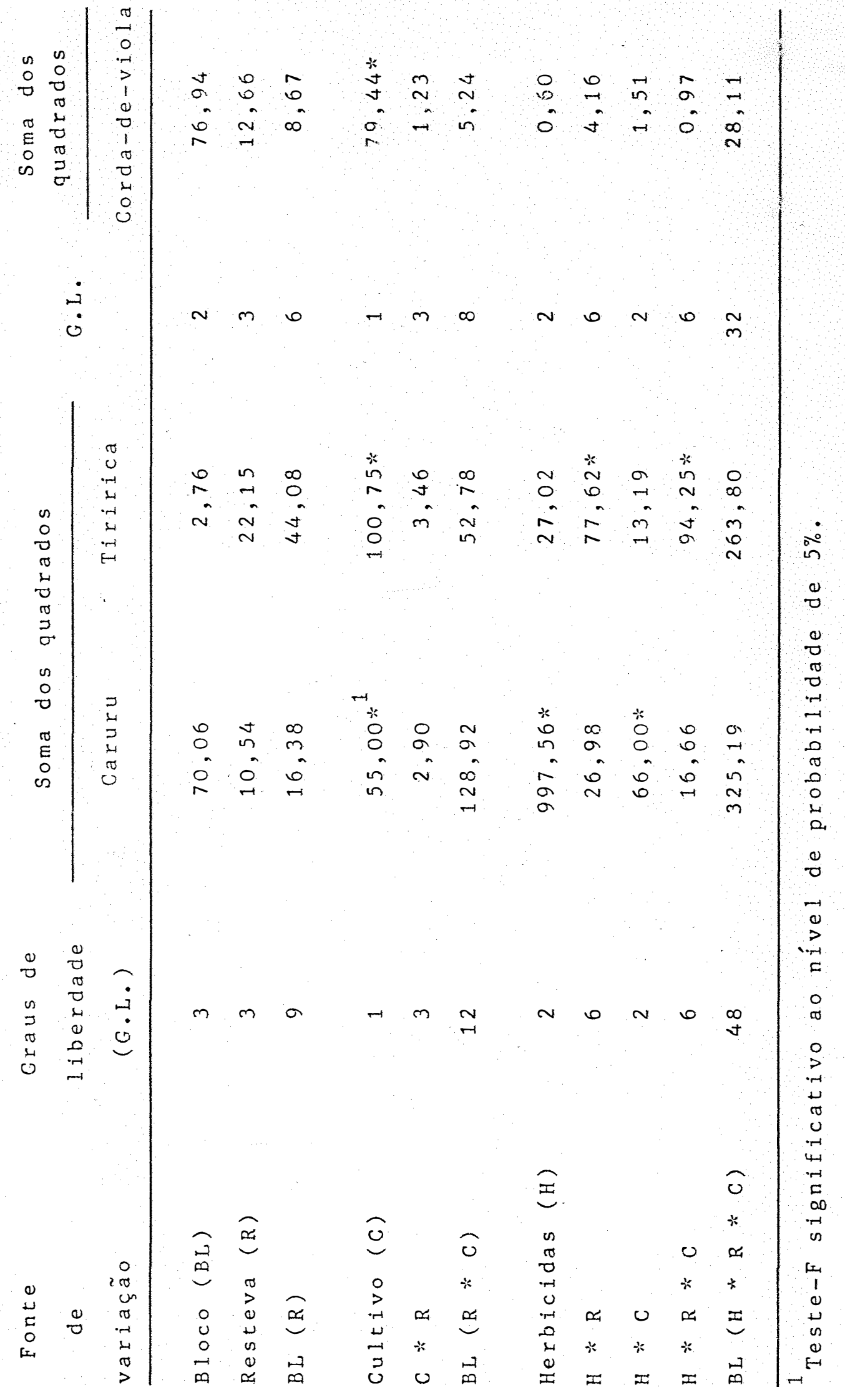

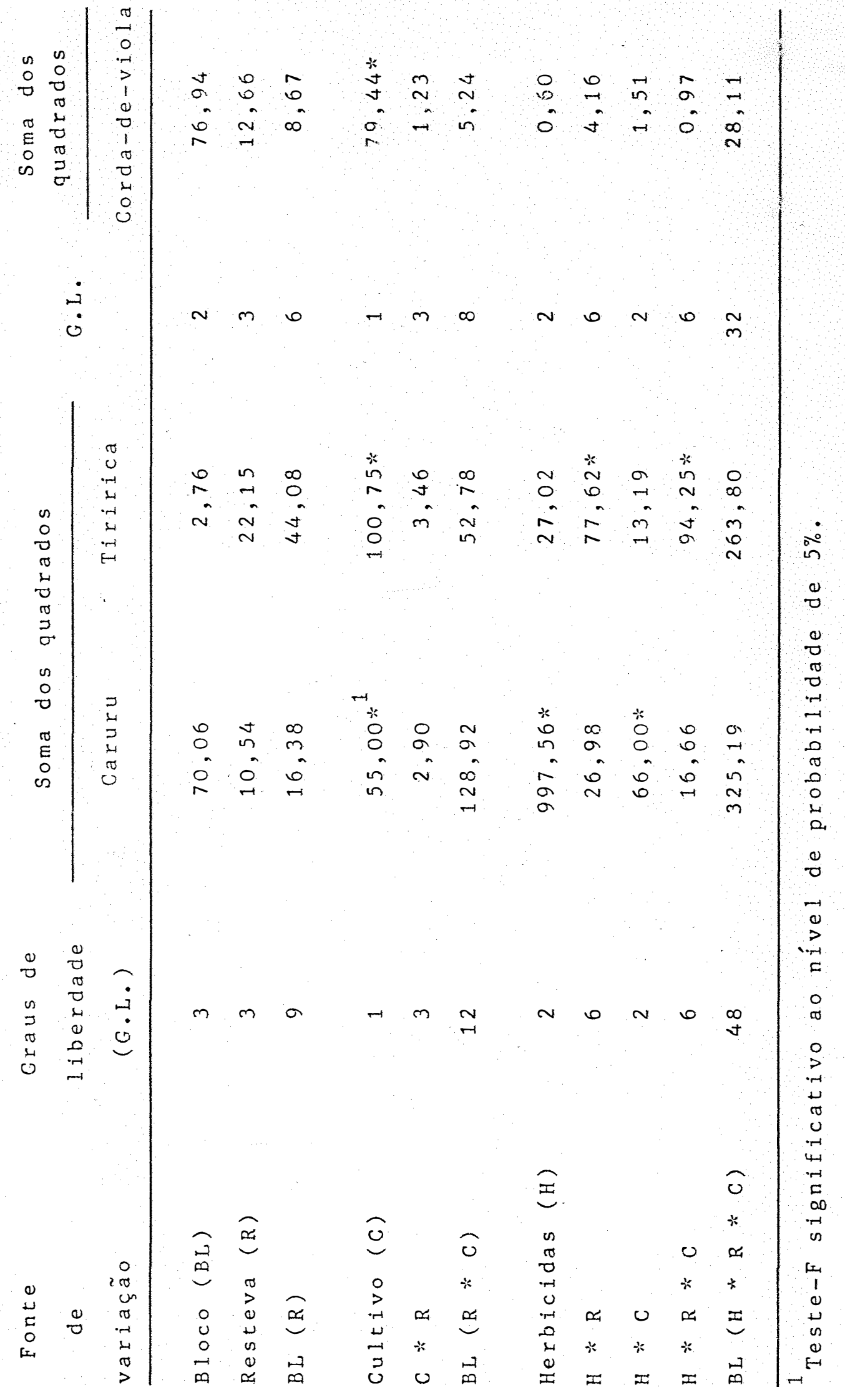

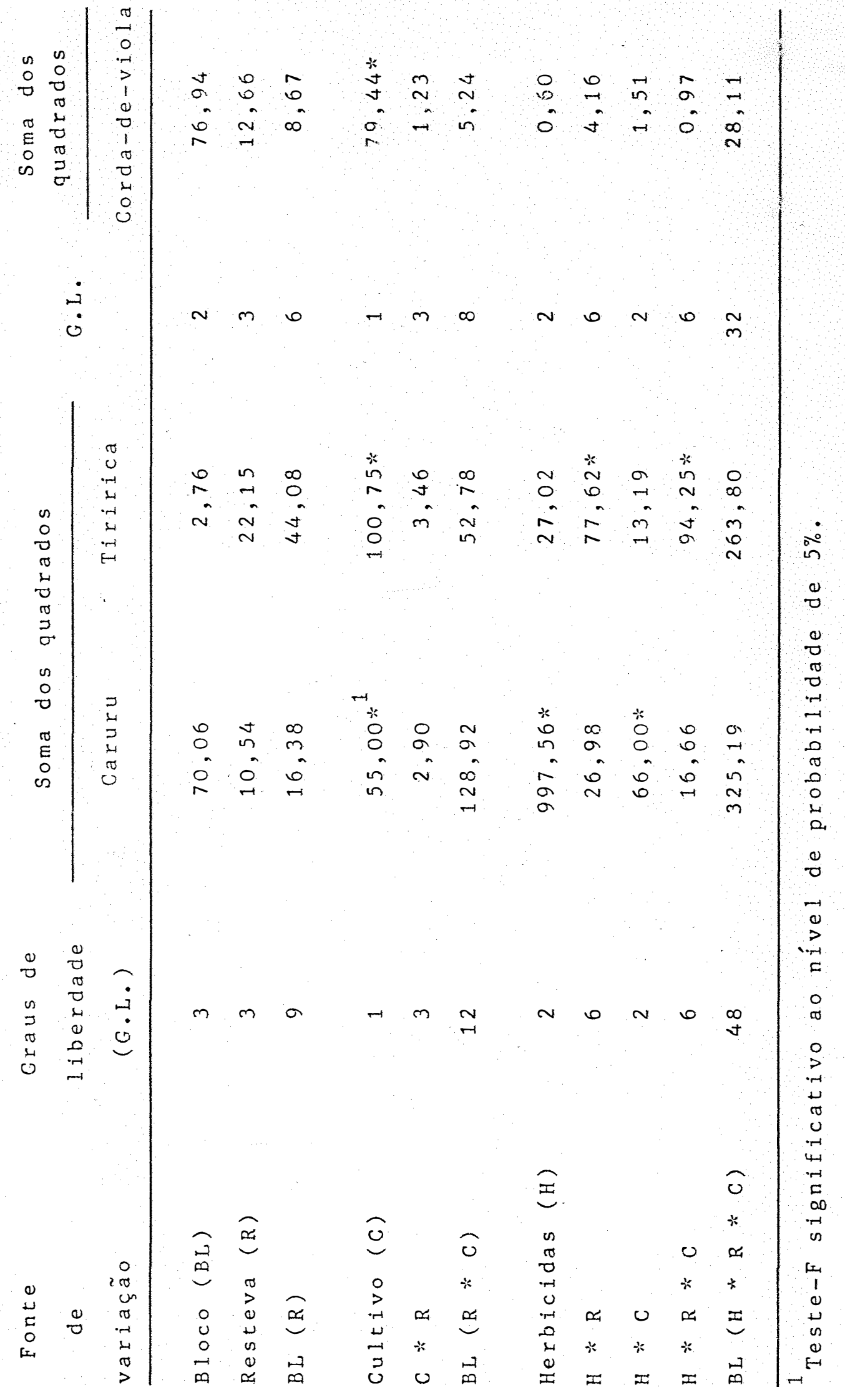

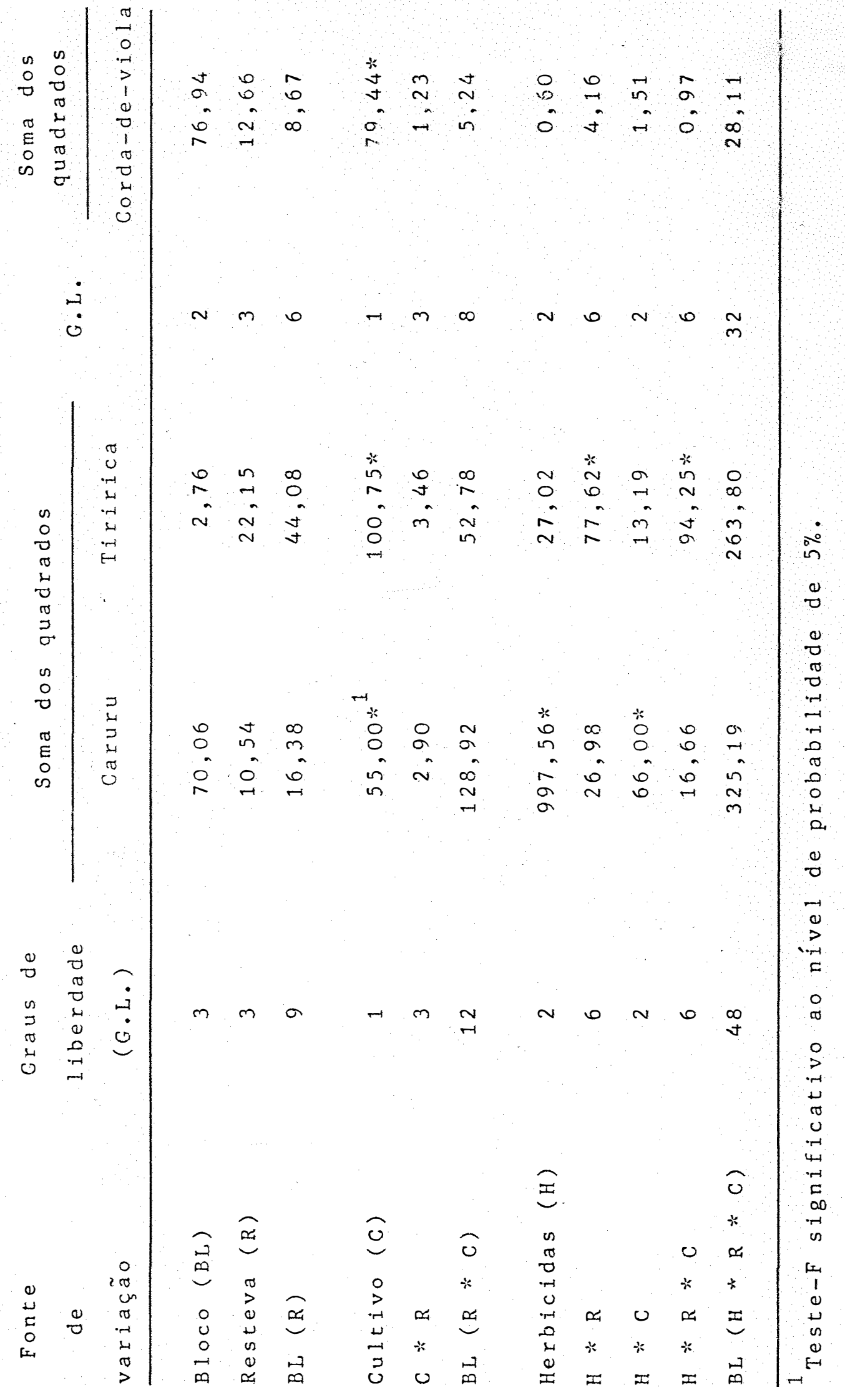

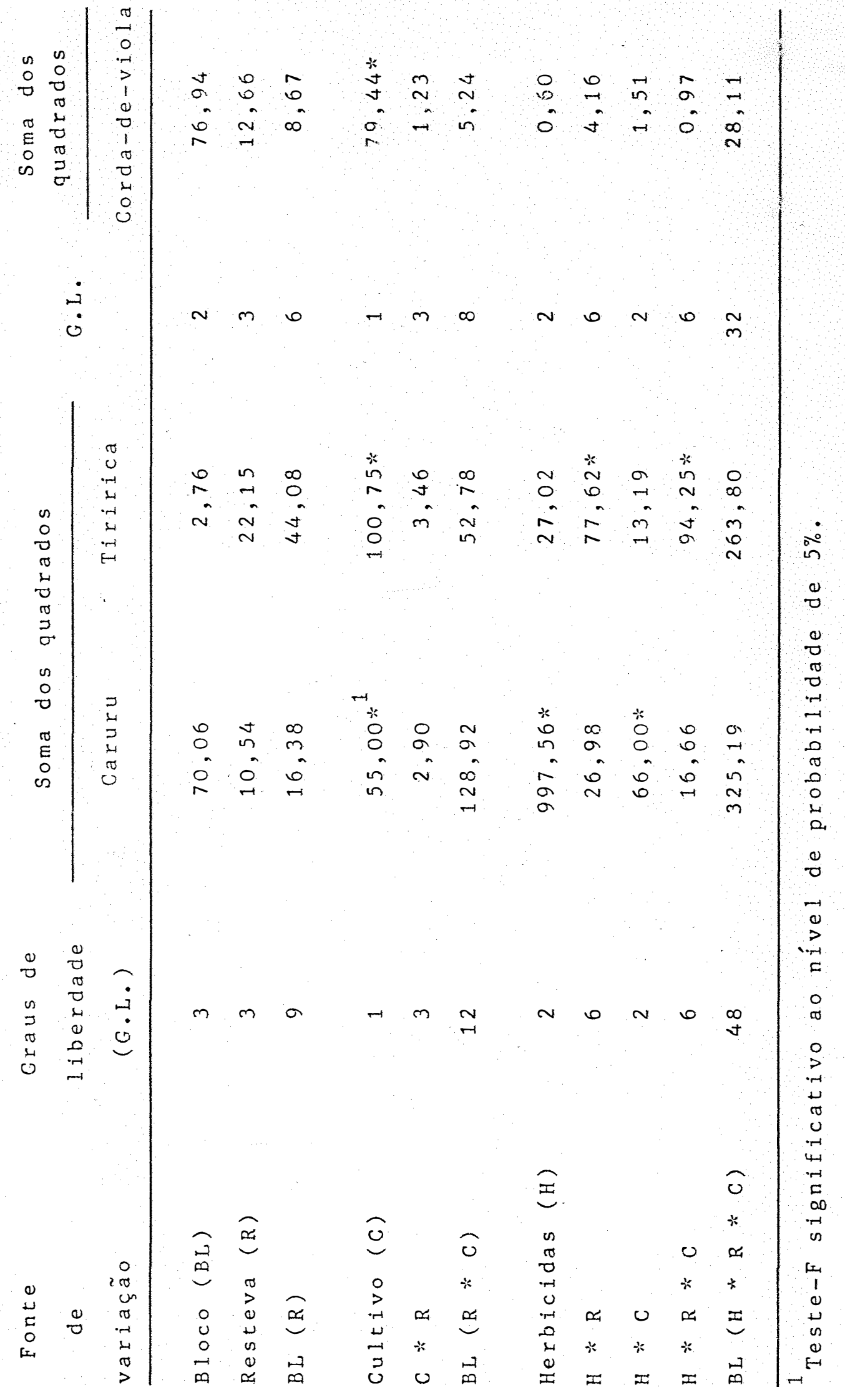

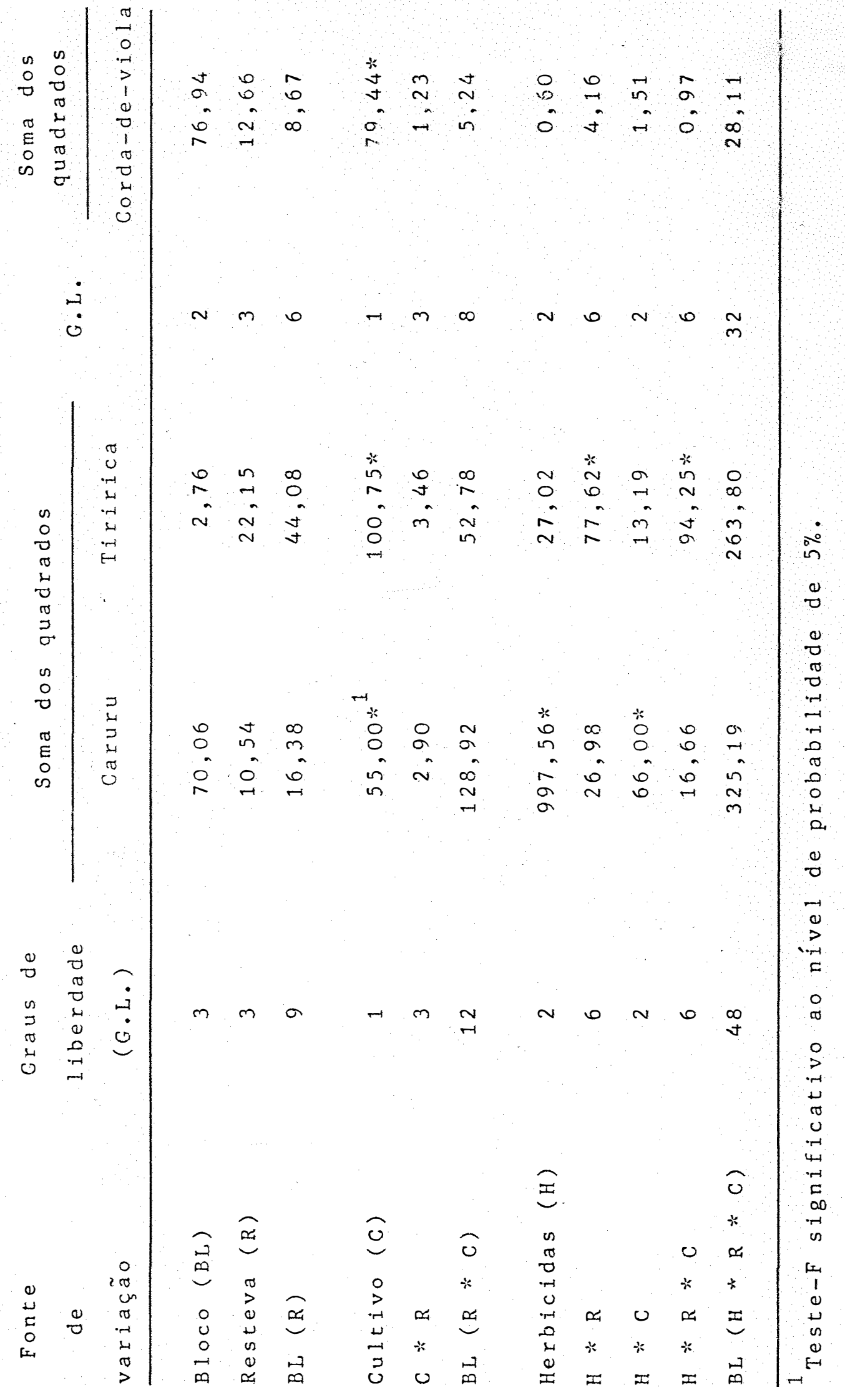

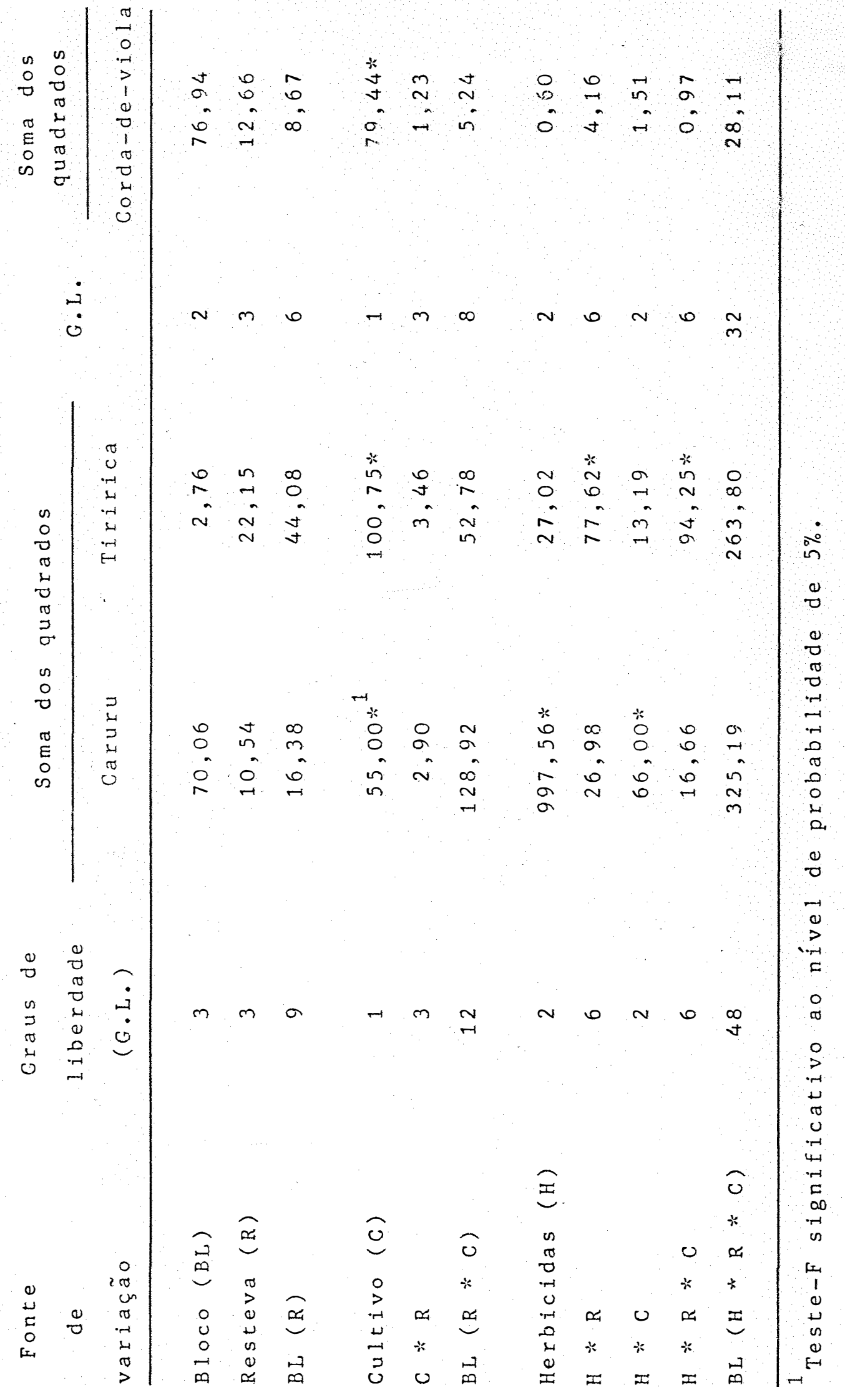

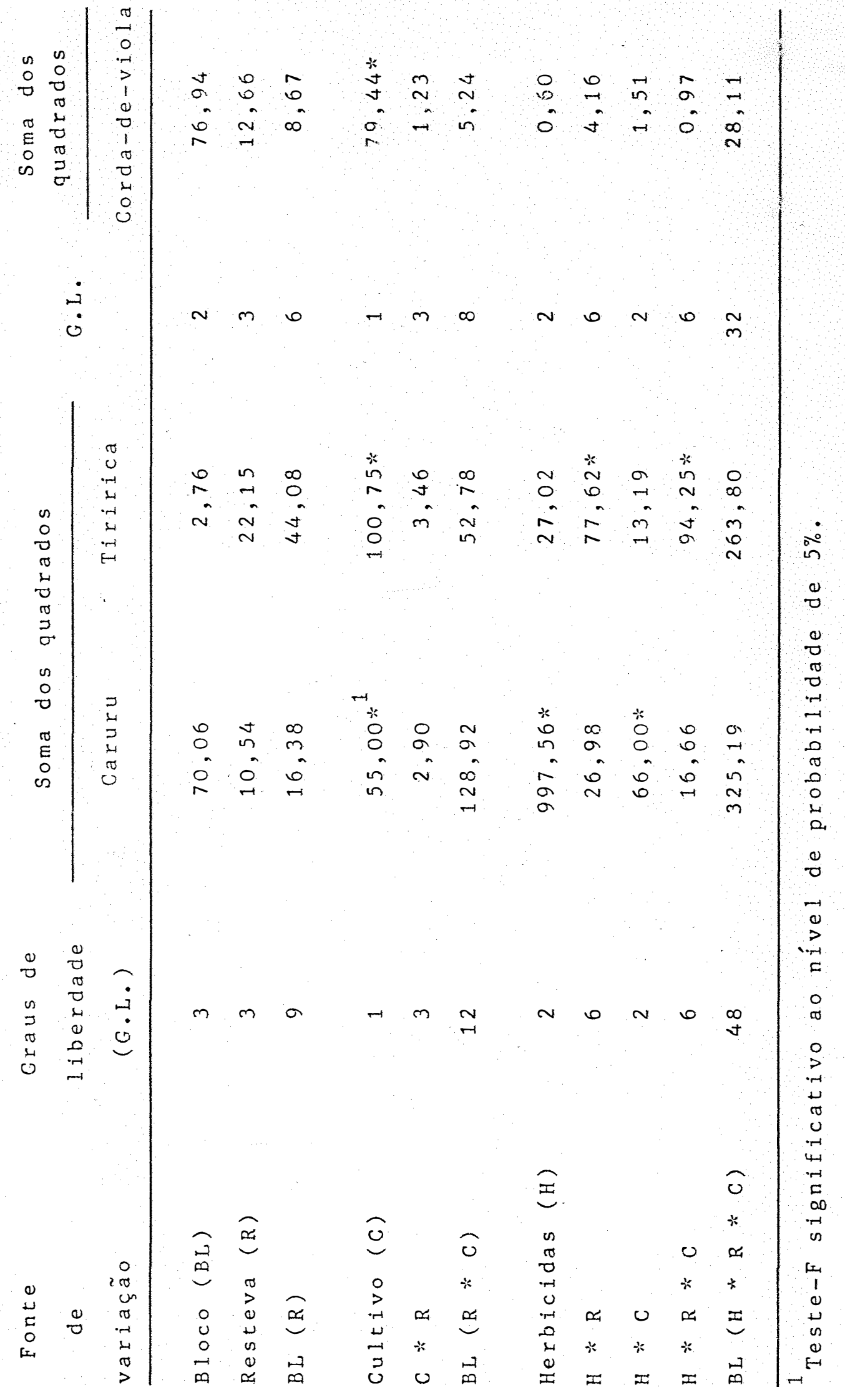

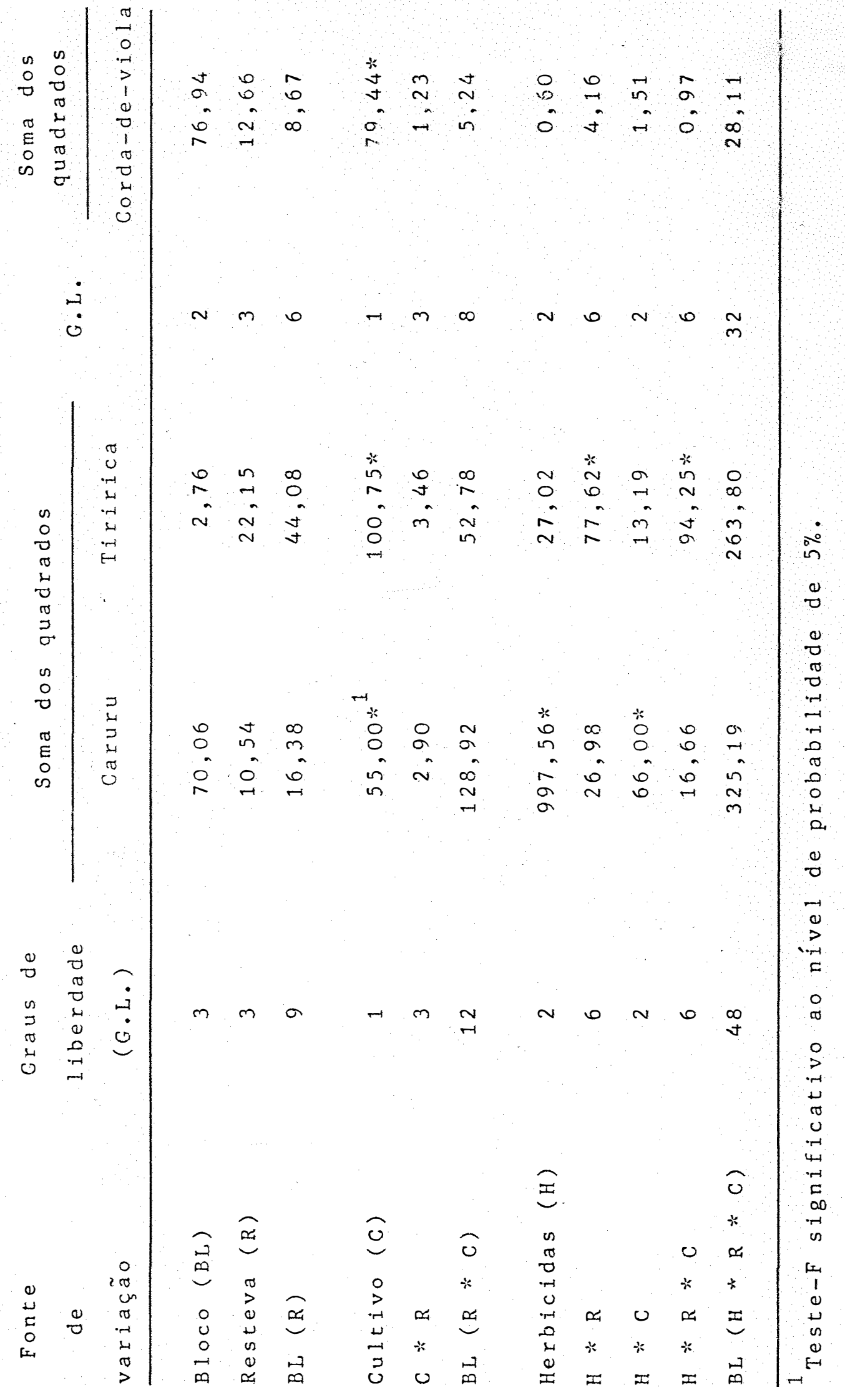

$$
\begin{aligned}
& \begin{array}{l}
0 \\
01 \\
0 \\
0 \\
0 \\
z \\
0 \\
0 \\
0
\end{array}
\end{aligned}
$$

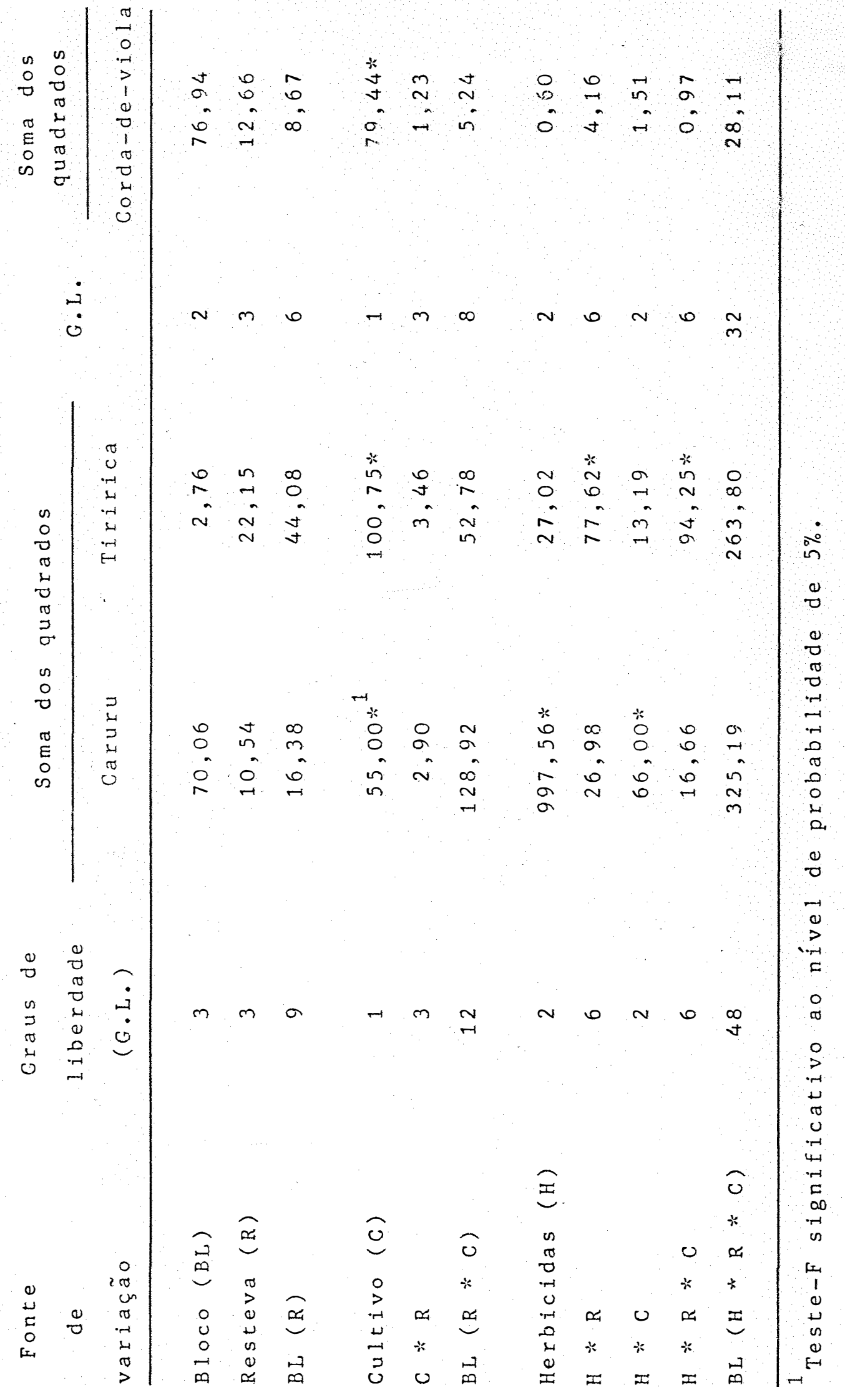

$$
\begin{aligned}
& \pi \quad 5 \\
& E \quad \begin{array}{lll}
E & E
\end{array} \\
& \dot{0} \\
& \text { 我 }
\end{aligned}
$$


APFWU, 7 Estimativa dos parâmetros de modelos e valores de $R^{2}$ para os dados de altura de plantas de soja (mm), biomassa fresca do dossel (cg) ebiomassa seca das raizes (cg), para combinações de doses de á cido ferúlico e glyphosate.

\begin{tabular}{|c|c|c|c|c|c|c|c|}
\hline \multirow{2}{*}{ Parâmetro } & \multicolumn{2}{|c|}{ Doses (ppm) } & \multicolumn{4}{|c|}{ Parâmetros } & \multirow{2}{*}{$\mathrm{R}^{2}$} \\
\hline & $\begin{array}{c}\text { Acido } \\
\text { ferúlico }\end{array}$ & Glyphosate & $\hat{A}$ & $\hat{B}$ & $\hat{\mathrm{C}}$ & $\hat{\mathrm{D}}$ & \\
\hline & 0 a 300 & 0 & 300,75 & 0,185 & - & - & 0,76 \\
\hline & 0 a 300 & 0,75 & 294,25 & 0,218 & - & - & 0,76 \\
\hline & 0 a 300 & 1,50 & 288,36 & 1,035 & $-0,0029$ & - & 0,89 \\
\hline & 0 a 300 & 2,25 & 301,61 & 0,889 & $-0,0025$ & - & 0,91 \\
\hline & 0 a 300 & 3,00 & 295,11 & 2,176 & $-0,0184$ & 0,00004 & 0,83 \\
\hline
\end{tabular}

Altura de

plantas

\begin{tabular}{|c|c|c|c|c|c|}
\hline 75 & 0 a 3,00 & 300,50 . & 21,000 & - & - \\
\hline 150 & 0 a 3,00 & 331,00 & 15,000 & - & - \\
\hline 225 & 0 a 3,00 & 351,78 & 64,238 & $-29,5238$ & 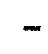 \\
\hline
\end{tabular}

Peso fresco 0 a 300

$\overline{\mathrm{X}}$

$521,00 \quad 1,020 \quad-0,0032 \quad-$

0,80

do dossel $\overline{\mathrm{X}}$

0 a 3,00

$591,69-17,960$

0,51

\begin{tabular}{|c|c|c|c|c|c|c|c|}
\hline Peso seco & 0 a 300 & 0 & 24,10 & $-0,033$ & - & - & 0,87 \\
\hline das raízes & 0 & 0 a 3,00 & 24,15 & $-3,500$ & - & - & 0,84 \\
\hline
\end{tabular}




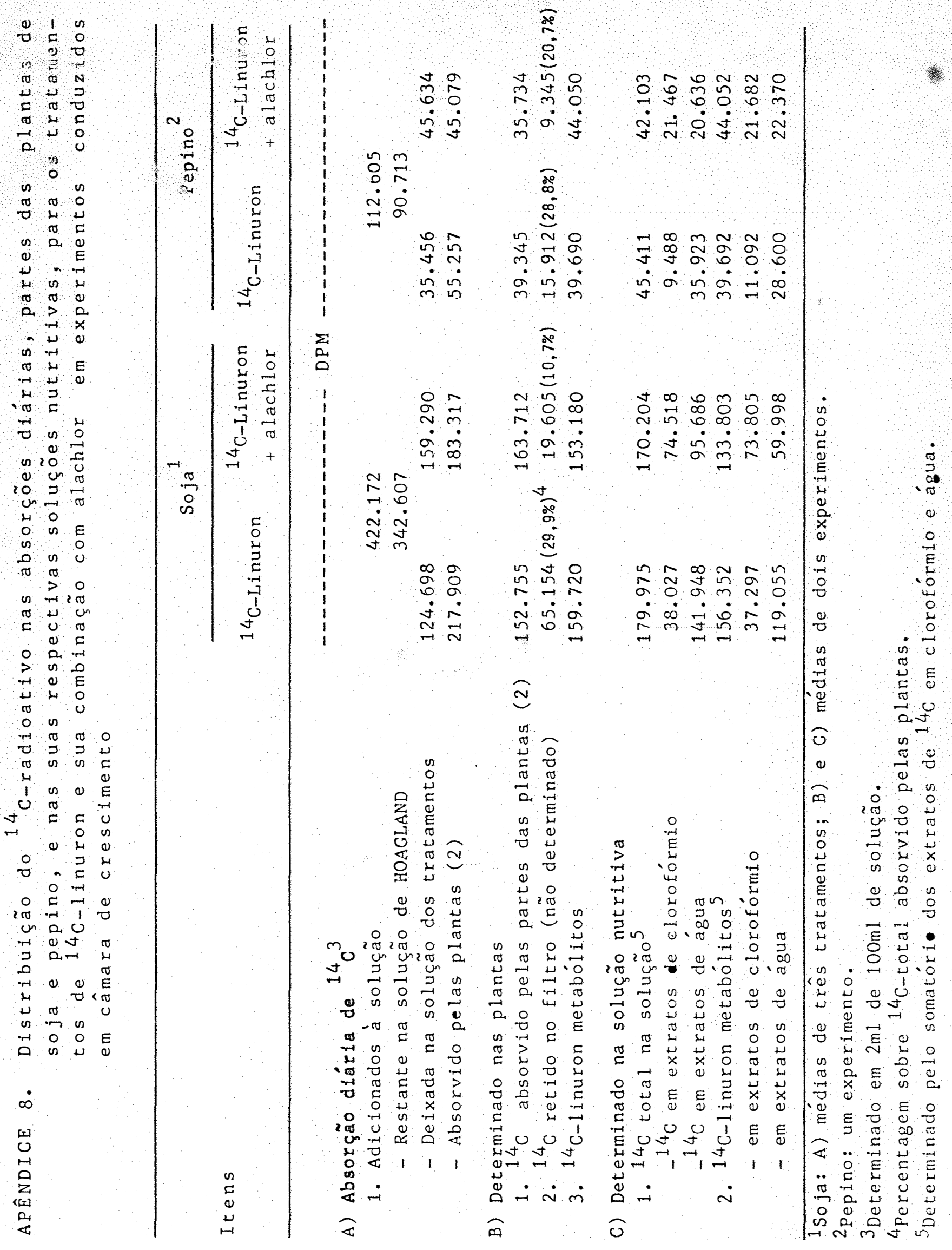

